\begin{tabular}{|c|c|}
\hline Citation & $\begin{array}{l}\text { Hermans G, De Jonghe B, (2014), } \\
\text { Interventions for preventing critical illness polyneuropathy and critical } \\
\text { illness myopathy. } \\
\text { Cochrane Database Syst Rev. } 2014 \text { Jan 30;1:CD006832. }\end{array}$ \\
\hline Archived version & Final publisher's version / pdf \\
\hline Published version & http://dx.doi.org/10.1002/14651858.CD006832.pub3 \\
\hline Journal homepage & http://www.thecochranelibrary.com \\
\hline Author contact & $\begin{array}{l}\text { your email greet.vandenberghe@med.kuleuven.be } \\
\text { your phone number + } 32(0) 16344021\end{array}$ \\
\hline IR & https://lirias.kuleuven.be/handle/123456789/439664 \\
\hline
\end{tabular}

(article begins on next page) 


\title{
Interventions for preventing critical illness polyneuropathy and critical illness myopathy (Review)
}

\author{
Hermans G, De Jonghe B, Bruyninckx F, Van den Berghe G
}
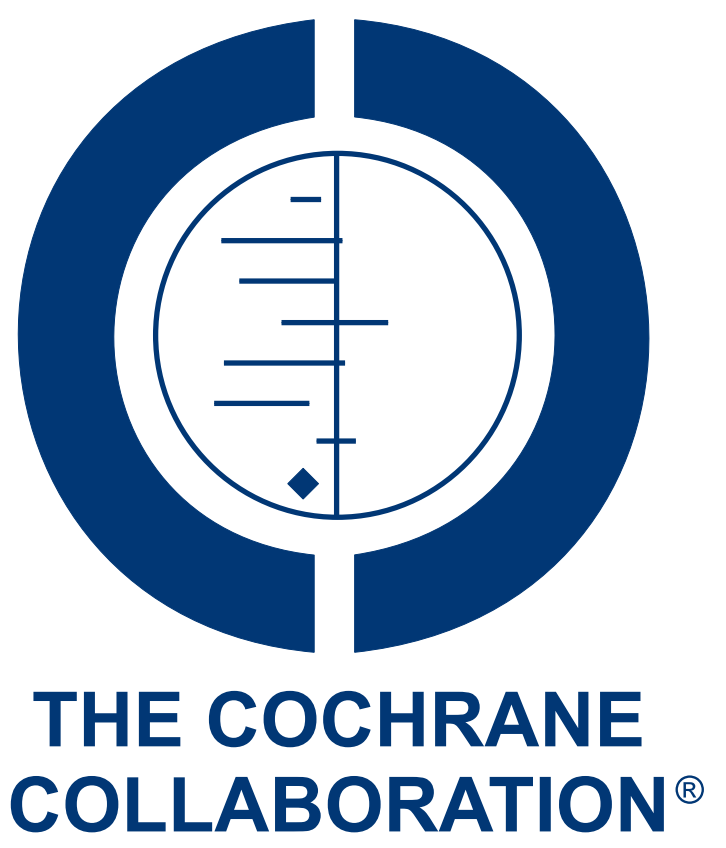

This is a reprint of a Cochrane review, prepared and maintained by The Cochrane Collaboration and published in The Cochrane Library 2014, Issue 1

http://www.thecochranelibrary.com

\section{WILEY}

Interventions for preventing critical illness polyneuropathy and critical illness myopathy (Review)

Copyright $\odot 2014$ The Cochrane Collaboration. Published by John Wiley \& Sons, Ltd. 
TABLE OF CONTENTS

HEADER

ABSTRACT

PLAIN LANGUAGE SUMMARY . . . . . . . . . . . . . . . . . . . . . . . . . . . . . . . . . . . .

SUMMARY OF FINDINGS FOR THE MAIN COMPARISON . . . . . . . . . . . . . . . . . . . . . . . 4

BACKGROUND . . . . . . . . . . . . . . . . . . . . . . . . . . . . . . . . . . . . 6

Figure 1. . . . . . . . . . . . . . . . . . . . . . . . . . . . . . . . . . . . . . . .

OBJECTIVES . . . . . . . . . . . . . . . . . . . . . . . . . . . . . . . . . . . . . .

METHODS . . . . . . . . . . . . . . . . . . . . . . . . . . . . . . . . . . . . . . 9

RESULTS . . . . . . . . . . . . . . . . . . . . . . . . . . . . . . . . . . . . . . . 10

Figure 2. . . . . . . . . . . . . . . . . . . . . . . . . . . . . . . . . . . . . . 13

Figure 3. . . . . . . . . . . . . . . . . . . . . . . . . . . . . . . . . . . . . . 415

Figure $4 . \quad$. . . . . . . . . . . . . . . . . . . . . . . . . . . . . . . . . . . . . 16

Figure 5. . . . . . . . . . . . . . . . . . . . . . . . . . . . . . . . . . . . . . 17

Figure 6.

ADDITIONAL SUMMARY OF FINDINGS . . . . . . . . . . . . . . . . . . . . . . . . . . . 18

DISCUSSION . . . . . . . . . . . . . . . . . . . . . . . . . . . . . . . . . . . . 23

AUTHORS' CONCLUSIONS . . . . . . . . . . . . . . . . . . . . . . . . . . . . . . . . 24

ACKNOWLEDGEMENTS . . . . . . . . . . . . . . . . . . . . . . . . . . . . . . . . . 24

REFERENCES . . . . . . . . . . . . . . . . . . . . . . . . . . . . . . . . . . . . . . . . . . . . .

CHARACTERISTICS OF STUDIES . . . . . . . . . . . . . . . . . . . . . . . . . . . . . . . . . . . . . . . .

DATA AND ANALYSES . . . . . . . . . . . . . . . . . . . . . . . . . . . . . . . . . . . . . . . . . . . . . . . . . . .

Analysis 1.1. Comparison 1 Intensive insulin therapy (IIT) versus conventional insulin therapy (CIT), Outcome 1

Occurrence of CIP/CIM. . . . . . . . . . . . . . . . . . . . . . . . . . . . . . . . . 48

Analysis 1.2. Comparison 1 Intensive insulin therapy (IIT) versus conventional insulin therapy (CIT), Outcome 2 Duration of mechanical ventilation. . . . . . . . . . . . . . . . . . . . . . . . . . . . . . . . . . . . . .

Analysis 1.3. Comparison 1 Intensive insulin therapy (IIT) versus conventional insulin therapy (CIT), Outcome 3 Duration of ICU stay.

Analysis 1.4. Comparison 1 Intensive insulin therapy (IIT) versus conventional insulin therapy (CIT), Outcome 4 Death. 51

Analysis 1.5. Comparison 1 Intensive insulin therapy (IIT) versus conventional insulin therapy (CIT), Outcome 5 Serious adverse events. . . . . . . . . . . . . . . . . . . . . . . . . . . . . . . . . . 52

Analysis 2.1. Comparison 2 Corticosteroids versus placebo, Outcome 1 Occurrence of CIP/CIM. . . . . . . . . 54

Analysis 2.2. Comparison 2 Corticosteroids versus placebo, Outcome 2 Death. . . . . . . . . . . . . . . . 55

Analysis 2.3. Comparison 2 Corticosteroids versus placebo, Outcome 3 Serious adverse events (dichotomous data). . 56

Analysis 2.4. Comparison 2 Corticosteroids versus placebo, Outcome 4 Serious adverse events (continuous data). $\quad 57$

Analysis 3.1. Comparison 3 Early physical therapy versus control, Outcome 1 Occurrence of CIP/CIM. . . . . . 58

Analysis 3.2. Comparison 3 Early physical therapy versus control, Outcome 2 Serious adverse events. . . . . . . 59

Analysis 4.1. Comparison 4 Electrical muscle stimulation versus control, Outcome 1 Occurrence of CIP/CIM. $\quad . \quad$. 60

ADDITIONAL TABLES . . . . . . . . . . . . . . . . . . . . . . . . . . . . . . . . . . . . . . . . . . . . 60

APPENDICES . . . . . . . . . . . . . . . . . . . . . . . . . . . . . . . . . . . . . . . .

WHAT'S NEW . . . . . . . . . . . . . . . . . . . . . . . . . . . . . . . . . . . . . . . . . . . .

HISTORY . . . . . . . . . . . . . . . . . . . . . . . . . . . . . . . . . . . . . . . . . . .

CONTRIBUTIONS OF AUTHORS . . . . . . . . . . . . . . . . . . . . . . . . . . . . . . . . . . . . . . . . . . . .

DECLARATIONS OF INTEREST . . . . . . . . . . . . . . . . . . . . . . . . . . . . . . . . . . . . . . 65

DIFFERENCES BETWEEN PROTOCOL AND REVIEW . . . . . . . . . . . . . . . . . . . . . . . . . . . . . . 65

INDEX TERMS . . . . . . . . . . . . . . . . . . . . . . . . . . . . . . . . . . . . 65

Interventions for preventing critical illness polyneuropathy and critical illness myopathy (Review)

Copyright @ 2014 The Cochrane Collaboration. Published by John Wiley \& Sons, Ltd. 


\title{
[Intervention Review] \\ Interventions for preventing critical illness polyneuropathy and critical illness myopathy
}

\author{
Greet Hermans ${ }^{1}$, Bernard De Jonghe ${ }^{2}$, Frans Bruyninckx ${ }^{3}$, Greet Van den Berghe ${ }^{4}$ \\ ${ }^{1}$ Department of Cellular and Molecular Medicine, KU Leuven, Leuven, Belgium. ${ }^{2}$ Réanimation Médico-Chirurgicale, Centre Hos- \\ pitalier de Poissy-Saint-Germain, Poissy, France. ${ }^{3}$ Physical Medicine and Rehabilitation, KU Leuven, University Hospitals, Leuven, \\ Belgium. ${ }^{4}$ Department of Intensive Care Medicine, KU Leuven, University Hospitals, Leuven, Belgium \\ Contact address: Greet Van den Berghe, Department of Intensive Care Medicine, KU Leuven, University Hospitals, Herestraat 49,3000, \\ Leuven, Belgium. Greta.vandenberghe@med.kuleuven.be.
}

Editorial group: Cochrane Neuromuscular Disease Group.

Publication status and date: New search for studies and content updated (conclusions changed), published in Issue 1, 2014.

Review content assessed as up-to-date: 4 October 2011.

Citation: Hermans G, De Jonghe B, Bruyninckx F, Van den Berghe G. Interventions for preventing critical illness polyneuropathy and critical illness myopathy. Cochrane Database of Systematic Reviews 2014, Issue 1. Art. No.: CD006832. DOI: 10.1002/14651858.CD006832.pub3.

Copyright (C) 2014 The Cochrane Collaboration. Published by John Wiley \& Sons, Ltd.

\begin{abstract}
A B S T R A C T
Background

Critical illness polyneuropathy or myopathy (CIP/CIM) is a frequent complication in the intensive care unit (ICU) and is associated with prolonged mechanical ventilation, longer ICU stay and increased mortality. This is an interim update of a review first published in 2009 (Hermans 2009). It has been updated to October 2011, with further potentially eligible studies from a December 2013 search characterised as awaiting assessment.
\end{abstract}

Objectives

To systematically review the evidence from RCTs concerning the ability of any intervention to reduce the incidence of CIP or CIM in critically ill individuals.

\section{Search methods}

On 4 October 2011, we searched the Cochrane Neuromuscular Disease Group Specialized Register, CENTRAL, MEDLINE, and EMBASE. We checked the bibliographies of identified trials and contacted trial authors and experts in the field. We carried out an additional search of these databases on 6 December 2013 to identify recent studies.

\section{Selection criteria}

All randomised controlled trials (RCTs), examining the effect of any intervention on the incidence of CIP/CIM in people admitted to adult medical or surgical ICUs. The primary outcome was the incidence of CIP/CIM in ICU, based on electrophysiological or clinical examination. Secondary outcomes included duration of mechanical ventilation, duration of ICU stay, death at 30 and 180 days after ICU admission and serious adverse events from the treatment regimens.

\section{Data collection and analysis}

Two authors independently extracted the data and assessed the risk of bias in included studies.

Interventions for preventing critical illness polyneuropathy and critical illness myopathy (Review)

Copyright $\odot 2014$ The Cochrane Collaboration. Published by John Wiley \& Sons, Ltd. 


\section{Main results}

We identified five trials that met our inclusion criteria. Two trials compared intensive insulin therapy (IIT) to conventional insulin therapy (CIT). IIT significantly reduced CIP/CIM in the screened ( $\mathrm{n}=825$; risk ratio (RR) $0.65,95 \%$ confidence interval $(\mathrm{CI}) 0.55$ to 0.77 ) and total ( $\mathrm{n}=2748$; RR $0.70,95 \%$ CI 0.60 to 0.82$)$ population randomised. IIT reduced duration of mechanical ventilation, ICU stay and 180-day mortality, but not 30-day mortality compared with CIT. Hypoglycaemia increased with IIT but did not cause early deaths.

One trial compared corticosteroids with placebo $(\mathrm{n}=180)$. The trial found no effect of treatment on CIP/CIM (RR $1.27,95 \%$ CI 0.77 to 2.08), 180-day mortality, new infections, glycaemia at day seven, or episodes of pneumonia, but did show a reduction of new shock events.

In the fourth trial, early physical therapy reduced CIP/CIM in 82/104 evaluable participants in ICU (RR 0.62.95\% CI 0.39 to 0.96). Statistical significance was lost when we performed a full intention-to-treat analysis (RR 0.81, 95\% CI 0.60 to 1.08 ). Duration of mechanical ventilation but not ICU stay was significantly shorter in the intervention group. Hospital mortality was not affected but 30 - and 180-day mortality results were not available. No adverse effects were noticed.

The last trial found a reduced incidence of CIP/CIM in 52 evaluable participants out of a total of 140 who were randomised to electrical muscle stimulation (EMS) versus no stimulation (RR 0.32, 95\% CI 0.10 to 1.01). These data were prone to bias due to imbalances between treatment groups in this subgroup of participants. After we imputed missing data and performed an intention-totreat analysis, there was still no significant effect (RR 0.94, 95\% CI 0.78 to 1.15 ). The investigators found no effect on duration of mechanical ventilation and noted no difference in ICU mortality, but did not report 30- and 180-day mortality.

We updated the searches in December 2013 and identified nine potentially eligible studies that will be assessed for inclusion in the next update of the review.

\section{Authors' conclusions}

There is moderate quality evidence from two large trials that intensive insulin therapy reduces CIP/CIM, and high quality evidence that it reduces duration of mechanical ventilation, ICU stay and 180-day mortality, at the expense of hypoglycaemia. Consequences and prevention of hypoglycaemia need further study. There is moderate quality evidence which suggests no effect of corticosteroids on CIP/ CIM and high quality evidence that steroids do not affect secondary outcomes, except for fewer new shock episodes. Moderate quality evidence suggests a potential benefit of early rehabilitation on CIP/CIM which is accompanied by a shorter duration of mechanical ventilation but without an effect on ICU stay. Very low quality evidence suggests no effect of EMS, although data are prone to bias. Strict diagnostic criteria for CIP/CIM are urgently needed for research purposes. Large RCTs need to be conducted to further explore the role of early rehabilitation and EMS and to develop new preventive strategies.

\section{PLAIN LANGUAGE SUMMARY}

Interventions to reduce neuromuscular complications acquired during the acute phase of critical illness

\section{Review question}

We reviewed the evidence about the effect of treatments to prevent or reduce complications affecting the nerves or muscles during the severe, early phase of critical illness. These complications are called critical illness polyneuropathy or myopathy (CIP/CIM) and can affect nerves, muscles or both.

\section{Background}

CIP/CIM is a frequent complication of critical care. CIP/CIM causes weakness of limbs and of muscles used for breathing. These difficulties can make it difficult for the person to come off a ventilator and start rehabilitation. CIP/CIM can also mean a longer stay in the intensive care unit (ICU) and increases the risk of death. Recovery takes weeks or months and in severe cases it may be incomplete or absent. Prevention and treatment of CIP/CIM is therefore very important.

\section{Study characteristics}

We searched for all randomised controlled trials (RCTs) that looked at the effects of any treatment to prevent CIP/CIM in adults admitted to an ICU. We identified and analysed five trials that were suitable for inclusion in our review. These trials studied four treatments: intensive insulin therapy (IIT), corticosteroid therapy, early rehabilitation, and electrical muscle stimulation. 


\section{Key results and quality of the evidence}

Two trials, with a total of 825 adults staying in ICU for one week or more, studied the effect of IIT versus conventional insulin therapy (CIT) on the incidence of CIP/CIM. IIT aimed to produce normal blood sugar levels (80 to $110 \mathrm{mg} / \mathrm{dL}$ ) and CIT aimed to avoid high blood sugar (blood sugar over $215 \mathrm{mg} / \mathrm{dL}$ ). Combining the results of both trials showed moderate quality evidence that IIT reduces CIP/CIM. There was high quality evidence that it reduced time spent on a ventilator, ICU stay and 180-day mortality but not 30day mortality. There were more episodes of low blood sugar with IIT. Although there was not an increase in deaths within 24 hours of episodes of low blood sugar, low blood sugar remains a concern as it can damage the brain. Neither trial reported the degree of limb weakness or on physical rehabilitation. The results came from a subgroup of people who were in the ICU for a long time, which may also limit the conclusions.

The third trial compared corticosteroid therapy with a placebo in 180 people with acute respiratory distress syndrome (ARDS). Moderate quality evidence suggested no effect of corticosteroids on CIP/CIM (in 92 participants evaluated). High quality evidence showed no effect on 180-day mortality, new serious infections, blood glucose levels on day seven or episodes of suspected or probable pneumonia. There were fewer episodes of shock (a life-threatening condition where there is a lack of blood flow to vital organs).

The fourth trial was of on early rehabilitation in 104 participants in a medical ICU. There was moderate quality evidence of a reduction in CIP/CIM in the 82 participants who could be evaluated in the ICU. This effect was not significant when imputation to intentionto-treat analysis was performed. Early rehabilitation reduced the duration of mechanical ventilation but did not affect ICU stay or deaths. The trial reported no serious adverse events.

Finally, a trial compared the effect of EMS of the lower limbs to no stimulation. The trial included 140 participants but provided results for only 52 of them. It supplied very low quality evidence that EMS was without effect in preventing CIP/CIM. There was no effect on duration of mechanical ventilation or deaths. Because the EMS and control groups differed in type and severity of disease, these findings may not be reliable. Results were even less significant when imputation to intention-to-treat analysis was performed. The study found no effect of EMS on duration of mechanical ventilation or deaths.

The evidence is up to date as of October 2011. We re-ran the search for studies in December 2013 and identified nine additional potentially eligible studies that we will assess in the next update of the review.

Interventions for preventing critical illness polyneuropathy and critical illness myopathy (Review) 


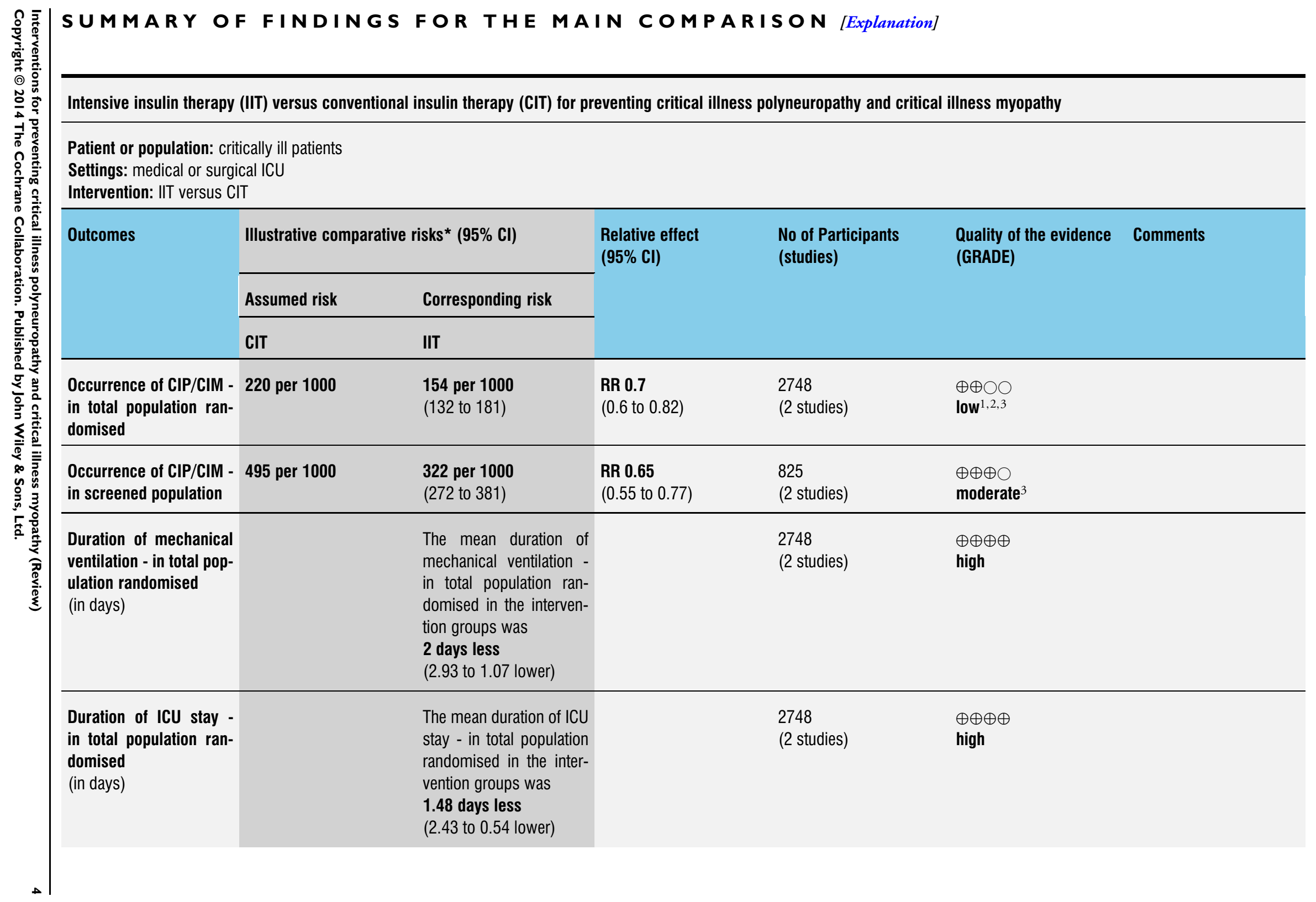




\begin{tabular}{|c|c|c|c|c|c|}
\hline $\begin{array}{l}\text { Death - at } 30 \text { days after } \\
\text { ICU admission, in total } \\
\text { population randomised }\end{array}$ & 171 per 1000 & $\begin{array}{l}161 \text { per } 1000 \\
(137 \text { to } 188)\end{array}$ & $\begin{array}{l}\text { RR } 0.94 \\
(0.8 \text { to } 1.1)\end{array}$ & $\begin{array}{l}2748 \\
\text { (2 studies) }\end{array}$ & $\begin{array}{l}\oplus \oplus \oplus \oplus \\
\text { high }\end{array}$ \\
\hline $\begin{array}{l}\text { Death - at } 180 \text { days after } \\
\text { ICU admission, in total } \\
\text { population randomised }\end{array}$ & 231 per 1000 & $\begin{array}{l}201 \text { per } 1000 \\
(176 \text { to } 231)\end{array}$ & $\begin{array}{l}\text { RR } 0.87 \\
(0.76 \text { to } 1)\end{array}$ & $\begin{array}{l}2748 \\
\text { (2 studies) }\end{array}$ & $\begin{array}{l}\oplus \oplus \oplus \bigcirc \\
\text { moderate }^{3}\end{array}$ \\
\hline $\begin{array}{l}\text { Serious adverse events, } \\
- \text { in total population } \\
\text { randomised - hypogly- } \\
\text { caemia }\end{array}$ & 18 per 1000 & $\begin{array}{l}113 \text { per } 1000 \\
(75 \text { to } 171)\end{array}$ & $\begin{array}{l}\text { RR } \mathbf{6 . 2 7} \\
\text { (4.15 to } 9.49 \text { ) }\end{array}$ & $\begin{array}{l}2748 \\
\text { (2 studies) }\end{array}$ & $\begin{array}{l}\oplus \oplus \oplus \oplus \\
\text { high }\end{array}$ \\
\hline
\end{tabular}

*The basis for the assumed risk (eg the median control group risk across studies) is provided in footnotes. The corresponding risk (and its $95 \%$ confidence interval) is based on the assumed risk in the comparison group and the relative effect of the intervention (and its $95 \% \mathrm{Cl}$ ).

CI: confidence interval; CIT: conventional insulin therapy; ICU: intensive care unit; IIT: intensive insulin therapy; RR: risk ratio

GRADE Working Group grades of evidence

High quality: further research is very unlikely to change our confidence in the estimate of effect.

Moderate quality: further research is likely to have an important impact on our confidence in the estimate of effect and may change the estimate.

Low quality: further research is very likely to have an important impact on our confidence in the estimate of effect and is likely to change the estimate.

Very low quality: we are very uncertain about the estimate.

${ }^{1}$ Imputation of a large amount of data because screening electrophysiological testing was only performed in patients in ICU for one week.

${ }^{2}$ Significantly fewer participants treated with IIT in the original surgical ICU study, but not in the medical study, reached the CIP/CIM screening period. The reason was the benefit of IIT in the first seven days, a possible source of bias in the subsequent results. Any bias as such, originated from earlier ICU discharge in the intervention group and is expected to reduce rather than inflate the effect.

${ }^{3}$ Substantial heterogeneity present, explained by clinical diversity. As only two studies are available, we could not perform a subanalysis

of medical and surgical participants. 


\section{B A C K G R O U N D}

\section{Description of the condition}

Critical illness polyneuropathy (CIP) is an acute and primary axonal motor and sensory polyneuropathy. It occurs in critically ill individuals and is related to severe limb weakness and difficulty in weaning from a ventilator. The term CIP was first used in 1986 (Bolton 1986). Later on it became apparent that in many individuals the disease primarily affected the muscles and the term myopathy in critical illness or critical illness myopathy (CIM), was introduced. It is now clear that the neuromuscular involvement during critical illness covers a spectrum of neuropathy and myopathy, and in many cases overlap syndromes are present.

Many clinical signs of CIP and CIM are similar and include flaccid weakness of the limbs. Weakness affects legs more often than arms. Although head, facial, tongue and jaw movement are relatively spared, facial muscles can be involved and ophthalmoplegia may occur. Involvement of the phrenic nerves and diaphragm may cause ventilator weaning problems. In CIP, distal loss of sensitivity to pain, temperature and vibration may also occur. Deep tendon reflexes are usually normal or reduced in pure CIM but may be absent in CIP.

Several diagnostic approaches are available. Muscle strength can be quantified using the Medical Research Council (MRC) sum-score (De Jonghe 2002). This score grades muscle weakness in six muscle groups between zero and five (Kleyweg 1991) (Table 1). When added up, a cut-off of 48 may be used to indicate clinically relevant weakness (De Jonghe 2002). This tool was validated in individuals who are awake and co-operative using standard evaluation of consciousness. During the early unconscious phase of critical illness, such evaluation may often not be possible. Information from clinical examination is then limited. Electrophysiological testing may be used also during this early stage to confirm the diagnosis and to exclude other causes of weakness. Nerve conduction studies (NCS) show normal or near normal nerve conduction velocity, in contrast to Guillain-Barré syndrome, in which demyelination occurs. In CIP, NCS also typically show reduced nerve conduction amplitudes. Electromyography (EMG) often reveals abundant spontaneous electrical activity. EMG and NCS findings are not specific, however, and occur in CIP as well as in CIM and in other disorders. Therefore, differentiating between CIP and CIM using electrophysiological data is often only possible when individuals are fully co-operative and voluntary motor unit potential recruitment can be studied. Also, direct muscle stimulation can be helpful, although it is technically demanding. Co-existence of CIP and CIM can also make interpretation difficult. Ultimately, electrophysiological findings always need to be correlated with clinical findings. Finally, muscle biopsy can confirm muscle involvement and differentiate between the three subtypes of CIM: diffuse nonnecrotising myopathy or CIM in the strict sense; thick filament myopathy; and acute necrotising myopathy.

Due to the difficulty in differentiating between CIP and CIM, and the frequent association of both, terminology used in the literature is often inconsistent and sometimes merely descriptive (for example 'ICU acquired paresis' and 'acquired neuromuscular disorders'), and both disorders are frequently grouped together as critical illness polyneuromyopathy or critical illness polyneuropathy and myopathy (CIP/CIM).

The incidence rates reported in the literature vary according to patient population, definition and timing of evaluation. For instance, in individuals with sepsis or systemic inflammatory response syndrome the incidence is $70 \%$ (Witt 1991), and rises up to $100 \%$ if complicated by multiple organ failure (MOF) (Tennilä 2000). Among individuals in the intensive care unit (ICU) for at least seven days, 25\% will develop weakness (De Jonghe 2002), and $49 \%$ to $84 \%$ electrophysiological abnormalities (Coakley 1998; Hermans 2007; Van den Berghe 2005).

Figure 1 outlines hypotheses on the pathophysiology of CIP/CIM. Many risk factors have been related to the incidence of CIP. Both prospective and retrospective trials have found sepsis, systemic inflammatory response syndrome (SIRS) and multiple organ failure to play a key part in the development of CIP. Many other factors have been incriminated, although results have not always been consistent. Factors identified as independent risk factors by prospective studies are: female sex (De Jonghe 2002), severity of illness (Bednarík 2005; de Letter 2001; Nanas 2008), duration of organ dysfunction (De Jonghe 2002), renal failure and renal replacement therapy (Garnacho-Montero 2001), hyperglycaemia (Hermans 2007; Nanas 2008; Van den Berghe 2005), hyperosmolality (Garnacho-Montero 2001), parenteral nutrition (Garnacho-Montero 2001), serum albumin (Witt 1991), duration of ICU stay (Van den Berghe 2005; Witt 1991), vasopressor and catecholamine support (Hermans 2007; Van den Berghe 2005), and central neurological failure (Garnacho-Montero 2001).

Interventions for preventing critical illness polyneuropathy and critical illness myopathy (Review) 
Figure I. Presumed pathophysiological mechanisms and their interactions involved in the development of CIP/CIM. Dark shaded area indicates events taking place in the nerves, light shaded area indicates events taking place in the muscle. (Additional abbreviations: ROS, reactive oxygen species; SR, sarcoplasmic reticulum).

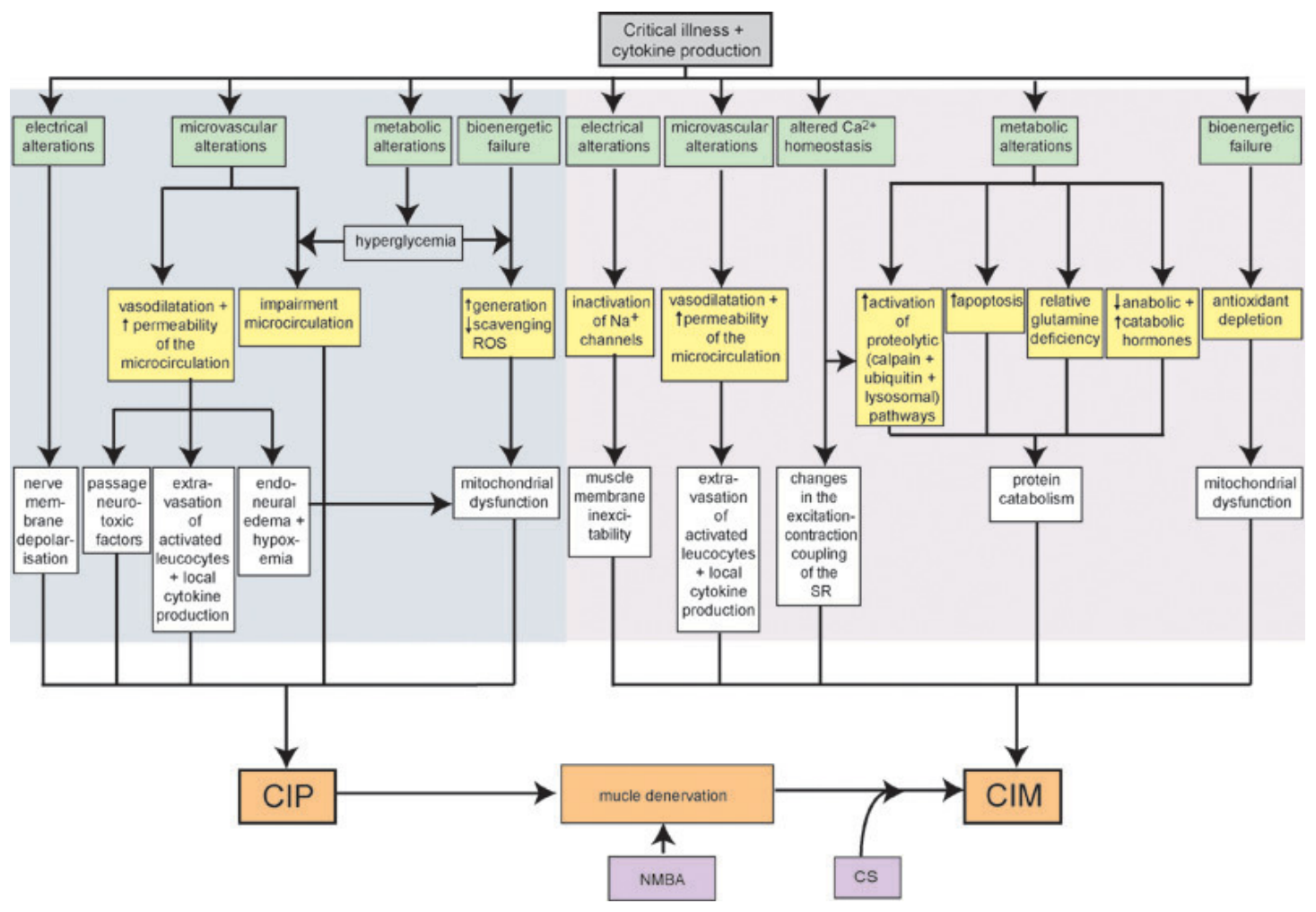

Data on the impact of corticosteroids on neuromuscular function are controversial. Many reports found CIM to occur in individuals treated with a combination of corticosteroids and neuromuscular blocking agents (NMBAs). However, most prospective studies could not identify corticosteroids as an independent risk factor for CIP (Garnacho-Montero 2001), CIP/CIM (Bednarík 2005; de Letter 2001; Nanas 2008; Van den Berghe 2005), or CIM (Weber-Carstens 2010), although two other prospective trials on weakness did (De Jonghe 2002; Herridge 2003). In one study, corticosteroids were even found to be an independent protective factor for the occurrence of CIP/CIM (Hermans 2007). Most prospective trials also could not identify NMBA use as an independent risk factor for CIP or CIP/CIM (Bednarík 2005; De Jonghe 2002; Nanas 2008; Van den Berghe 2005), although other trials did (Garnacho-Montero 2001; Hermans 2007). A recent randomised controlled trial (RCT) in severe acute respiratory distress syndrome (ARDS) did not show increased muscle weakness in participants randomised to an early, short course of NMBAs, compared with controls (Papazian 2010).

Until recently, the only possible way to affect the incidence of CIP and CIM was by controlling risk factors. This includes aggressive treatment of sepsis and avoiding or limiting the use of corticosteroids and NMBAs to the lowest dose possible and the shortest time feasible.

\section{Description of the interventions and how they might work}

\section{Nutritional therapy}

Caloric deficit rapidly develops during critical illness due to the dysfunctional gastro-intestinal tract. This catabolic state is considered to contribute to muscle wasting and weakness. Whether addition of parenteral feeding can reverse this and improve muscle function is unclear (Berek 1997a; Bolton 1984; Waldhausen 1997). Glutamine is relatively deficient in critically ill individuals, markedly reduced in muscle biopsies taken during critical illness and possibly pathogenically linked to CIM (Burnham 2005; Weitzel 2009). Arginine is another conditionally essential amino acid, potentially crucial for maintaining body protein homeostasis in critical illness (Burnham 2005). We therefore examined the effects of various feeding protocols such as enteral feeding, parenteral feeding and therapies such as protein and amino acid sup- 
plementation.

\section{Antioxidant therapy}

Excess production of free oxygen radicals and diminished endogenous antioxidant mechanisms have been implicated in multiple organ failure and septic shock (Brealey 2002). Muscle biopsies in critically ill individuals also show decreased levels of glutathione (GSH), an intracellular antioxidant (Hammarqvist 1997). Antioxidant therapy may therefore, improve outcome because of its ability to scavenge free oxygen radicals and replete GSH stores.

\section{Hormonal therapy}

The loss of lean body mass in critical illness is associated with a disturbed balance between catabolic and anabolic hormones. Correcting this balance by hormonal therapy may therefore be beneficial. Testosterone derivates increase weight (Berger 1996), survival (Mendenhall 1993), improve nitrogen balance (Michelsen 1982), and increase inspiratory muscle strength (Schols 1995), in various settings. Evidence of hypogonadism was found in males with CIP/CIM (Sharshar 2010). Therefore, the use of testosterone in critically ill males is theoretically attractive.

Basal growth hormone secretion is increased in acute critical illness but circulating levels of insulin-like growth factor 1 (IGF-1) are low secondary to resistance to growth hormone. This may contribute to increased protein turnover and negative nitrogen balance in this condition. Treatment with recombinant human growth hormone improves nitrogen balance (Gore 1991; Jeevanandam 1995; Pape 1991; Ponting 1988; Voerman 1992; Voerman 1995; Ziegler 1990), which opens perspectives for clinical effects on muscle function.

Hyperglycaemia is possibly detrimental for the peripheral nerve in critical illness due to impairment of the microcirculation (Bolton 2005; Witt 1991). Passive uptake of glucose with increased generation or deficient scavenging of reactive oxygen species may also have neurotoxic effects (Van den Berghe 2004). Avoiding hyperglycaemia by using insulin, on the other hand, might exert a protective effect on the neural mitochondrial function (Van den Berghe 2005), and also reduce organ damage by endothelial protection through diminished release of nitric oxide (Langouche 2005).

Some rationale also exists for treatment with corticosteroids as these drugs may not only improve survival in some ICU subpopulations (for example, septic shock, ARDS and acute asthma) but could also reduce the duration and severity of multiple organ failure, a major determinant of CIP/CIM (Bollaert 1998; Boyer 2006; Briegel 1999; Chalwa 1999; Meduri 1998; Rowe 2001; Steinberg 2006). Furthermore, corticosteroids independently protected against CIP/CIM in one prospective trial (Hermans 2007).

\section{Intravenous immunoglobulins}

Immune mechanisms may be implicated in the pathogenesis of CIP/CIM. In a retrospective study, early treatment of Gram-negative sepsis with immunoglobulins may have prevented CIP (Mohr 1997).

\section{Physical therapy and rehabilitation programs}

Early physical therapy and mobilisation of critically ill individuals appear feasible and safe (Morris 2008). As duration of immobilisation is a risk factor for CIP/CIM, early mobilisation could affect its incidence, possibly by obviating disuse atrophy that undoubtedly dominates this disorder (Pandit 2006).

\section{Electrical muscle stimulation}

Electrical muscle stimulation (EMS) increased exercise tolerance and muscle strength in several populations, such as chronic obstructive pulmonary disease (COPD) (Vivodtzev 2006), and chronic heart failure (Deley 2005; Nuhr 2004). In the setting of critical illness, EMS has been shown to preserve muscle mass (Gerovasili 2009b) and to exert a short-term systemic effect on the microcirculation (Gerovasili 2009a), which makes it a potentially interesting strategy.

\section{Why it is important to do this review}

This review is important for several reasons. Two previous systematic reviews on CIP/CIM have been published (De Jonghe 1998; Stevens 2007). The first review considered prospective cohort studies and focused on assessment and outcomes. The second review aimed to determine prevalence, risk factors and outcome. In the current systematic review, we aimed to specifically assess the effect of any intervention, studied in an RCT, on the incidence of CIP/CIM. In ICU, interventions to reduce mortality are obviously of paramount importance. However, in acute phase survivors, reduction of morbidity is also imperative. CIP/CIM is now recognised as a major complication of severe critical illness and its highly sophisticated management in the ICU. As both locomotor and respiratory muscles can be involved, CIP/CIM can significantly affect weaning from mechanical ventilation and recovery of physical autonomy. Therefore, interventions demonstrated to reduce the incidence of CIP/CIM are expected to have a beneficial effect on weaning and mechanical ventilation duration, muscle function and overall locomotor autonomy in the recovery phase as well as long-term functional disability. Improvement may take weeks in mild cases and months in severe cases. In more severe cases, recovery may be incomplete or not occur at all. Accumulating evidence points to CIP/CIM as an important contributor to profound long-term disability after ICU stay (Herridge 2011). Although less clearly investigated to date, other potential adverse consequences of CIP/CIM include negative psychological impact, higher residual mortality after the acute phase, and increased costs. 
No systematic review of interventions to prevent CIP/CIM is currently available. This review was first published in 2009 (Hermans 2009), and this is the first update.

\section{O B J E C T I V E S}

To systematically review the evidence from RCTs concerning the ability of any intervention to reduce the incidence of CIP or CIM in critically ill individuals.

\section{METHODS}

\section{Criteria for considering studies for this review}

\section{Types of studies}

We included all RCTs in humans that compared the efficacy of any treatment used to prevent or reduce the incidence of CIP or CIM as a primary or secondary outcome to placebo, no treatment or a different treatment.

\section{Types of participants}

Adults (over 18 years) of either sex, admitted to a medical, surgical or mixed ICU.

\section{Types of interventions}

We included in the review any form of intervention that has been related in the literature to a decreased risk of CIP or CIM or both. Interventions include:

- nutritional interventions:

○ enteral versus parenteral feeding; and

○ supplemental therapies such as protein and amino acid supplementation (glutamine and arginine);

- antioxidant therapy (for example, glutathione or n-acetyl cysteine);

- hormone therapy: testosterone, oxandrolone, growth hormone, IGF-1, intensive insulin therapy (IIT) and glucocorticoids;

- intravenous immunoglobulin;

- physiotherapy;

- EMS; and

- rehabilitation programs.

\section{Types of outcome measures}

\section{Primary outcomes}

The primary outcome measure was the incidence of CIP/CIM during ICU stay. We extracted this outcome measure in ICU. As no internationally accepted criteria exist for this diagnosis, we defined CIP/CIM for the purpose of this review as weakness of the limbs or respiratory muscles, or as EMG documented peripheral polyneuropathy or myopathy for which causes other than CIP/ CIM have been excluded.

\section{Secondary outcomes}

Secondary outcome measures included clinically relevant consequences from a possible reduction in the incidence of CIP/CIM and also any possible side effects of the therapy. The secondary outcomes are limited by their surrogate nature as outcome measures for CIP/CIM, as they can be influenced by other ICU complications.

(a) Duration of mechanical ventilation. This was defined as the time to actual and final liberation from the ventilator

(b) Duration of ICU stay

(c) Death at 30 days (after ICU admission)

(d) Death at 180 days (after ICU admission)

(e) Serious adverse events from the treatment regimens, which were fatal, life-threatening or required prolonged hospital stay (eg hypoglycaemia, hyperglycaemia, and organ failure)

\section{Search methods for identification of studies}

\section{Electronic searches}

On 4 October 2011, we searched the Cochrane Central Register of Controlled Trials (CENTRAL) (2011, Issue 3 in The Cochrane Library), MEDLINE (January 1966 to September 2011) and EMBASE (January 1980 to September 2011). We used a combination of $\mathrm{MeSH}$ and keyword searching in these databases. The detailed search strategies are listed in the appendices: CENTRAL (Appendix 1), MEDLINE (Appendix 2), and EMBASE (Appendix 3). Shortly before publication, on 3 December 2013, we updated the electronic database searches. We screened titles and abstracts to identify any studies potentially eligible for inclusion. We have included these studies as Studies awaiting classification, for full assessment in the next update of the review.

\section{Searching other resources}

We reviewed the bibliographies of the RCTs identified and contacted trial authors and known experts in the field to identify additional unpublished data. 


\section{Data collection and analysis}

\section{Selection of studies}

Two of the four review authors independently checked titles and abstracts identified from the searches. We obtained the full text of all potentially relevant studies and the authors decided which trials fit the inclusion criteria. If the two authors did not agree, the authors achieved consensus by discussion.

\section{Data extraction and management}

Two review authors independently extracted data. We obtained data on 'Risk of bias' criteria, baseline characteristics and relevant data for the primary and secondary outcome measures if available. When there were missing data we contacted the investigator whenever possible. We also sought information about participants who were randomised but excluded from analyses in the original trial publications and, if available, incorporated their data into the analysis.

\section{Assessment of risk of bias in included studies}

Our 'Risk of bias' assessment took into account security of randomisation, allocation concealment, observer and participant blinding, completeness of follow-up, intention-to-treat analysis and explicit diagnostic criteria. Allocation concealment relates to the randomisation procedures, whereby investigators involved in participant allocation should not be able to influence how the groups are assembled. It involves concealment of the next allocation in the randomisation sequence, such that neither the investigator nor the participants can be aware of the next group assignment until after the decision about whether an individual is eligible for the trial has been finalised. We graded these items as low, unclear or high risk of bias according to the criteria formulated in the Cochrane Handbook for Systematic Reviews of Interventions (Higgins 2011a). If the information needed to make an assessment was not available, we graded the item as at an unclear risk of bias. For some items where there was insufficient information to form a judgement, we attempted to contact the study authors to obtain additional information about the trial design. Two review authors independently assessed the risk of bias. In the event of disagreement between the two authors, agreement was reached by consensus. One review author entered data into the Cochrane statistical package, Review Manager 5 (RevMan 2012), and a second author checked the data entry.

\section{Measures of treatment effect}

We analysed and presented results according to the statistical guidelines of The Cochrane Collaboration as described in Chapter 9 of the Cochrane Handbook for Systematic Reviews of Interventions
(Deeks 2011). The reliability of the various pieces of evidence obtained form part of the Discussion. We analysed and presented trials of each intervention separately. We presented dichotomous outcome data as risk ratios (RRs) and risk differences (RD) with 95\% confidence intervals (CIs). We presented continuous outcome data as mean differences (MDs) with $95 \%$ CIs. We used the fixed-effect model and where there was heterogeneity we repeated the analysis using the random-effects model.

\section{Assessment of reporting biases}

There were too few included studies for a funnel plot to be appropriate.

\section{'Summary of findings' tables}

We applied the Grading of Recommendations Assessment, Development and Evaluation (GRADE) assessment method to the studies included to determine the quality of evidence across outcomes. We used methods and recommendations described in Section 8.5 and Chapter 12 of the Cochrane Handbook for Systematic Reviews of Interventions (Higgins 2011a) using GRADEpro software. The GRADE method considers risk of bias, directness of evidence, unexplained heterogeneity or inconsistency of results, precision of effect and risk of publication bias as factors determining the quality of evidence (Atkins 2004). We included all our primary and secondary outcomes for which data were available.

\section{Sensitivity analysis}

We did not perform a sensitivity analysis excluding studies with the lowest quality as we could only pool data for two studies.

\section{Risk of bias in the review process}

We have reported any discrepancies between the review and the published protocol (Hermans 2007) in Differences between protocol and review.

\section{R E S U L T S}

\section{Description of studies}

The search strategy in 2009 identified 23 potentially relevant references, of which 14 were excluded. Nine trials fulfilled the selection criteria (Caruso 2005; Hermans 2007; Johnson 1993; Pichard 1996; Steinberg 2006; Takala 1999a; Takala 1999b; Van den Berghe 2005; Watters 1997). For this revision, we defined our inclusion criteria more clearly and more strictly, to consider only those trials that actually reported the incidence of CIP/CIM as 
a primary or secondary outcome. Therefore, we excluded studies that reported other neuromuscular outcomes but not the incidence of CIP/CIM (Caruso 2005; Johnson 1993; Pichard 1996; Takala 1999a; Takala 1999b; Watters 1997). We also modified the search strategy to increase its sensitivity. The MEDLINE search in October 2011 revealed another 10 possibly relevant references, out of the 343 that were retrieved. We excluded eight of these: one was not an intervention trial (Brunello 2010), another two trials were not performed in the ICU (Chiang 2006; Toledo 2007) and finally, five trials did not provide the incidence of CIP/CIM as a primary or secondary outcome (Burtin 2009; Gerovasili 2009a; Gruther 2010; Morris 2008; Zanotti 2003). Two trials remained that fulfilled the selection criteria (Routsi 2010; Schweickert 2009). Our search of EMBASE up to October 2011 revealed another seven out of 408 retrieved studies, for possible inclusion. One trial was a subanalysis of the EMS trial (Karatzanos 2012), and five others did not provide the incidence of CIP/CIM as a primary or secondary outcome (Alia 2010; Chen 2011; Martin 2011; Miao 2005; Routsi 2009). One trial randomised body parts rather than participants (Rodriguez 2012). Additionally, two out of the 159 references retrieved by CENTRAL were of potential interest. Both were excluded because of the absence of the incidence of CIP/CIM as a primary or secondary outcome (Huang 2006), or because the intervention was not investigated with the potential to reduce the incidence of CIP/CIM (Papazian 2010). Searching the Cochrane Neuromuscular Disease Group Specialized Register produced another 10 hits which did not result in any new references. Other data sources revealed another four references which were all excluded because the studies were not performed in the ICU (Menadue 2010; Salisbury 2010; Vivodtzev 2006) or did not present the incidence of CIP/CIM as a primary or secondary outcome (Gerovasili 2009a).

We excluded a total of 41 studies. Five trials fulfilling the inclusion criteria for this review remained (Hermans 2007; Routsi 2010; Schweickert 2009; Steinberg 2006; Van den Berghe 2005).

We updated the searches in December 2013 and identified nine trial reports that require further assessment (see Characteristics of studies awaiting classification). We will assess these trials for inclusion in the next update of the review. We also identified two trial protocols from these searches (see Characteristics of ongoing studies).

Two of the five included trials (Hermans 2007; Van den Berghe 2005) were planned subgroup analyses of the secondary outcomes of two prior trials that compared treatment with IIT versus conventional insulin therapy (CIT) on mortality and morbidity outcomes in ICU (Van den Berghe 2001; Van den Berghe 2006a). The two primary trials included 2748 participants randomised to IIT or CIT, of whom 1548 were in a surgical ICU following cardiac surgery $(63 \%)$ or had medical/surgical complications after other surgery or trauma (37\%) (Van den Berghe 2001), and 1200 were in a medical ICU, with a variety of conditions (Van den Berghe 2006a). Between 13\% and 17\% of the participants had diabetes prior to admission. At day seven, 1923 participants in these primary trials had been discharged from the ICU or had died, leaving a total of 825 participants who were evaluable for 'screening' for CIP/CIM and were included in the two secondary trials (see Characteristics of included studies). Van den Berghe 2005 evaluated patients treated in the surgical ICU and included 405 participants who reached seven days of ICU care, from among the 1548 participants in the original surgical ICU randomisation. Hermans 2007 enrolled patients in the sister medical ICU study, and included 420 of the 1200 participants in the primary study. The investigators diagnosed CIP/CIM in these 825 participants by weekly electrophysiological examination. The neurophysiologist performing the EMG screening, who determined the presence or absence of diagnostic EMG changes, was blinded to the treatment group. Assessments of mortality and length of stay were not blinded. Significantly fewer participants treated with IIT in the original surgical ICU study (Van den Berghe 2001), but not in the medical study (Van den Berghe 2006a), reached the CIP/CIM screening period because of the benefit of IIT in the first seven days, a possible source of bias in the subsequent results. Any bias as such originated from earlier ICU discharge in the intervention group and would be expected to reduce rather than inflate the effect. Both trials were single centre trials.

One trial compared therapy with corticosteroids versus placebo in 180 participants with unresolving ARDS (Steinberg 2006). Intravenous methylprednisolone was given at a starting dose of $2 \mathrm{mg} /$ $\mathrm{kg} /$ day then gradually tapered over more than three weeks. During this trial, six adverse events of neuromyopathy were reported. This was followed by a retrospective chart review of all the 88 previously enrolled participants, ordered by the safety board. From then on, neuromyopathy was prospectively evaluated in the next 92 participants.

One trial randomised 104 critically ill medical individuals within 72 hours of mechanical ventilation to early physical and occupational therapy co-ordinated with daily interruption of sedatives, versus standard care (Schweickert 2009). The latter included the interruption of sedatives and physiotherapy as ordered by the treating physician. The participating sites did not usually order physiotherapy for individuals mechanically ventilated for less than two weeks. Participants were all living independently premorbidly and expected to be ventilated for at least one more day. CIP/CIM was evaluated using the MRC sum-score. For participants who never awakened, the authors of the study imputed a zero MRC score. One trial randomised 140 participants on the second day of ICU stay to daily sessions of bilateral lower limb EMS versus control, without sham stimulation (Routsi 2010). CIP/CIM was diagnosed using the MRC sum-score with a cut-off of 48. Only 24 EMS and 28 control participants were actually evaluable. The reasons for missing MRC data included death, impaired cognitive state or dropout because of prolonged neuromuscular blocking treatment or no EMS sessions received. In the evaluable participants, a significant baseline difference was present between EMS and control 
participants in their APACHE II score (EMS $16 \pm 4$, control 19 \pm 5 ; $\mathrm{MD}-3.00,95 \% \mathrm{CI}-5.45$ to -0.55$)$, diagnostic categories on admission $(\mathrm{P}=0.05)$ and the presence of comorbid renal disease (EMS 0\%, control 21\%; P $=0.03$; RR 0.07, 95\% CI 0 to 1.33 ) (Karatzanos 2012), which possibly influences the significance of any results.

\section{Risk of bias in included studies}

The risk of bias for the individual trials is described in Characteristics of included studies and Figure 2 provides a summary of review authors' judgements across all domains for all studies. 
Figure 2. Risk of bias summary: review authors' judgements about each risk of bias item for each included study. Red (-) = high risk of bias; green $(+)=$ low risk of bias; yellow (?) = unclear risk of bias (not shown).

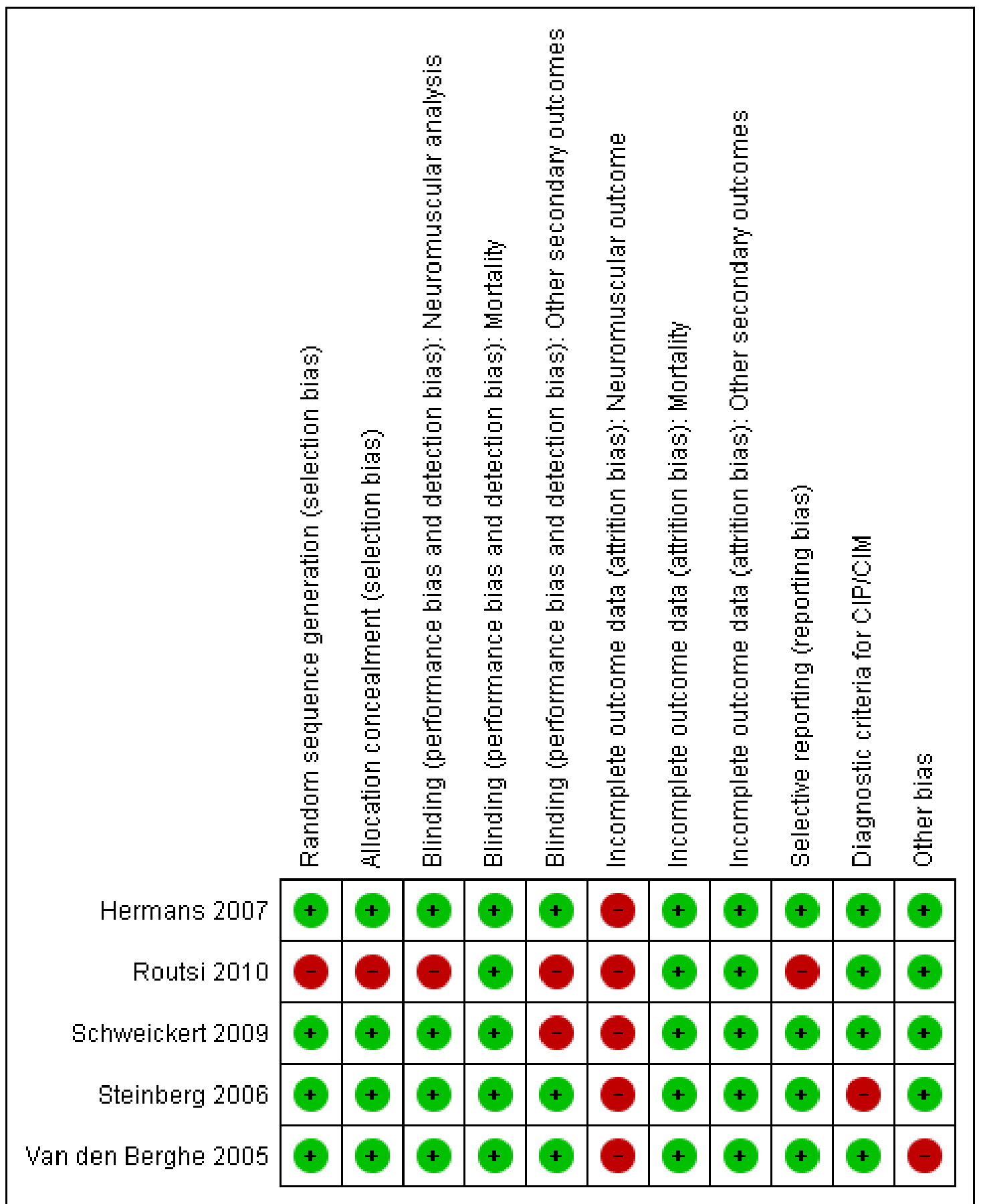

Interventions for preventing critical illness polyneuropathy and critical illness myopathy (Review) 
In four trials, we considered random sequence generation, allocation concealment, and blinding for the neuromuscular outcome to be at low risk of bias (Hermans 2007; Schweickert 2009; Steinberg 2006; Van den Berghe 2005). In one trial, we considered sequence generation and allocation concealment to be at high risk of bias because the trialists used odd and even numbers for group assignments (Routsi 2010). In Routsi 2010, blinding for neuromuscular outcome data was also judged to be at high risk of bias because outcome assessors were not blinded to the participant allocation. We considered blinding for mortality at low risk of bias in all trials, as knowledge of the intervention is unlikely to affect this outcome (Higgins 2011b). Blinding for other secondary outcomes was at high risk of bias in two trials (Routsi 2010; Schweickert 2009) and at low risk in the remaining trials. We judged completeness of follow-up for the neuromuscular outcome as at high risk of bias because of the substantial amount of imputed data in four trials (Hermans 2007; Schweickert 2009; Steinberg 2006; Van den Berghe 2005). We also assigned a high risk of bias for this item to the EMS trial because of imbalance in the screened patients and because it was necessary to impute a large amount of data to perform an intention-to-treat analysis (Routsi 2010). Attrition bias for mortality and for other secondary outcomes was low in all studies. One study lacked adequate diagnostic criteria (Steinberg 2006). In this trial, no clear predefined diagnostic criteria were used for either the retrospectively or prospectively evaluated participants. In the four other trials reporting data on our primary outcome measure, predefined electrophysiological or clinical criteria were used (Hermans 2007; Routsi 2010; Schweickert 2009; Van den Berghe 2005). We therefore graded them as at low risk of bias in this respect. In one trial, we identified an additional risk of bias as the trial was stopped due to a formal, but data-dependent, stopping rule (Van den Berghe 2005).

We used unpublished information derived from the authors to assess certain items for three trials (Hermans 2007; Schweickert 2009; Van den Berghe 2005).

\section{Effects of interventions}

See: Summary of findings for the main comparison Intensive insulin therapy versus conventional insulin therapy for preventing critical illness polyneuropathy and critical illness myopathy; Summary of findings 2 Corticosteroids versus placebo compared for preventing critical illness polyneuropathy and critical illness myopathy; Summary of findings 3 Early physical therapy versus control for preventing critical illness polyneuropathy and critical illness myopathy; Summary of findings 4 Electrical muscle stimulation versus control for preventing critical illness polyneuropathy and critical illness myopathy

\section{Intensive insulin therapy versus conventional insulin therapy}

\section{Primary outcome measure: occurrence of CIP/CIM}

Data on the incidence of CIP/CIM were available from both insulin trials for individuals in the ICU for at least seven days (Hermans 2007; Van den Berghe 2005). In the individual studies, significantly fewer participants in the ongoing IIT group developed CIP/CIM compared to the CIT group. In Van den Berghe 2005, the RR was 0.52 (95\% CI 0.39 to 0.69 ) and in Hermans 2007, the RR was 0.77 (95\% CI 0.62 to 0.96). Analysis of the whole surgical population who received CIT or IIT was performed as a post hoc intention-to-treat analysis $(\mathrm{n}=1548)$ with negative imputation performed for participants who were not screened by EMG because they were no longer in the ICU on day seven. In the whole population IIT reduced the risk of CIP/CIM, as assessed by weekly EMG screenings (RR $0.49,95 \%$ CI 0.37 to 0.66 ), but this analysis involved imputing data for $74 \%$ of the participants. A similar analysis in the medical population revealed an RR of 0.84 (95\% CI 0.70 to 1.01 ), with imputation of $72 \%$ of the data.

A meta-analysis of the two insulin trials was possible, which comprised 389 participants treated with IIT and 436 participants treated with CIT. In the surgical trial, but not in the medical trial, significantly fewer IIT participants entered the screened phase. Any bias originated from earlier ICU discharge in the intervention group and would be expected to reduce rather than inflate the effect. Meta-analysis using a fixed-effect model showed a significant benefit of IIT in the 'screened' patients, with an RR of $0.65(95 \%$ CI 0.55 to 0.77 ) (Analysis 1.1, Figure 3). As the statistical heterogeneity here is the result of clinical diversity, the fixed-effect analysis provides the best estimate of the intervention effect (Deeks 2011). Use of a more conservative random-effects model, to account for heterogeneity, changes the RR to 0.64 (95\% CI 0.44 to 0.94 ). With only two studies in the meta-analysis, however, a random-effects analysis provides poor estimates of the distribution of intervention effects (Deeks 2011). Based on the current data, we cannot exclude a real or artificial difference in the effect size between medical and surgical patients. 
Figure 3. Forest plot of comparison: I Intensive insulin therapy (IIT) versus conventional insulin therapy (CIT), outcome: I.I Occurrence of CIP/CIM.

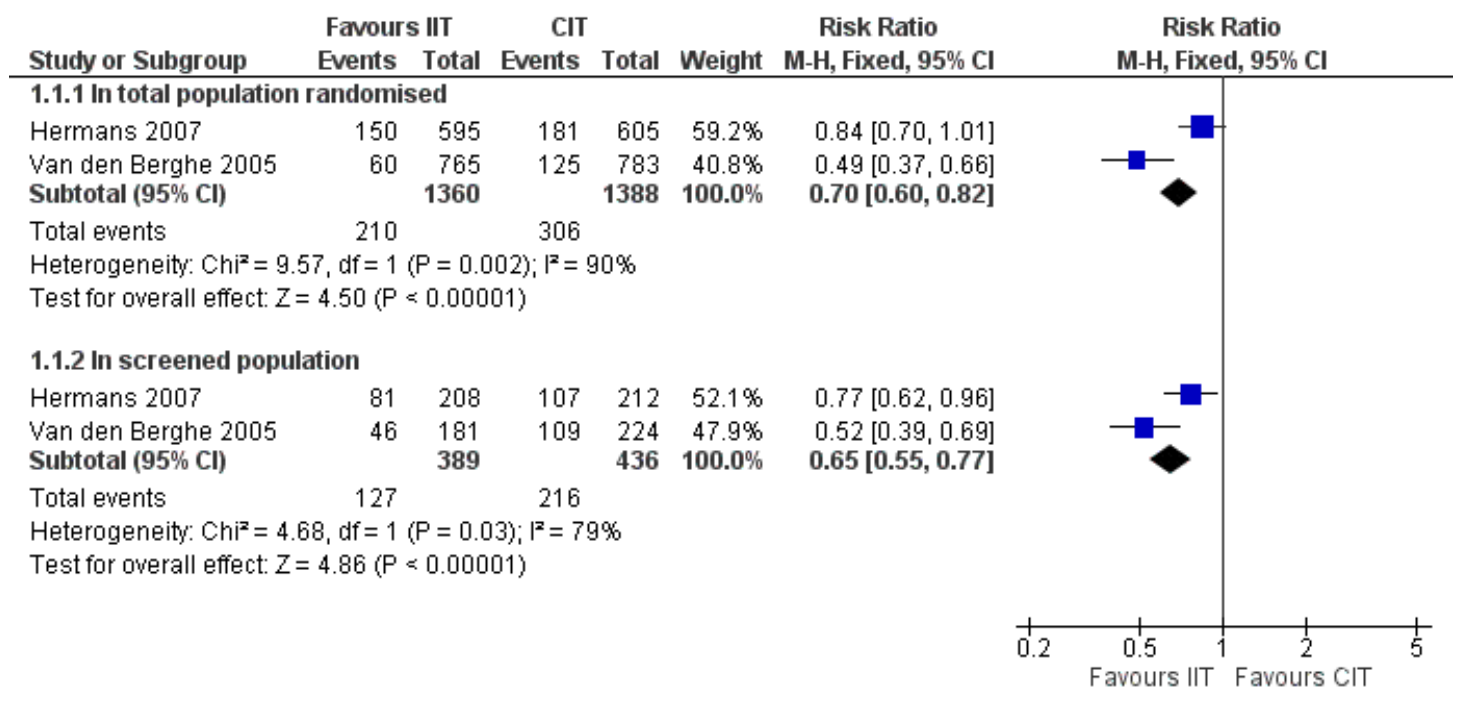

We have also performed an analysis of practicality, as it is not possible to identify individuals upon admission to ICU as needing ICU for at least one week. We analysed data on the primary outcome measure as well as on the secondary outcome measures in the total randomised population (1360 IIT and 1388 CIT participants). As participants who were in the ICU for less than one week did not undergo an electrophysiological examination, we imputed data for them. For the purpose of the analysis, we categorised those who died as having CIP/CIM, whereas we categorised patients discharged early, and therefore not evaluated, as not having CIP/ CIM. This showed that IIT had a significantly beneficial effect on CIP/CIM, with an RR of 0.70 (95\% CI 0.60 to 0.82) (Analysis $1.1)$ but the effect was lost in the random-effects analysis (RR $0.65,95 \%$ CI 0.38 to 1.11 ). This conclusion remained when we imputed data only for participants who had been discharged alive and did not make assumptions about the neuromuscular status of those who died early (fixed-effect model RR 0.60, 95\% CI 0.49 to 0.73 ; random-effects model RR $0.58,95 \%$ CI 0.33 to 1.02 , analysis not shown).

\section{Secondary outcome measures}

\section{Duration of mechanical ventilation}

For the insulin trials, the need for prolonged mechanical ventilation (a surrogate measure of neuromuscular weakness) was defined as mechanical ventilation for at least 14 days. The need for mechanical ventilation was significantly reduced in the IIT group compared to the CIT group, with an RR of 0.76 (95\% CI 0.58 to
0.99) for Van den Berghe 2005 and an RR of 0.74 (95\% CI 0.59 to 0.94 ) for Hermans 2007. In meta-analysis, IIT had a significant beneficial effect on the duration of mechanical ventilation, with an MD of -2.00 days (95\% CI -2.93 to -1.07$)$ for the total population randomised and an MD of -2.55 days (95\% CI -4.60 to $0.51)$ for the population actually included at seven days or more of ICU stay (Analysis 1.2). In practical terms, only people surviving the ICU will benefit from an intervention that reduces CIP/CIM, and so we analysed data for ICU survivors (1181 participants with IIT and 1163 participants with CIT). IIT reduced the duration of mechanical ventilation in the ICU survivors as part of the total population randomised (MD - $1.00,95 \% \mathrm{CI}-1.86$ to -0.14 ) (Analysis 1.2), but not in the subpopulation of ICU survivors who were included with seven or more days of ICU admission.

\section{Duration of ICU stay}

IIT significantly reduced the duration of ICU stay (Hermans 2007; Van den Berghe 2005). The MD was -1.48 days (95\% CI -2.43 to -0.54$)$ for the total population randomised and MD 3.59 days (95\% CI -5.70 to -1.48 ) in the screened population (Analysis 1.3). When we analysed only the population of ICU survivors, the statistical benefit remained in the total randomised group (MD -1.00 days, $95 \% \mathrm{CI}-1.90$ to -0.10 ), but not in the screened population (MD -2.18 days, $95 \%$ CI -4.66 to 0.30 ).

Death at 30 and 180 days 
In the insulin trials, there was no statistically significant effect on mortality at 30 days in the total population (RR $0.94,95 \%$ CI 0.80 to 1.10 ) or in the screened population (RR $0.91,95 \% \mathrm{CI} 0.72$ to 1.14) (Analysis 1.4). With a fixed-effect model, the meta-analysis showed a significant beneficial effect on 180-day mortality (total population RR $0.87,95 \%$ CI 0.76 to 1.00 , screened population RR $0.78,95 \%$ CI 0.66 to 0.93 ). When we used a more conservative random-effects model to take into account the heterogeneity, this effect was lost in the total population (RR $0.83,95 \%$ CI 0.60 to 1.13 ) but confirmed in the screened population (RR $0.79,95 \% \mathrm{CI}$ 0.63 to 0.98$)$. However, this random-effects analysis is bound to provide poor estimates of the distribution of intervention effects, as there were only two studies in the meta-analysis (see primary outcome measure above).

\section{Serious adverse events}

The insulin trials defined hypoglycaemia as blood glucose below $40 \mathrm{mg} / \mathrm{dL}$ and the occurrence of at least two hypoglycaemic events. The incidence of hypoglycaemia was significantly higher in the IIT than the CIT group in both the total patient population randomised (RR 6.27, 95\% CI 4.15 to 9.49), as well as in the screened participants (RR 6.93, 95\% CI 4.10 to 11.72) (Analysis 1.5). There was no increase in death 24 hours after the last hypoglycaemic event in the total population randomised (RR 1.6, 95\% CI 0.42-6.10).

\section{Corticosteroids versus placebo}

\section{Primary outcome measure: occurrence of CIP/CIM}

The steroid trial (Steinberg 2006) provided primary outcome data on clinical weakness. The trial involved 92 participants, of whom 48 received placebo and 44 received corticosteroids. There was no significant difference between the treatment groups according to the data that the trialists obtained prospectively (incidence of CIP/CIM in the placebo group was $11 / 48(23 \%)$, and in the intervention group, $11 / 44$ (25\%); RR 1.09 , 95\% CI 0.53 to 2.26 ) (Analysis 2.1, Figure 4). We also performed an intention-to-treat analysis, by imputing data for the first 88 participants, whom the trial authors did not evaluate prospectively. For this purpose we used the retrospective data available for these participants. With imputed data there was also no significant effect (RR 1.27, 95\% CI 0.77 to 2.08).

Figure 4. Forest plot of comparison: 2 Corticosteroids versus placebo, outcome: 2.I Occurrence of CIP/CIM.

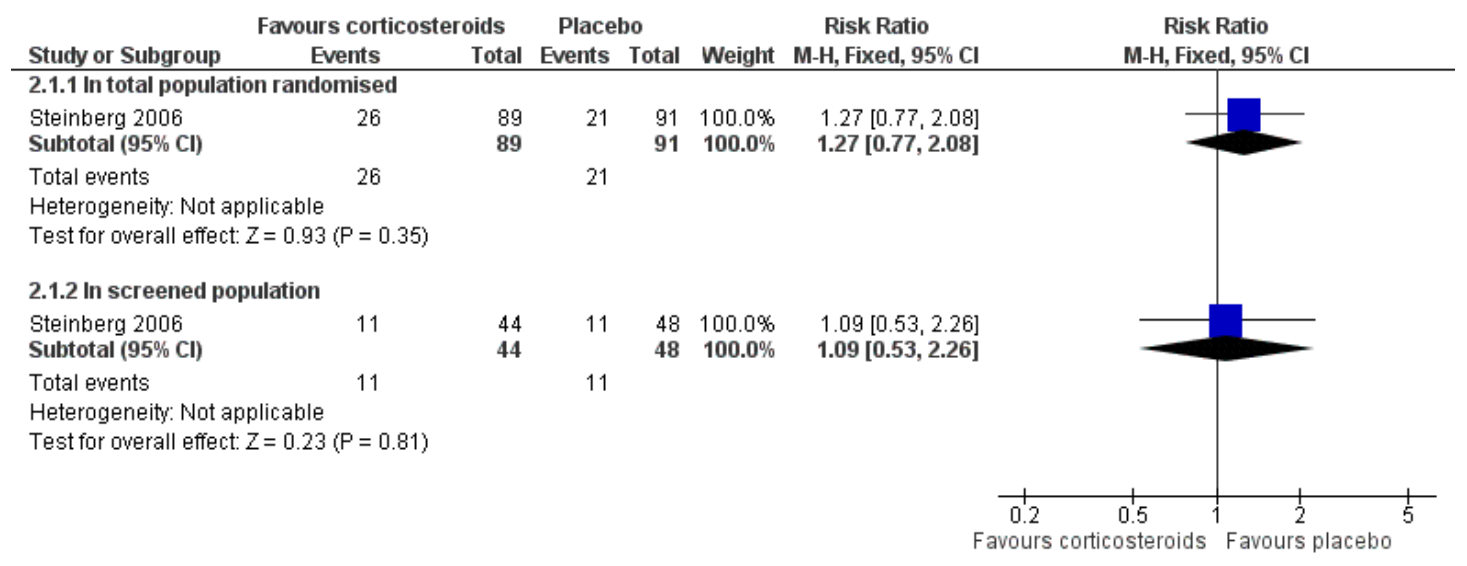

Secondary outcome measures

\section{Duration of mechanical ventilation}

Not reported
Duration of ICU stay

Not reported

Death at 30 and 180 days

Interventions for preventing critical illness polyneuropathy and critical illness myopathy (Review) 
Steroids had no effect on mortality at 180 days (RR 0.99 , 95\% CI 0.64 to 1.52 ) (Analysis 2.2). No data were available at 30 days, as the primary outcome measure of this trial was death at 60 days (which also showed no difference). Subanalyses, however, revealed increased mortality in the steroid-treated participants in the subgroup enrolled at least 14 days after the onset of ARDS at 60 days, as well as at 180 days.

\section{Serious adverse events}

Treatment with corticosteroids appeared to have a protective effect on the occurrence of new episodes of shock (RR 0.41, 95\% CI 0.17 to 1.01 ) (Analysis 2.3), and no significant effect on new serious infections (RR $0.68,95 \%$ CI 0.42 to 1.11 ) or episodes of suspected or probable pneumonia (RR $0.44,95 \%$ CI 0.18 to 1.09). Blood glucose levels reported in this trial on day seven were not significantly different in corticosteroid and placebo groups (MD $15.00 \mathrm{mg} / \mathrm{dL}, 95 \% \mathrm{CI}-3.41$ to 33.41) (Analysis 2.4).

\section{Early physical therapy versus control}

\section{Primary outcome measure: occurrence of CIP/CIM}

The early physical therapy trial reported data on CIP/CIM at hospital discharge and included imputation using an MRC value of zero for non-survivors (Schweickert 2009). There was no significant difference in the incidence of CIP/CIM in the total randomised population at hospital discharge (15/49 in the intervention group versus $27 / 55$ in the control group with significant weakness, RR 0.62 , 95\% CI 0.38 to 1.03 , analysis not shown). We obtained further data about participants with weakness at ICU discharge through personal communication with the study authors. For the total population randomised to early therapy versus standard care (intention-to-treat analysis, imputing worst values for participants who were not evaluable), the RR for the intervention was not significant at ICU discharge (RR 0.81, 95\% CI 0.60 to 1.08) (Analysis 3.1, Figure 5). For participants both randomised and actually screened (alive and co-operative), the RR of CIP/CIM at ICU discharge judged by weakness was 0.62 (95\% CI 0.39 to 0.96) (Analysis 3.1, Figure 5).

Figure 5. Forest plot of comparison: 6 Early physical therapy versus control, outcome: 6.1 Occurence of CIP/CIM.

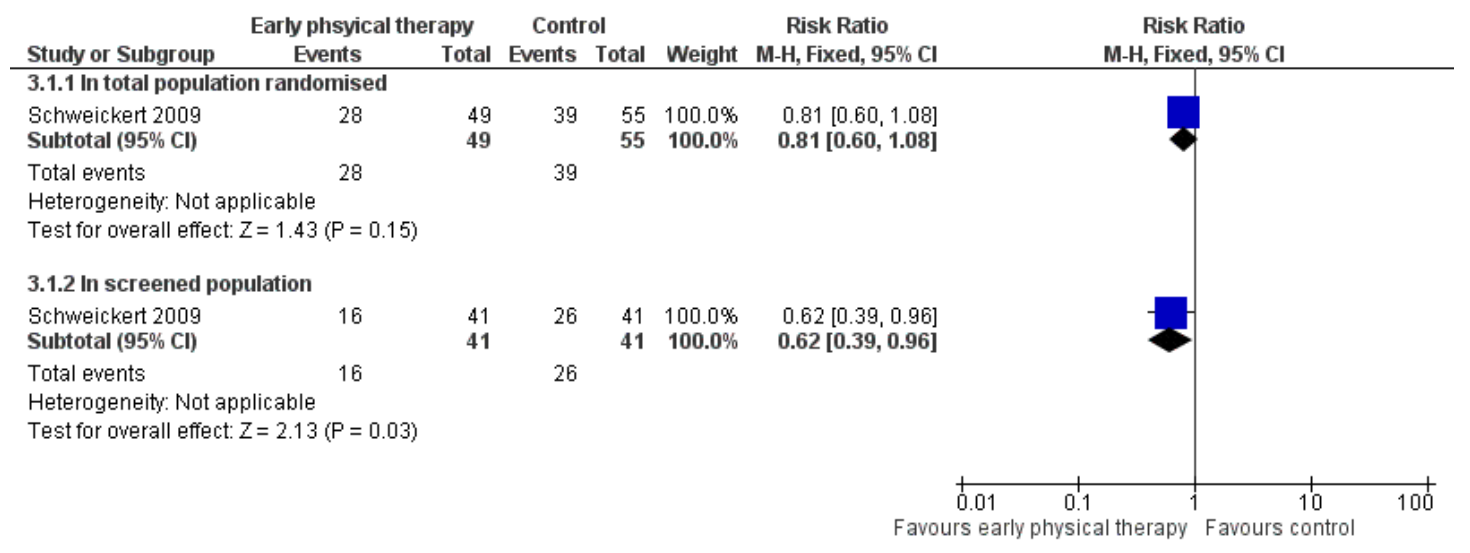

\section{Secondary outcome measures}

\section{Duration of mechanical ventilation}

The early physical therapy trial (Schweickert 2009) reported a significant reduction in the duration of mechanical ventilation (median (IQR) 3.4 days (2.3 to 7.3) versus 6.1 days (4.0 to 9.6)).

\section{Duration of ICU stay}

Schweickert 2009 showed that early physiotherapy had no effect on duration of ICU stay (intervention median 5.9 days (IQR 4.5 to 13.2); control median 7.9 days (IQR 6.1 to 12.9 ), $\mathrm{P}=0.08$ ).

Death at 30 and 180 days 
Schweickert 2009 did not report 30- or 180-day mortality, but hospital mortality was not significantly different.

\section{Serious adverse events}

In one participant in the early physiotherapy group, desaturation < $80 \%$ occurred, which was related to the intervention (Schweickert 2009). From the available data, no significant severe adverse events were observed from early physiotherapy (Analysis 3.2).

\section{Electrical muscle stimulation versus control}

\section{Primary outcome measure: occurrence of CIP/CIM}

Routsi 2010 reported the incidence of weakness in the 52 evaluable participants from among the 140 participants who were randomised to EMS or control groups. The evaluable treatment and control groups were not completely comparable. There were considerable differences in the baseline characteristics and severity of illness between the EMS and control groups (see Description of studies). In this evaluable subset of participants, EMS had no effect on reducing the incidence of CIP/CIM (EMS 3/24, control 11/ 28; RR $0.32,95 \%$ CI 0.10 to 1.01 ). After imputing worst values for the non-evaluated 88 participants, as in Schweickert 2009, the effect of EMS on CIP/CIM was even less significant (RR 0.94, 95\% CI 0.78 to 1.15 ) (Figure 6).

Figure 6. Forest plot of comparison: 4 Elecrical magnetic stimulation versus control, outcome: 4.I Occurrence of CIP/CIM.

\begin{tabular}{|c|c|c|c|c|c|c|c|}
\hline Study or Subgroup & \multicolumn{2}{|c|}{ EMS } & \multicolumn{2}{|c|}{ Control } & Weight & $\begin{array}{c}\text { Risk Ratio } \\
\text { M-H, Fixed, 95\% Cl }\end{array}$ & $\begin{array}{c}\text { Risk Ratio } \\
\text { M-H, Fixed, 95\% Cl }\end{array}$ \\
\hline \multicolumn{8}{|c|}{ 4.1.1 In the total population randomised } \\
\hline $\begin{array}{l}\text { Routsi } 2010 \\
\text { Subtotal }(95 \% \mathrm{Cl})\end{array}$ & 49 & $\begin{array}{l}68 \\
68\end{array}$ & 55 & $\begin{array}{l}72 \\
72\end{array}$ & $\begin{array}{l}100.0 \% \\
\mathbf{1 0 0 . 0} \%\end{array}$ & $\begin{array}{c}0.94[0.78,1.15] \\
\mathbf{0 . 9 4}[0.78, \mathbf{1 . 1 5}]\end{array}$ & \\
\hline $\begin{array}{l}\text { Total events } \\
\text { Heterogeneity: Not a } \\
\text { Test for overall effect }\end{array}$ & $\begin{array}{r}49 \\
\text { plicable } \\
Z=0.58\end{array}$ & $P=0.5$ & 55 & & & & \\
\hline 4.1.2 In screened po & ulation & & & & & & \\
\hline $\begin{array}{l}\text { Routsi } 2010 \\
\text { Subtotal }(95 \% \mathrm{Cl})\end{array}$ & 3 & $\begin{array}{l}24 \\
24\end{array}$ & 11 & $\begin{array}{l}28 \\
28\end{array}$ & $\begin{array}{l}100.0 \% \\
\mathbf{1 0 0 . 0} \%\end{array}$ & $\begin{array}{c}0.32[0.10,1.01] \\
\mathbf{0 . 3 2}[\mathbf{0 . 1 0}, \mathbf{1 . 0 1}]\end{array}$ & \\
\hline $\begin{array}{l}\text { Total events } \\
\text { Heterogeneity: Not a } \\
\text { Test for overall effect }\end{array}$ & $\begin{array}{l}{ }^{3} \\
\text { plicable } \\
Z=1.94\end{array}$ & $P=0.0$ & 11 & & & & \\
\hline
\end{tabular}

\section{Secondary outcome measures}

\section{Duration of mechanical ventilation}

EMS did not significantly reduce the duration of mechanical ventilation (Routsi 2010).

\section{Duration of ICU stay}

Routsi 2010 also found no effect for EMS on duration of ICU stay (mean (range): EMS 14 days (4 to 62); control 22 days (2 to 92), $\mathrm{P}=0.11)$.

\section{Death at 30 and 180 days}

Routsi 2010 reported no difference in ICU mortality with EMS, but no data are available for mortality at 30 or 180 days.

\section{Serious adverse events}

The EMS trial provided no systematic evaluation of adverse events (Routsi 2010). 


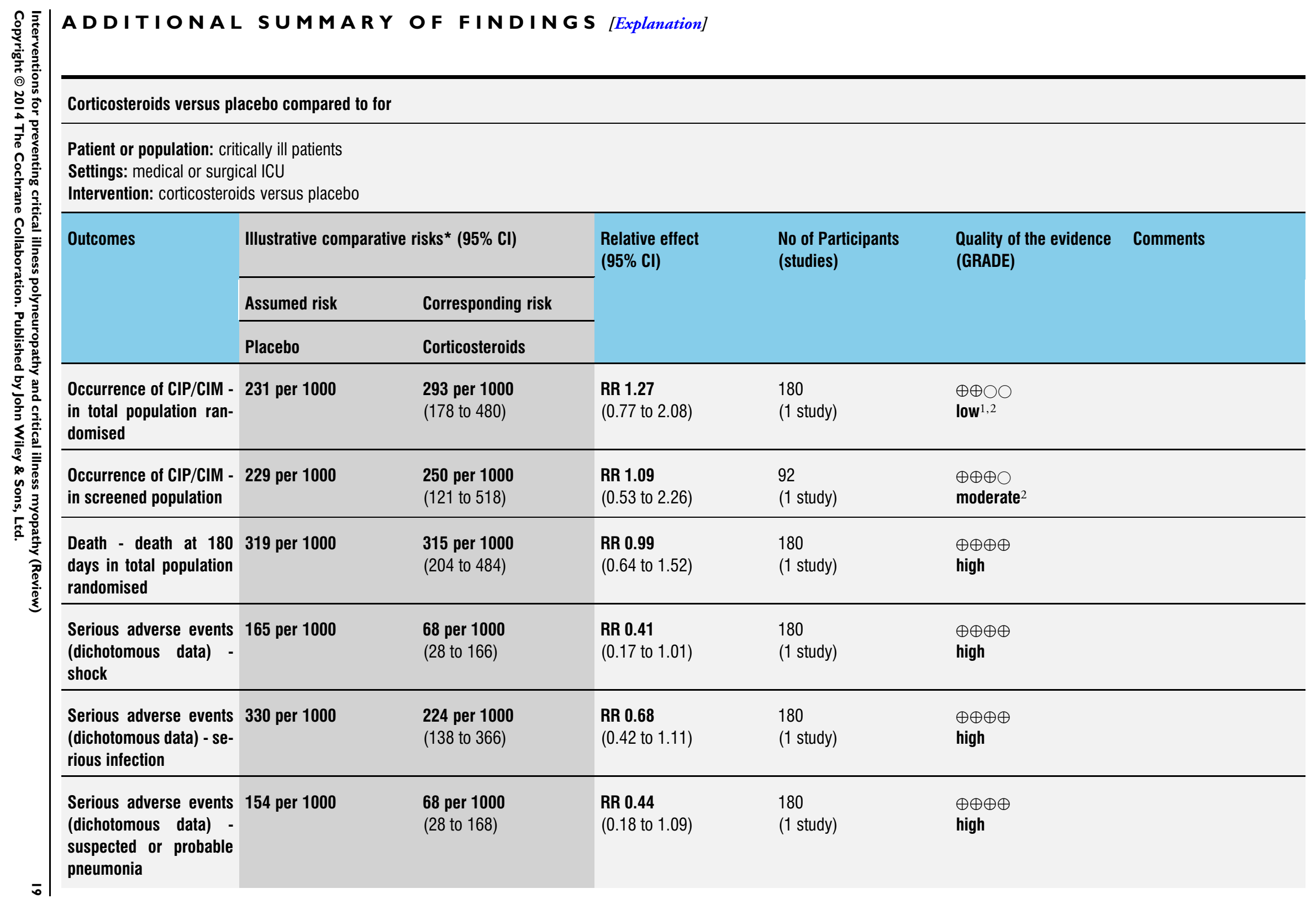




\begin{tabular}{|c|c|c|c|}
\hline $\begin{array}{l}\text { Serious adverse events } \\
\text { (continuous data) - } \\
\text { blood glucose (mg/dL) } \\
\text { on day } 7\end{array}$ & $\begin{array}{l}\text { The mean blood glucose } \\
\text { on day } 7 \text { in the interven- } \\
\text { tion groups was } \\
\mathbf{1 5} \mathbf{~ m g / d L ~ h i g h e r ~} \\
\text { ( } 3.41 \text { lower to } 33.41 \\
\text { higher) }\end{array}$ & $\begin{array}{l}180 \\
\text { (1 study) }\end{array}$ & $\begin{array}{l}\oplus \oplus \oplus \oplus \\
\text { high }\end{array}$ \\
\hline
\end{tabular}

*The basis for the assumed risk (eg the median control group risk across studies) is provided in footnotes. The corresponding risk (and its $95 \%$ confidence interval) is based on the assumed risk in the comparison group and the relative effect of the intervention (and its $95 \% \mathrm{Cl}$ ).

CI: confidence interval; ICU: intensive care unit; RR: risk ratio

GRADE Working Group grades of evidence

High quality: further research is very unlikely to change our confidence in the estimate of effect.

Moderate quality: further research is likely to have an important impact on our confidence in the estimate of effect and may change the estimate.

Low quality: further research is very likely to have an important impact on our confidence in the estimate of effect and is likely to change the estimate.

Very low quality: we are very uncertain about the estimate.

Imputation of a substantial amount of data

2 No clear diagnostic criteria for CIP/CIM stated. 
Early physical therapy versus control for preventing critical illness polyneuropathy and critical illness myopathy

Patient or population: critically ill patients

Settings: medical or surgical ICU

Intervention: early physical therapy versus control

\begin{tabular}{|c|c|c|c|c|c|c|}
\hline \multirow[t]{3}{*}{ Outcomes } & \multicolumn{2}{|c|}{ Illustrative comparative risks* $(95 \% \mathrm{Cl})$} & \multirow{3}{*}{$\begin{array}{l}\text { Relative effect } \\
(95 \% \mathrm{Cl})\end{array}$} & \multirow{3}{*}{$\begin{array}{l}\text { No of Participants } \\
\text { (studies) }\end{array}$} & \multirow{3}{*}{$\begin{array}{l}\text { Quality of the evidence } \\
\text { (GRADE) }\end{array}$} & \multirow[t]{3}{*}{ Comments } \\
\hline & Assumed risk & Corresponding risk & & & & \\
\hline & Control & Early physical therapy & & & & \\
\hline $\begin{array}{l}\text { Occurrence of CIP/CIM } \\
\text { - in the total population } \\
\text { randomised }\end{array}$ & 709 per 1000 & $\begin{array}{l}\mathbf{5 7 4} \text { per } 1000 \\
\text { (425 to } 766)\end{array}$ & $\begin{array}{l}\text { RR } \mathbf{0 . 8 1} \\
\text { (0.6 to } 1.08)\end{array}$ & $\begin{array}{l}104 \\
\text { (1 study) }\end{array}$ & $\begin{array}{l}\oplus \oplus \bigcirc \bigcirc \\
\text { low }^{1,2}\end{array}$ & \\
\hline $\begin{array}{l}\text { Occurrence of CIP/CIM - } \\
\text { in screened population }\end{array}$ & 634 per 1000 & $\begin{array}{l}393 \text { per } 1000 \\
\text { (247 to } 609)\end{array}$ & $\begin{array}{l}\text { RR } \mathbf{0 . 6 2} \\
\text { (0.39 to } 0.96)\end{array}$ & $\begin{array}{l}82 \\
\text { (1 study) }\end{array}$ & $\begin{array}{l}\oplus \oplus \oplus \bigcirc \\
\text { moderate }^{2}\end{array}$ & \\
\hline $\begin{array}{l}\text { Serious adverse events } \\
\text { - in total population ran- } \\
\text { domised }\end{array}$ & 0 per 1000 & $\begin{array}{l}\mathbf{0} \text { per } 1000 \\
(0 \text { to } 0)\end{array}$ & $\begin{array}{l}\text { RR 3.36 } \\
\text { (0.14 to 80.62) }\end{array}$ & $\begin{array}{l}104 \\
\text { (1 study) }\end{array}$ & $\begin{array}{l}\oplus \oplus \oplus \bigcirc \\
\text { moderate }\end{array}$ & \\
\hline
\end{tabular}

* The basis for the assumed risk (eg the median control group risk across studies) is provided in footnotes. The corresponding risk (and its $95 \%$ confidence interval) is based on the assumed risk in the comparison group and the relative effect of the intervention (and its $95 \% \mathrm{Cl}$ ).

Cl: confidence interval; ICU: intensive care unit; RR: risk ratio

GRADE Working Group grades of evidence

High quality: further research is very unlikely to change our confidence in the estimate of effect.

Moderate quality: further research is likely to have an important impact on our confidence in the estimate of effect and may change the estimate.

Low quality: further research is very likely to have an important impact on our confidence in the estimate of effect and is likely to change the estimate.

Very low quality: we are very uncertain about the estimate.

Imputation of a substantial amount of data.

2 Data were obtained from a single, though high quality study, with a limited number of participants. 
Electrical muscle stimulation versus control for preventing critical illness polyneuropathy and critical illness myopathy

Patient or population: critically ill patients

Settings: medical or surgical ICU

Intervention: electrical muscle stimulation versus control

\begin{tabular}{|c|c|c|c|c|c|c|}
\hline \multirow[t]{3}{*}{ Outcomes } & \multicolumn{2}{|c|}{ Illustrative comparative risks* $(95 \% \mathrm{Cl})$} & \multirow{3}{*}{$\begin{array}{l}\text { Relative effect } \\
(95 \% \mathrm{Cl})\end{array}$} & \multirow{3}{*}{$\begin{array}{l}\text { No of Participants } \\
\text { (studies) }\end{array}$} & \multirow{3}{*}{$\begin{array}{l}\text { Quality of the evidence } \\
\text { (GRADE) }\end{array}$} & \multirow[t]{3}{*}{ Comments } \\
\hline & Assumed risk & Corresponding risk & & & & \\
\hline & Control & $\begin{array}{l}\text { Electrical muscle stimu- } \\
\text { lation }\end{array}$ & & & & \\
\hline $\begin{array}{l}\text { Occurrence of CIP/CIM } \\
\text { - in the total population } \\
\text { randomised }\end{array}$ & 764 per 1000 & $\begin{array}{l}718 \text { per } 1000 \\
\text { (596 to } 878)\end{array}$ & $\begin{array}{l}\text { RR } 0.94 \\
\text { (0.78 to } 1.15)\end{array}$ & $\begin{array}{l}140 \\
\text { (1 study) }\end{array}$ & $\begin{array}{l}\oplus \bigcirc \bigcirc \bigcirc \\
\text { very low } 1,2,3,4,5\end{array}$ & \\
\hline $\begin{array}{l}\text { Occurrence of CIP/CIM - } \\
\text { in screened population }\end{array}$ & 393 per 1000 & $\begin{array}{l}126 \text { per } 1000 \\
(39 \text { to } 397)\end{array}$ & $\begin{array}{l}\text { RR } 0.32 \\
\text { (0.1 to } 1.01)\end{array}$ & $\begin{array}{l}52 \\
\text { (1 study) }\end{array}$ & $\begin{array}{l}\oplus \bigcirc \bigcirc \bigcirc \\
\text { very low } \mathbf{l}^{1,2,3,5}\end{array}$ & \\
\hline
\end{tabular}

*The basis for the assumed risk (eg the median control group risk across studies) is provided in footnotes. The corresponding risk (and its $95 \%$ confidence interval) is based on the assumed risk in the comparison group and the relative effect of the intervention (and its $95 \% \mathrm{Cl}$ ).

Cl: confidence interval; ICU: intensive care unit; RR: risk ratio

GRADE Working Group grades of evidence

High quality: further research is very unlikely to change our confidence in the estimate of effect.

Moderate quality: further research is likely to have an important impact on our confidence in the estimate of effect and may change the estimate.

Low quality: further research is very likely to have an important impact on our confidence in the estimate of effect and is likely to change the estimate.

Very low quality: we are very uncertain about the estimate.

${ }^{1}$ Lack of blinding may have introduced bias.

${ }^{2}$ Non-random component in the sequence generation may have introduced bias.

${ }^{3}$ Important differences in baseline characteristics and severity of illness between the screened intervention group and the control group,

which may have artificially increased the treatment effect.

${ }^{4}$ Imputation of a substantial amount of data.

${ }^{5}$ Data are from a single study with relatively small number of participants and events of neuromyopathy. 


\section{DISCUSSION}

Our review includes five studies examining the effects of four interventions on the incidence of CIP/CIM, although only one of these specifically evaluated this as a primary outcome (Routsi 2010). This is a very small number of trials. One of the main reasons for this is that no clear and uniformly accepted diagnostic criteria for CIP/CIM exist. The literature reports various evaluations of peripheral or respiratory muscle force in the critically ill, such as maximal inspiratory pressure, hand grip force, quadriceps strength and thumb muscle force, but these lack a cut-off value that allows differentiation between weak and not weak individuals and therefore do not allow diagnosis of CIP/CIM. An arbitrary cut-off value is only described for the MRC sum-score, which is employed by two of the included studies. Several other trials only evaluated nitrogen metabolism and protein balance or muscle mass after various interventions, without any clinical or electrophysiological correlation. As these are not validated or accepted criteria for CIP/ CIM, we excluded these studies from this review.

Two included trials evaluated the effect of IIT on CIP/CIM and studied a total of 825 participants (see Summary of findings for the main comparison). One trial was in a surgical ICU and one trial in a medical ICU. Both were at the same single centre. IIT significantly reduced our primary outcome measure, incidence of CIP/ CIM after at least one week in ICU (fixed-effect model RR 0.65, 95\% CI 0.55 to 0.77 ; random-effects model RR $0.64,95 \%$ CI 0.44 to 0.94 ). Baseline characteristics, including severity of illness, were well balanced between both treatment groups in this screened long-stay population of medical patients. Although no differences were identified in the surgical population, significantly fewer participants treated with IIT reached the CIP/CIM screening period because of the benefit of IIT in the first seven days. Any potential bias induced hereby originated from earlier ICU discharge in the intervention group and would be expected to reduce rather than inflate the effect. As ICU stay of at least seven days cannot be predicted accurately on admission, we also evaluated all outcome measures for the total population randomised to receive IIT or CIT. As participants discharged or dead within one week were not screened for CIP/CIM, we used imputation of positive results for those participants who died and negative results for those alive discharged. Meta-analysis then showed a significant beneficial effect in the total population randomised (RR $0.70,95 \%$ CI 0.60 to 0.82 ). As we imputed a large amount of data, this analysis is prone to bias and imputation of data does have limitations. Furthermore, there is significant heterogeneity in the meta-analysis. This heterogeneity is due to clinical diversity, as methodology was identical in both ICUs. We performed a more conservative statistical analysis using a random-effects model to potentially take account of this heterogeneity. This showed that the effect was lost (RR 0.65, 95\% CI 0.38 to 1.11). However, this type of analysis provides poor estimates of the width of the distribution of intervention effects when the meta-analysis includes only two studies. In participants discharged within one week, it is likely that no clinically relevant CIP/CIM was present. Participants who died within the first week clearly had a bad outcome. The trialists made the diagnosis of CIP/ CIM using only the presence of abundant spontaneous electrical activity on electrophysiological examination, which is observed either in axonopathy or muscle necrosis, two important components of the neuromuscular involvement in individuals with CIP/CIM. On the other hand, some myopathies with muscle membrane inexcitability may therefore have been missed. The issues identified here might be addressed in future studies.

Concerning the secondary outcome measures, IIT had a beneficial effect on duration of mechanical ventilation, ICU stay and 180day mortality in the total population randomised, as well as in the population screened for CIP/CIM, but had no beneficial effect on mortality at 30 days, which is likely to be too early to see the benefit of this intervention. When the analysis was redone taking account of heterogeneity, which was only present in the 180-day mortality analysis, the reduction in 180-day mortality was confirmed in the screened population but lost in the total population. Whether the reduction in duration of mechanical ventilation is the result of improved respiratory muscle force or other beneficial effects of IIT, such as reduced infections or reduced organ failure, remains unclear.

Hypoglycaemia and at least two hypoglycaemic events occurred more frequently in the IIT group than in the CIT group, in the total population randomised as well as in the screened participants. There was no increase in mortality within 24 hours of the hypoglycaemia. Although retrospective analysis from these trials did not show any long-lasting detrimental effects in participants developing hypoglycaemia (Van den Berghe 2006b), this complication is a major concern when implementing IIT in ICU, as hypoglycaemia may not be easily recognised in critically ill individuals, and profound and prolonged hypoglycaemia can cause coma, epilepsy and neurological sequelae. Finally, pointing to the potential harm to overall outcome, there have been calls for caution to be used in implementing this treatment on a large scale but with methods and protocols that are different from the original setting (Finfer 2009).

The third RCT compared corticosteroids with placebo in people with persisting ARDS (see Summary of findings 2). The trial randomised a total of 180 participants, but prospectively evaluated only 92 for the incidence of CIP/CIM. The results found no significant difference between steroids and placebo (RR 1.09, 95\% CI 0.53 to 2.26). We performed an intention-to-treat analysis by imputing results for the first 88 participants, for which we used the retrospective data from the analysis of these participants in the trial. There was no significant difference in effect between steroid and placebo (RR $1.27,95 \%$ CI 0.77 to 2.08 ). There were no significant differences in 180-day mortality, infection, pneumonia or glycaemia, although new episodes of shock occurred less frequently with corticosteroids (RR $0.41,95 \%$ CI 0.17 to 1.01 ). 
The third intervention involved early physical therapy versus control (Schweickert 2009) (see Summary of findings 3). Only 82 of the 104 randomised participants were available for measurement in ICU, being alive and co-operative. In this evaluated population, the intervention significantly reduced the risk of CIP/CIM (RR 0.62 , 95\% CI 0.39 to 0.96 ). To obtain a full intention-totreat analysis, we imputed data and gave participants that were not evaluable a score of zero on the MRC scale. The intention-to-treat analysis did not confirm a significant treatment effect (RR 0.81, $95 \%$ CI 0.60 to 1.08 ). The trial reported a significant shortening of duration of mechanical ventilation with early physical therapy, but no effect on duration of ICU stay, hospital mortality, or severe adverse events.

Finally, one trial examined the effects of daily EMS sessions on the lower limbs on the incidence of CIP/CIM (see Summary of findings 4). Only 50 out of 140 participants were evaluable. In this subset of screened participants, there was no reduction in the incidence of CIP/CIM (RR 0.32, 95\% CI 0.10 to 1.01 ). Importantly, there was an imbalance between intervention and control participants in this screened subset concerning severity of illness, diagnostic categories and renal disease as a comorbidity, some of which may have introduced significant bias in these results favouring the intervention arm. Imputation of worst values for participants not evaluable negated any significant treatment effect (RR $0.94,95 \%$ CI 0.78 to 1.15 ). As we imputed a large amount of data, this analysis is also prone to substantial bias.

\section{A U THORS, CONCLUSIONS Implications for practice}

Moderate quality evidence from two large single-centre trials shows a significant benefit of intensive insulin therapy on the electrophysiological incidence of critical illness polyneuropathy/critical illness myopathy in individuals in the intensive care unit for at least one week, and on its most important associated problem of prolonged mechanical ventilation (high quality evidence). Whether this is the result of improved respiratory muscle force or other beneficial effects of intensive insulin therapy is unclear. No data are available concerning the effect of intensive insulin therapy on clinical weakness of peripheral muscles and physical rehabilitation. There were also significant reductions in prolonged intensive care unit stay and mortality rate at 180 days. Hypoglycaemia remains a major issue of concern and follow-up studies in which the treatment has been implemented on a large scale call for caution on overall outcome. In neither trial was critical illness polyneuropathy/critical illness myopathy a primary outcome measure and results derive from subgroup analysis, which may limit conclusions. Moderate quality evidence from one multicentre trial showed no evidence of an effect of corticosteroid treatment on critical illness polyneuropathy/critical illness myopathy, but the number of new events of shock was reduced. Moderate quality evidence from a single randomised controlled trial suggests possible benefit in preventing critical illness polyneuropathy/critical illness myopathy from an early rehabilitation strategy in the evaluable participants with associated reduction in the duration of mechanical ventilation. Finally, also very low quality evidence from a single study suggests no benefit from electrical muscle stimulation, and the data are prone to bias.

\section{Implications for research}

This review underlines the need for debate and consensus on criteria to define critical illness polyneuropathy/critical illness myopathy for the purpose of research. This is the first step towards the design of future high quality randomised trials on the subject. Several theoretically appealing interventions should be studied in randomised controlled trials. More particularly, further evaluation of early rehabilitation strategies and optimal timing during critical illness should be pursued. Possible preventive effects of electrical muscle stimulation should be further examined. Additional research is needed concerning the impact of hypoglycaemia in critically ill individuals and into strategies that minimise the risk for hypoglycaemia when implementing strict glycaemic control.

\section{ACKNOWLEDGEMENTS}

We thank Jens de Groot for his advice concerning search strategies and Emmanuel Lesaffre for his statistical support. We also thank Jingjing Zhang for the translation. Greet Hermans is the recipient of a post doctoral fellowship from the Clinical Research Fund of the Leuven University Hospital and holds a research grant from the Flanders Research Foundation (FWO), Belgium (G.0399.12). Greet Van den Berghe receives funding from the Methusalem program of the Flemish Government (METH08/07) and holds a European Research Council Advanced Grant (AdvG-2012-321670) from the Ideas Program of the EU FP7.

The editorial base of the Cochrane Neuromuscular Disease Group is supported by the MRC Centre for Neuromuscular Diseases. The Cochrane Neuromuscular Disease Group Trials Search Coordinator developed and ran the searches. 


\section{R E F E R E N C E S}

\section{References to studies included in this review}

Hermans 2007 \{published and unpublished data\}

Hermans G, Wilmer A, Meersseman W, Milants I, Wouters PJ, Bobbaers $\mathrm{H}$, et al.Impact of intensive insulin therapy on neuromuscular complications and ventilator-dependency in MICU. American Journal of Respiratory Critical Care Medicine 2007;175(5):480-9. [PUBMED: 17138955]

Routsi 2010 \{published data only\}

Routsi C, Gerovasili V, Vasileiadis I, Karatzanos E, Pitsolis $\mathrm{T}$, Tripodaki E, et al.Electrical muscle stimulation prevents critical illness polyneuromyopathy: a randomized parallel intervention trial. Critical Care (London, England) 2010;14 (2):R74. [PUBMED: 20426834]

Schweickert 2009 \{published and unpublished data\} Schweickert WD, Pohlman MC, Pohlman AS, Nigos C, Pawlik AJ, Esbrook CL, et al.Early physical and occupational therapy in mechanically ventilated, critically ill patients: a randomised controlled trial. Lancet 2009;373 (9678):1874-82. [PUBMED: 19446324]

Steinberg 2006 \{published data only (unpublished sought but not used)\}

Steinberg KP, Hudson LD, Goodman RB, Hough CL, Lanken PN, Hyzy R, et al.Efficacy and safety of corticosteroids for persistent acute respiratory distress syndrome. New England Journal of Medicine 2006;354(16): 1671-84. [PUBMED: 16625008]

Van den Berghe 2005 \{published and unpublished data\} Van den Berghe G, Schoonheydt K, Becx P, Bruyninckx F, Wouters PJ. Insulin therapy protects the central and peripheral nervous system of intensive care patients. Neurology 2005;64(8):1348-53. [PUBMED: 15851721]

\section{References to studies excluded from this review}

Berard 2000 \{published data only\}

Bérard MP, Zazzo JF, Condat P, Vasson MP, Cynober L. Total parenteral nutrition enriched with arginine and glutamate generates glutamine and limits protein catabolism in surgical patients hospitalized in intensive care units. Critical Care Medicine 2000;28(11):3637-44. [PUBMED: 11098966]

Bouletreau 1985 \{published data only\}

Bouletreau P, Patricot MC, Saudin F, Guiraud M, Mathian B. Effects of intermittent electrical stimulations on muscle catabolism intensive care patients. JPEN. Journal of Parenteral and Enteral Nutrition 1987;11(6):552-5. [PUBMED: 3501482]

Brunello 2010 \{published data only\} Brunello AG, Haenggi M, Wigger O, Porta F, Takala J, Jakob SM. Usefulness of a clinical diagnosis of ICUacquired paresis to predict outcome in patients with SIRS and acute respiratory failure. Intensive Care Medicine 2010; 36(1):66-74. [PUBMED: 19760204]
Burtin 2009 \{published and unpublished data\}

Burtin C, Clerckx B, Robbeets C, Ferdinande P, Langer $\mathrm{D}$, Troosters $\mathrm{T}$, et al.Early exercise in critically ill patients enhances short-term functional recovery. Critical Care Medicine 2009;37(9):2499-505. [PUBMED: 19623052]

Caruso 2005 \{published and unpublished data\} Caruso P, Denari SD, Ruiz SA, Bernal KG, Manfrin GM, Friedrich C, et al.Inspiratory muscle training is ineffective in mechanically ventilated critically ill patients. Clinics (Sao Paulo, Brazil) 2005;60(6):479-84. [PUBMED: 16358138]

\section{Chen 2011 \{published data only\}}

Chen F, Wang J, Jiang Y. Influence of different routes of nutrition on the respiratory muscle strength and outcome of elderly patients in respiratory intensive care unit. Chinese Journal of Clinical Nutrition 2011;19(1):7-11.

Chiang 2006 \{published data only\} Chiang LL, Wang LY, Wu CP, Wu HD, Wu YT. Effects of physical training on functional status in patients with prolonged mechanical ventilation. Physical Therapy 2006; 86(9):1271-81. [PUBMED: 16959675]

Fläring 2003 \{published data only\} Fläring UB, Rooyackers OE, Wernerman J, Hammarqvist F. Glutamine attenuates post-traumatic glutathione depletion in human muscle. Clinical Science 2003;104(3):275-82. [PUBMED: 12605586]

Gamrin 2000 \{published data only\} Gamrin L, Essén P, Hultman E, McNurlan MA, Garlick PJ, Wernerman J. Protein-sparing effect in skeletal muscle of growth hormone treatment in critically ill patients. Annals of Surgery 2000;231(4):577-86. [PUBMED: 10749620]

Gerovasili 2009a \{published data only\} Gerovasili V, Tripodaki E, Karatzanos E, Pitsolis T, Markaki $\mathrm{V}$, Zervakis D, et al.Short-term systemic effect of electrical muscle stimulation in critically ill patients. Chest 2009;136 (5):1249-56. [PUBMED: 19710290]

Gerovasili 2009b \{published data only\} Gerovasili V, Stefanidis K, Vitzilaios K, Karatzanos E, Politis P, Koroneos A, et al.Electrical muscle stimulation preserves the muscle mass of critically ill patients: a randomized study. Critical Care (London, England) 2009;13(5):R161. [PUBMED: 19814793]

Gruther 2010 \{published data only\} Gruther W, Kainberger F, Fialka-Moser V, PaternostroSluga T, Quittan M, Spiss C, et al.Effects of neuromuscular electrical stimulation on muscle layer thickness of knee extensor muscles in intensive care unit patients: a pilot study. Journal of Rehabilitation Medicine 2010;42(6):593-7. [PUBMED: 20549166]

Hsieh 2006 \{published data only\} Hsieh LC, Chien SL, Huang MS, Tseng HF, Chang CK. Anti-inflammatory and anticatabolic effects of short-term beta-hydroxy-beta-methylbutyrate supplementation on chronic obstructive pulmonary disease patients in intensive 
care unit. Asia Pacific Journal of Clinical Nutrition 2006;15 (4):544-50. [PUBMED: 17077073]

Huang 2006 \{published data only\}

Huang CJ, Lin HC. Association between adrenal insufficiency and ventilator weaning. American Journal of Respiratory and Critical Care Medicine 2006;173(3):276-80. [PUBMED: 16272449]

Johnson 1993 \{published data only (unpublished sought but not used)\} Johnson D, Gallagher C, Cavanaugh M, Yip R, Mayers I. The lack of effect of routine magnesium administration on respiratory function in mechanically ventilated patients. Chest 1993;104(2):536-41. [PUBMED: 8339645]

Karatzanos 2012 \{published data only\}

Karatzanos E, Gerovasili V, Zervakis D, Tripodaki ES, Apostolou K, Vasileiadis I, et al.Electrical muscle stimulation: an effective form of exercise and early mobilization to preserve muscle strength in critically ill patients. Critical Care Research and Practice 2012;2012: 432752. [PUBMED: 22545212]

Knox 1996 \{published data only\} Knox JB, Wilmore DW, Demling RH, Sarraf P, Santos AA. Use of growth hormone for postoperative respiratory failure. American Journal of Surgery 1996;171(6):576-80. [PUBMED: 8678203]

Kuhls 2007 \{published data only\} Kuhls DA, Rathmacher JA, Musngi MD, Frisch DA, Nielson J, Barber A, et al.Beta-hydroxy-beta-methylbutyrate supplementation in critically ill trauma patients. Journal of Trauma 2007;62(1):125-31. [PUBMED: 17215743]

Martin 2011 \{published and unpublished data\}

Martin AD, Smith BK, Davenport PD, Harman E, Gonzalez-Rothi RJ, Baz M, et al.Inspiratory muscle strength training improves weaning outcome in failure to wean patients: a randomized trial. Critical Care (London, England) 2011;15(2):R84. [PUBMED: 21385346]

Menadue 2010 \{published data only\} Menadue C, Alison JA, Piper AJ, Flunt D, Ellis ER. Bilevel ventilation during exercise in acute on chronic respiratory failure: a preliminary study. Respiratory Medicine 2010;104 (2):219-27. [PUBMED: 19804963]

Miao 2005 \{published data only\}

Miao LJ, Wang J, Liu H, Cheng Z. Role of enteral nutrition combined with parenteral nutrition in supporting mechanical ventilation of patients with chronic obstructive pulmonary disease accompanied by respiratory failure. Chinese Journal of Clinical Rehabilitation 2005;9(31):27-9.

Mohr 1997 \{published data only\}

Mohr M, Englisch L, Roth A, Burchardi H, Zielmann S. Effects of early treatment with immunoglobulin on critical illness polyneuropathy following multiple organ failure and gram-negative sepsis. Intensive Care Medicine 1997;23(11): 1144-9. [PUBMED: 9434920]

Morris 2008 \{published data only\}

Morris PE, Goad A, Thompson C, Taylor K, Harry B, Passmore L, et al.Early intensive care unit mobility therapy in the treatment of acute respiratory failure. Critical Care Medicine 2008;36(8):2238-43. [PUBMED: 18596631]

\section{Nava 1998 \{published data only\}}

Nava S. Rehabilitation of patients admitted to a respiratory intensive care unit. Archives of Physical Medicine and Rehabilitation 1998;79(7):849-54. [PUBMED: 9685104]

Paddon-Jones 2005 \{published data only\} Paddon-Jones D, Wolfe RR, Ferrando AA. Amino acid supplementation for reversing bed rest and steroid myopathies. Journal of Nutrition 2005;135(7):1809-12S. [PUBMED: 15987870]

Pichard 1996 \{published data only (unpublished sought but not used)\} Pichard C, Kyle U, Chevrolet JC, Jolliet P, Slosman D, Mensi N. Lack of effects of recombinant growth hormone on muscle function in patients requiring prolonged mechanical ventilation: a prospective, randomized, controlled study. Critical Care Medicine 1996;24(3):403-13. [PUBMED: 8625627]

\section{Porta 2005 \{published data only\}}

Porta R, Vitacca M, Gilè LS, Clini E, Bianchi L, Zanotti $\mathrm{E}$, et al.Supported arm training in patients recently weaned from mechanical ventilation. Chest 2005;128(4):2511-20. [PUBMED: 16236917]

Rodriguez 2012 \{published and unpublished data\} Rodriguez PO, Setten M, Maskin LP, Bonelli I, Vidomlansky SR, Attie S, et al.Muscle weakness in septic patients requiring mechanical ventilation: protective effect of transcutaneous neuromuscular electrical stimulation. Journal of Critical Care 2012;27(3):319 e1-8. [PUBMED: 21715139]

Routsi 2009 \{published data only\}

Routsi C, Gerovasili V, Zevakis D, Karatzanos E, Papadopoulos E, Pitsolis T, et al.Electrical muscle stimulation prevents critical illness polyneuromyopathy in ICU patients. Intensive Care Medicine. Conference: 22nd Annual Congress of the European Society of Intensive Care Medicine, ESICM Vienna, Austria 2009;35:s133.

Salisbury 2010 \{published data only\} Salisbury LG, Merriweather JL, Walsh TS. Rehabilitation after critical illness: could a ward-based generic rehabilitation assistant promote recovery?. Nursing in Critical Care 2010;15(2):57-65. [PUBMED: 20236432]

Sevette 2005 \{published data only\}

Sevette A, Smith RC, Aslani A, Kee AJ, Hansen R, Barratt $\mathrm{SM}$, et al.Does growth hormone allow more efficient nitrogen sparing in postoperative patients requiring parental nutrition? A double-blind placebo-controlled randomised trial. Clinical Nutrition 2005;24(6):943-55. [PUBMED: 16083996]

Takala 1999a \{published and unpublished data\} Takala J, Ruokonen E, Webster NR, Nielsen MS, Zandstra DF, Vundelinckx G, et al.Increased mortality associated with growth hormone treatment in critically ill adults. New England Journal of Medicine 1999;341(11):785-92. [PUBMED: 10477776] 
Takala 1999b \{published and unpublished data\}

Takala J, Ruokonen E, Webster NR, Nielsen MS, Zandstra DF, Vundelinckx G, et al.Increased mortality associated with growth hormone treatment in critically ill adults. New England Journal of Medicine 1999;341(11):785-92. [PUBMED: 10477776]

Tjäder 2004 \{published data only\}

Tjäder I, Rooyackers O, Forsberg AM, Vesali RF, Garlick PJ, Wernerman J. Effects on skeletal muscle of intravenous glutamine supplementation to ICU patients. Intensive Care Medicine 2004;30(2):266-75. [PUBMED: 14722645]

Toledo 2007 \{published data only\}

Toledo A, Borghi-Silva A, Sampaio LM, Ribeiro KP, Baldissera V, Costa D. The impact of noninvasive ventilation during the physical training in patients with moderate-tosevere chronic obstructive pulmonary disease (COPD). Clinics (Sao Paulo, Brazil) 2007;62(2):113-20. [PUBMED: 17505694]

Vivodtzev 2006 \{published data only\} Vivodtzev I, Pépin JL, Vottero G, Mayer V, Porsin B, Lévy $\mathrm{P}$, et al.Improvement in quadriceps strength and dyspnea in daily tasks after 1 month of electrical stimulation in severely deconditioned and malnourished COPD. Chest 2006;129 (6):1540-8. [PUBMED: 16778272]

Watters 1997 \{published data only (unpublished sought but not used)\} Watters JM, Kirkpatrick SM, Norris SB, Sharmji FM, Wells GA. Immediate postoperative enteral feeding results in impaired respiratory mechanics and decreased mobility. Annals of Surgery 1997;226(3):369-77. [PUBMED: 9339943]

Zanotti 2003 \{published data only (unpublished sought but not used)\} Zanotti E, Felicetti G, Maini M, Fracchia C. Peripheral muscle strength training in bed-bound patients with COPD receiving mechanical ventilation: effect of electrical stimulation. Chest 2003;124(1):292-6. [PUBMED: 12853536]

Ziegler 1990 \{published data only\} Ziegler TR, Young LS, Ferrari-Baliviera E, Demling RH, Wilmore DW. Use of human growth hormone combined with nutritional support in a critical care unit. JPEN. Journal of Parenteral and Enteral Nutrition 1990;14(6): 574-81. [PUBMED: 2273531]

\section{References to studies awaiting assessment}

Abokhabar 2012 \{published data only\}

Abokhabar H, Abouelela A, Abdelkarim I. Effect of electrical muscle stimulation in prevention of ICU acquired muscle weakness and facilitation of weaning from mechanical ventilation. Intensive Care Medicine. 2012; Vol. 38:S132.

Alia 2011 \{published data only\}

Alía I, de la Cal MA, Esteban A, Abella A, Ferrer R, Molina FJ, et al.Efficacy of corticosteroid therapy in patients with an acute exacerbation of chronic obstructive pulmonary disease receiving ventilatory support. Archives of Internal Medicine 2011;171(21):1939-46. [PUBMED: 22123804]
Brunner 2013 \{published data only\}

Brunner R, Rinner W, Haberler C, Kitzberger R, Sycha $\mathrm{T}$, Herkner $\mathrm{H}$, et al.Early treatment with IgM-enriched intravenous immunoglobulin does not mitigate critical illness polyneuropathy and/or myopathy in patients with multiple organ failure and SIRS/sepsis: a prospective, randomized, placebo-controlled, double-blinded trial. Critical Care (London, England) 2013;17(5):R213. [PUBMED: 24088271]

Devost 2011 \{published data only\}

Devost A-A, Boilard G, Vovodtzev, Saey D, Mainguy $\mathrm{V}$, Maltais F, et al.Efficiency of neuromuscular electrical stimulation to prevent ICU-acquired weakness in mechanically ventilated patients. Intensive Care Medicine. 2011:S13.

Files 2013 \{published data only\}

Files D, Morris P, Shrestha S, Dhar S, Young M, Hauser J, et al.Randomized, controlled pilot study of early rehabilitation strategies in acute respiratory failure. Critical Care 2013;17 (Suppl 2):P540.

Gerovasili 2011 \{published data only\}

Gerovasili V, Karatzanos L, Zervakis D, Dimopoulos S, Tripodaki E-S, Pitsolis T, et al. Electrical muscle simulation is an effective form of excercise and early rehabilitation in ICU patients. American Journal of Respiratory and Critical Care Medicine. 2011; Vol. 183:A3740.

Hermans 2013 \{published data only\}

Hermans G, Casaer MP, Clerckx B, Güiza F, Vanhullebusch $T$, Derde $S$, et al.Effect of tolerating macronutrient deficit on the development of intensive-care unit acquired weakness: a subanalysis of the EPaNIC trial. The Lancet Respiratory Medicine 2013;1 (8):621-9.

Mikaeili 2012 \{published data only\}

Mikaeili H, Yazdchi M, Barazandeh F, Ansarin K. Euglycemic state reduces the incidence of critical illness polyneuropathy and duration of ventilator dependency in medical intensive care unit. Bratislavské Lekárske Listy 2012; 113(10):616-9. [PUBMED: 23094903]

Paternostro-Sluga 2012 \{published data only\} Paternostro-Sluga T, Hiesmayr M, Janda D, Senekowitsch S. Early neuromuscular electrical stimulation for intensive care unit patients: effect on muscle strength and urinary nitrogen excretion. The Journal of Injury, Function, and Rehabilitation 2012;4(10 Suppl):S310.

\section{References to ongoing studies}

Kho 2012 \{published data only\}

Kho ME, Truong AD, Brower RG, Palmer JB, Fan E, Zanni $\mathrm{JM}$, et al.Neuromuscular electrical stimulation for intensive care unit-acquired weakness: protocol and methodological implications for a randomized, sham-controlled, phase II trial. Physical Therapy 2012;92(12):1564-79. [PUBMED: 22421734]

Parry 2012 \{published data only\}

Parry SM, Berney S, Koopman R, Bryant A, El-Ansary D, Puthucheary Z, et al.Early rehabilitation in critical care 
(eRiCC): functional electrical stimulation with cycling protocol for a randomised controlled trial. BMJ Open 2012; 2(5):e001891. [PUBMED: 22983782]

\section{Additional references}

\section{Atkins 2004}

Atkins D, Eccles M, Flottorp S, Guyatt GH, Henry D, Hill $S$, et al.GRADE Working Group. Systems for grading the quality of evidence and the strength of recommendations I: critical appraisal of existing approaches The GRADE Working Group. BMC Health Services Research 2004;4(1): 38. [PUBMED: 15615589]

\section{Bednarík 2005}

Bednarík J, Vondracek P, Dusek L, Moravcova E, Cundrle I. Risk factors for critical illness polyneuromyopathy. Journal of Neurology 2005;252(3):343-51. [PUBMED: 15791390]

\section{Berek 1997a}

Berek K, Margreiter J, Willeit J, Berek A, Schmutzhard E, Mutz N. Critical illness polyneuropathy--only due to parenteral nutrition?. Intensive care medicine 1997; Vol. 23, issue 8:923-4. [PUBMED: 9310818]

\section{Berger 1996}

Berger JR, Pall L, Hall CD, Simpson DM, Berry PS, Dudley R. Oxandrolone in AIDS-wasting myopathy. AIDS 1996; 10(14):1657-62. [PUBMED: 8970686]

\section{Bollaert 1998}

Bollaert PE, Charpentier C, Levy B, Debouverie M, Audibert G, Larcan A. Reversal of late septic shock with supraphysiologic doses of hydrocortisone. Critical Care Medicine 1998;26(4):645-50. [PUBMED: 9559600]

\section{Bolton 1984}

Bolton CF, Gilbert JJ, Hahn AF, Sibbald WJ. Polyneuropathy in critically ill patients. Journal of Neurology, Neurosurgery \& Psychiatry 1984;47(11):1223-31. [PUBMED: 6094735]

\section{Bolton 1986}

Bolton CF, Laverty DA, Brown JD, Witt NJ, Hahn AF, Sibbald WJ. Critically ill polyneuropathy: electrophysiological studies and differentiation from Guillain-Barré syndrome. Journal of Neurology, Neurosurgery \& Psychiatry 1986;49(5):563-73. [PUBMED: 3011996]

Bolton 2005

Bolton CF. Neuromuscular manifestations of critical illness. Muscle \& Nerve 2005;32(2):140-63. [PUBMED: 15825186]

\section{Boyer 2006}

Boyer A, Chadda K, Salah A, Annane D. Glucocorticoid treatment in patients with septic shock: effects on vasopressor use and mortality. International Journal of Clinical Pharmacology and Therapeutics 2006;44(7):309-18. [PUBMED: 16961159]

Brealey 2002

Brealey D, Brand M, Hargreaves I, Heales S, Land J, Smolenski R, et al.Association between mitochondrial dysfunction and severity and outcome of septic shock. Lancet 2002;360(9328):219-23. [PUBMED: 12133657]

\section{Briegel 1999}

Briegel J, Forst H, Haller M, Schelling G, Kilger E, Kuprat $\mathrm{G}$, et al.Stress doses of hydrocortisone reverse hyperdynamic septic shock: a prospective, randomized, double-blind, single-center study. Critical Care Medicine 1999;27(4): 723-32. [PUBMED: 10321661]

\section{Burnham 2005}

Burnham EL, Moss M, Ziegler TR. Myopathies in critical illness: characterization and nutritional aspects. The Journal of Nutrition 2005;135(7):1818S-23S. [PUBMED: 15987872]

\section{Chalwa 1999}

Chalwa K, Kupfer Y, Goldmann I, Tessler S. Hydrocortisone reverses refractory shock. Critical Care Medicine 1999;27 (1S):33A

\section{Coakley 1998}

Coakley JH, Nagendran K, Yarwood GD, Honavar M, Hinds CJ. Patterns of neurophysiological abnormality in prolonged critical illness. Intensive Care Medicine 1998;24 (8):801-7. [PUBMED: 9757924]

\section{De Jonghe 1998}

De Jonghe B, Cook D, Sharshar T, Lefaucheur JP, Carlet J, Outin H. Acquired neuromuscular disorders in critically ill patients: a systematic review. Groupe de Reflexion et d'Etude sur les Neuromyopathies En Reanimation. Intensive Care Medicine 1998;24(12):1242-50. [PUBMED: 9885875]

\section{De Jonghe 2002}

De Jonghe B, Sharshar T, Lefaucheur JP, Authier FJ, Durand-Zaleski I, Boussarsar M, et al.Paresis acquired in the intensive care unit: a prospective multicenter study. JAMA 2002;288(22):2859-67. [PUBMED: 12472328]

\section{de Letter 2001}

de Letter MA, Schmitz PI, Visser LH, Verheul FA, Schellens RL, Op de Coul DA, et al.Risk factors for the development of polyneuropathy and myopathy in critically ill patients. Critical Care Medicine 2001;29(12):2281-6. [PUBMED: 11801825]

\section{Deeks 2011}

Deeks JJ, Higgins JPT, Altman DG (editors). Chapter 9: Analysing data and undertaking meta-analyses. In: Higgins JPT, Green S (editors). Cochrane Handbook for Systematic Reviews of Interventions Version 5.1.0 (updated March 2011). Available from www.cochrane-handbook.org. Higgins JPT, Green S, 2011.

\section{Deley 2005}

Deley G, Kervio G, Verges B, Hannequin A, Petitdant MF, Salmi-Belmihoub $S$, et al.Comparison of low-frequency electrical myostimulation and conventional aerobic exercise training in patients with chronic heart failure. European Journal of Cardiovascular Prevention \& Rehabilitation 2005; 12(3):226-33. [PUBMED: 15942420]

\section{Finfer 2009}

NICE-SUGAR Study Investigators, Finfer $S$, Chittock DR, Su SY, Blair D, Foster D, Dhingra V, et al.Intensive versus conventional glucose control in critically ill patients. 
New England Journal of Medicine 2009;360(13):1283-97. [PUBMED: 19318384]

\section{Garnacho-Montero 2001}

Garnacho-Montero J, Madrazo-Osuna J, Garcia-Garmendia JL, Ortiz-Leyba C, Jimenez-Jimenez FJ, Barrero-Almodovar A, et al.Critical illness polyneuropathy: risk factors and clinical consequences. A cohort study in septic patients. Intensive Care Medicine 2001;27(8):1288-96. [PUBMED: 11511941]

\section{Gore 1991}

Gore DC, Honeycutt D, Jahoor F, Wolfe RR, Herndon DN. Effect of exogenous growth hormone on whole-body and isolated-limb protein kinetics in burned patients. Archives of Surgery 1991;126(1):38-43. [PUBMED: 1898697]

\section{Hammarqvist 1997}

Hammarqvist F, Luo JL, Cotgeave IA, Andersson K, Wernerman J. Skeletal muscle glutathione is depleted in critically ill patients. Critical Care Medicine 1997;25(1): 78-84. [PUBMED: 8989180]

Herridge 2003

Herridge MS, Cheung AM, Tansey CM, Matte-Martyn A, Diaz-Granados N, Al Saidi F, et al.One-year outcomes in survivors of the acute respiratory distress syndrome. New England Journal of Medicine 2003;348(8):683-93. [PUBMED: 12594312]

\section{Herridge 2011}

Herridge MS, Tansey CM, Matté A, Tomlinson G, DiazGranados N, Cooper A, et al.Functional disability 5 years after acute respiratory distress syndrome. New England Journal of Medicine 2011;364(14):1293-304. [PUBMED: 21470008]

Higgins 2011a

Higgins JPT, Green S (editors). Cochrane Handbook for Systematic Reviews of Interventions Version 5.1.0 [updated March 2011]. The Cochrane Collaboration, 2011. Available from www.cochrane-handbook.org.

\section{Higgins 2011b}

Higgins JPT, Altman DG, Sterne JAC (editors). Chapter 8: Assessing risk of bias in included studies. In: Higgins JPT, Green S (editors). Cochrane Handbook for Systematic Reviews of Interventions Version 5.1.0 (updated March 2011). The Cochrane Collaboration, 2011. Available from www.cochrane-handbook.org.

\section{Jeevanandam 1995}

Jeevanandam M, Ali MR, Holaday NJ, Petersen SR. Adjuvant recombinant human growth hormone normalizes plasma amino acids in parenterally fed trauma patients. JPEN. Journal of Parenteral and Enteral Nutrition 1995;19 (2):137-44. [PUBMED: 7609279]

\section{Kleyweg 1991}

Kleyweg RP, van der Meché FG, Schmitz PI. Interobserver agreement in the assessment of muscle strength and functional abilities in Guillain-Barré syndrome. Muscle \& Nerve 1991;14(11):1103-9. [PUBMED: 1745285]

\section{Langouche 2005}

Langouche L, Vanhorebeek I, Vlasselaers D, Vander PS, Wouters PJ, Skogstrand K, et al.Intensive insulin therapy protects the endothelium of critically ill patients. Journal of Clinical Investigation 2005;115(8):2277-86. [PUBMED: 16075063]

\section{Meduri 1998}

Meduri GU, Headley AS, Golden E, Carson SJ, Umberger RA, Kelso T, et al.Effect of prolonged methylprednisolone therapy in unresolving acute respiratory distress syndrome: a randomized controlled trial. JAMA 1998;280(2):159-65. [PUBMED: 9669790]

\section{Mendenhall 1993}

Mendenhall CL, Moritz TE, Roselle GA, Morgan TR, Nemchausky BA, Tamburro CH, et al.A study of oral nutritional support with oxandrolone in malnourished patients with alcoholic hepatitis: results of a Department of Veterans Affairs cooperative study. Hepatology 1993;17(4): 564-76. [PUBMED: 8477961]

\section{Michelsen 1982}

Michelsen CB, Askanazi J, Kinney JM, Gump FE, Elwyn $\mathrm{DH}$. Effect of an anabolic steroid on nitrogen balance and amino acid patterns after total hip replacement. Journal of Trauma 1982;22(5):410-3. [PUBMED: 6804639]

\section{Nanas 2008}

Nanas S, Kritikos K, Angelopoulos E, Siafaka A, Tsikriki $\mathrm{S}$, Poriazi $\mathrm{M}$, et al.Predisposing factors for critical illness polyneuromyopathy in a multidisciplinary intensive care unit. Acta Neurologica Scandinavica 2008;118(3):175-81. [PUBMED: 18355395]

\section{Nuhr 2004}

Nuhr MJ, Pette D, Berger R, Quittan M, Crevenna R, Huelsman $M$, et al.Beneficial effects of chronic lowfrequency stimulation of thigh muscles in patients with advanced chronic heart failure. European Heart Journal 2004;25(2):136-43. [PUBMED: 14720530]

Pandit 2006

Pandit L, Agrawal A. Neuromuscular disorders in critical illness. Clinical Neurology and Neurosurgery 2006;108(7): 621-7. [PUBMED: 16730883]

\section{Papazian 2010}

Papazian L, Forel JM, Gacouin A, Penot-Ragon C, Perrin G, Loundou A, et al.ACURASYS Study Investigators. Neuromuscular blockers in early acute respiratory distress syndrome. New England Journal of Medicine 2010;363(12): 1107-16. [PUBMED: 20843245]

Pape 1991

Pape GS, Friedman M, Underwood LE, Clemmons DR. The effect of growth hormone on weight gain and pulmonary function in patients with chronic obstructive lung disease. Chest 1991;99(6):1495-500. [PUBMED: 2036835 ]

\section{Ponting 1988}

Ponting GA, Halliday D, Teale JD, Sim AJ. Postoperative positive nitrogen balance with intravenous hyponutrition 
and growth hormone. Lancet 1988;1(8583):438-40.

[PUBMED: 2893867]

\section{RevMan 2012}

The Nordic Cochrane Centre, The Cochrane Collaboration. Review Manager (RevMan). 5.2. Copenhagen: The Nordic Cochrane Centre, The Cochrane Collaboration, 2012.

\section{Rowe 2001}

Rowe BH, Spooner C, Ducharme FM, Bretzlaff JA, Bota GW. Early emergency department treatment of acute asthma with systemic corticosteroids. Cochrane Database of Systematic Reviews 2001, Issue 1. [DOI: 10.1002/ 14651858.CD002178; PUBMED: 11279756]

\section{Schols 1995}

Schols AM, Soeters PB, Mostert R, Pluymers RJ, Wouters EF. Physiologic effects of nutritional support and anabolic steroids in patients with chronic obstructive pulmonary disease. A placebo-controlled randomized trial. American Journal of Respiratory and Critical Care Medicine 1995;152 (4 Pt 1):1268-74. [PUBMED: 7551381]

\section{Sharshar 2010}

Sharshar T, Bastuji-Garin S, De Jonghe B, Stevens RD, Polito A, Maxime V, et al.Hormonal status and ICUacquired paresis in critically ill patients. Intensive Care Medicine 2010;36(8):1318-26. [PUBMED: 20333354]

\section{Stevens 2007}

Stevens RD, Dowdy DW, Michaels RK, Mendez-Tellez PA, Pronovost PJ, Needham DM. Neuromuscular dysfunction acquired in critical illness: a systematic review. Intensive Care Medicine 2007;33(11):1876-91. [PUBMED: 17639340]

\section{Tennilä 2000}

Tennilä A, Salmi T, Pettilä V, Roine RO, Varpula T, Takkunen O. Early signs of critical illness polyneuropathy in ICU patients with systemic inflammatory response syndrome or sepsis. Intensive Care Medicine 2000;26(9): 1360-3. [PUBMED: 11089765]

\section{Van den Berghe 2001}

Van den Berghe G, Wouters P, Weekers F, Verwaest C, Bruyninckx F, Schetz M, et al.Intensive insulin therapy in the critically ill patients. New England Journal of Medicine 2001;345(19):1359-67. [PUBMED: 11794168]

\section{Van den Berghe 2004}

Van den Berghe G. How does blood glucose control with insulin save lives in intensive care?. Journal of Clinical Investigation 2004;114(9):1187-95. [PUBMED: 15520847]

\section{Van den Berghe 2006a}

Van den Berghe G, Wilmer A, Hermans G, Meersseman W, Wouters PJ, Milants I, et al.Intensive insulin therapy in the medical ICU. New England Journal of Medicine 2006;354 (5):449-61. [PUBMED: 16452557]

\section{Van den Berghe 2006b}

Van den Berghe G, Wilmer A, Milants I, Wouters PJ, Bouckaert B, Bruyninckx F, et al.Intensive insulin therapy in mixed medical/surgical intensive care units: benefit versus harm. Diabetes 2006;55(11):3151-9. [PUBMED: 17065355]

\section{Voerman 1992}

Voerman HJ, van Schijndel RJ, Groeneveld AB, de Boer $\mathrm{H}$, Nauta JP, van der Veen EA, et al.Effects of recombinant human growth hormone in patients with severe sepsis. Annals of Surgery 1992;216(6):648-55. [PUBMED: 1466618]

\section{Voerman 1995}

Voerman BJ, Strack van Schijndel RJ, Groeneveld AB, de Boer H, Nauta JP, Thijs LG. Effects of human growth hormone in critically ill nonseptic patients: results from a prospective, randomized, placebo-controlled trial. Critical Care Medicine 1995;23(4):665-73. [PUBMED: 7712756]

Waldhausen 1997 Waldhausen E, Mingers B, Lippers P, Keser G. Critical illness polyneuropathy due to parenteral nutrition. Intensive Care Medicine 1997; Vol. 23, issue 8:922-3. [PUBMED: 9310817]

\section{Weber-Carstens 2010}

Weber-Carstens S, Deja M, Koch S, Spranger J, Bubser F, Wernecke $\mathrm{KD}$, et al.Risk factors in critical illness myopathy during the early course of critical illness: a prospective observational study. Critical Care (London, England) 2010; 14(3):R119. [PUBMED: 20565863]

\section{Weitzel 2009}

Weitzel LR, Sandoval PA, Mayles WJ, Wischmeyer PE. Performance-enhancing sports supplements: role in critical care. Critical Care Medicine 2009;37(10 Suppl):S400-9. [PUBMED: 20046127]

Witt 1991

Witt NJ, Zochodne DW, Bolton CF, Grand'Maison F, Wells G, Young GB, et al.Peripheral nerve function in sepsis and multiple organ failure. Chest 1991;99(1):176-84. [PUBMED: 1845860]

\section{References to other published versions of this review}

\section{Hermans 2007}

Hermans G, De Jonghe B, Bruyninckx F, Van den Berghe G. Interventions for preventing critical illness polyneuropathy and critical illness myopathy (Protocol). Cochrane Database of Systematic Reviews. Cochrane Database of Systematic Reviews 2007, Issue 4. [DOI: 10.1002/14651858.CD006832]

\section{Hermans 2009}

Hermans G, De Jonghe B, Bruyninckx F, Van den Berghe G. Interventions for preventing critical illness polyneuropathy and critical illness myopathy. Cochrane Database of Systematic Reviews 2009, Issue 1. [DOI: 10.1002/ 14651858.CD006832.pub2; PUBMED: 19160304]

* Indicates the major publication for the study 


\section{CHARACTERISTICS OF STUDIES}

\section{Characteristics of included studies [ordered by study ID]}

\section{Hermans 2007}

\begin{tabular}{ll}
\hline Methods & Parallel-group RCT \\
\hline Participants & $\begin{array}{l}420 \text { participants staying in a medical ICU for at least } 7 \text { days } \\
\text { Age (in years): intervention group } 61 \pm 15 ; \text { control group } 64 \pm 16 \\
\text { Percentage male: intervention group } 59 \% \text { control group } 61 \%\end{array}$ \\
\hline Interventions & $\begin{array}{l}\text { Intensive insulin therapy (IIT) (insulin infusion titrated to achieve blood glucose levels } \\
80 \text { to } 110 \mathrm{mg} / \mathrm{dL}), \text { vs conventional insulin therapy (CIT) (insulin started if blood glucose } \\
>215 \mathrm{mg} / \mathrm{dL}, \text { tapered if }<180 \mathrm{mg} / \mathrm{dL})\end{array}$ \\
\hline Outcomes & $\begin{array}{l}\text { Incidence of CIP/CIM, based on presence of abundant spontaneous electrical activity } \\
\text { on electrophysiological examination and need for prolonged mechanical ventilation (at } \\
\text { least } 14 \text { days of mechanical ventilation) }\end{array}$ \\
\hline Notes & $\begin{array}{l}\text { Single centre } \\
\text { Sponsors of the study were not involved in the study design, data collection, analysis or } \\
\text { interpretation of the data, or preparation of the manuscript }\end{array}$ \\
\hline
\end{tabular}

\section{Risk of bias}

\begin{tabular}{|c|c|c|}
\hline Bias & Authors' judgement & Support for judgement \\
\hline $\begin{array}{l}\text { Random sequence generation (selection } \\
\text { bias) }\end{array}$ & Low risk & $\begin{array}{l}\text { Quote: "Treatment assignment was performed with the use of } \\
\text { sealed envelopes, stratified according to diagnostic category, and } \\
\text { balanced with the use of permuted blocks of } 10 . " \\
\text { Personal communication: "randomisation sequence was deter- } \\
\text { mined by shuffling envelopes" } \\
\text { Comment: probably done }\end{array}$ \\
\hline Allocation concealment (selection bias) & Low risk & $\begin{array}{l}\text { Quote: "Treatment assignment was performed with the use of } \\
\text { sealed envelopes" } \\
\text { Personal communication: numbered and opaque }\end{array}$ \\
\hline $\begin{array}{l}\text { Blinding (performance bias and detection } \\
\text { bias) } \\
\text { Neuromuscular analysis }\end{array}$ & Low risk & $\begin{array}{l}\text { Quote: "ENMGs were evaluated by an independent investigator, } \\
\text { unaware of treatment allocation" } \\
\text { Comment: Review authors judge that blinding outcome assessor } \\
\text { probably sufficient to avoid bias }\end{array}$ \\
\hline $\begin{array}{l}\text { Blinding (performance bias and detection } \\
\text { bias) } \\
\text { Mortality }\end{array}$ & Low risk & $\begin{array}{l}\text { Personal communication: Mortality was obtained by review of } \\
\text { participant charts by a study nurse, unaware of treatment allo- } \\
\text { cation } \\
\text { Comment: Review authors judge that blinding of the outcome } \\
\text { assessor was probably sufficient to avoid bias }\end{array}$ \\
\hline
\end{tabular}


Hermans 2007 (Continued)

\begin{tabular}{l|l}
$\begin{array}{l}\text { Blinding (performance bias and detection } \\
\text { bias) }\end{array}$ & Low risk \\
$\begin{array}{l}\text { Other secondary outcomes } \\
\end{array}$ & $\begin{array}{l}\text { Quote: "This study could not be blinded for obvious reasons. } \\
\text { To minimize the bias, however, clear guidelines were used for se- } \\
\text { dation, mechanical ventilation, weaning, and patient discharge" } \\
\text { Comment: Review authors judge that the use of strict protocols } \\
\text { was probably sufficient to avoid a substantial risk of bias despite } \\
\text { unblinding of treating personnel }\end{array}$ \\
\hline
\end{tabular}

Incomplete outcome data (attrition bias) High risk

605 and 595 participants were randomised respectively to CIT

Neuromuscular outcome and IIT. 74 vs 69 died within 7 days, 379 vs 378 were discharged within 7 days, 14 vs 9 were excluded because of pre-existing neuromuscular disease or technical problems

212 participants in the CIT group and 208 in the IIT group were analysed

Comment: Missing outcome data balanced across intervention groups, with similar reasons for missing data across groups, and similar demographic data and baseline characteristics in treatment groups

Review authors performed imputation for participants with missing data but this involved a substantial amount of data

Incomplete outcome data (attrition bias) Low risk

Figures are reported for the total population randomised Mortality

Incomplete outcome data (attrition bias) Low risk Other secondary outcomes

Selective reporting (reporting bias) Low risk

Study protocol published at www.clinicaltrials.gov

The paper reports all the prespecified outcome measures

\begin{tabular}{lll}
\hline Diagnostic criteria for CIP/CIM & Low risk & Predetermined electrophysiological criteria were used
\end{tabular}

\begin{tabular}{ll|l}
\hline Other bias & Low risk & The study appears to be free of other sources of bias
\end{tabular}

\section{Routsi 2010}

\begin{tabular}{ll}
\hline Methods & Quasi-RCT \\
\hline Participants & $\begin{array}{l}140 \text { participants with APACHE II }>13 \text {, second day in the ICU } \\
\text { Age (in years): intervention group } 61 \pm 19 ; \text { control group } 58 \pm 18 \\
\text { Percentage male: intervention group } 68 \% \text {; control group } 68 \%\end{array}$ \\
\hline Interventions & $\begin{array}{l}\text { Electrical muscle stimulation (EMS): daily sessions (vastus lateralis, vastus medialis, } \\
\text { peroneus longus) of both lower extremities starting from the second day after admission } \\
\text { until ICU discharge. The EMS consisted of bilaterally, biphasic symmetric impulses of } 45 \\
\text { Hz, } 400 \mu \text { sulse duration, } 12 \mathrm{~s} \text { on and } 6 \text { s off, intensity able to cause visible contractions, } \\
\text { duration of session } 55 \text { min, including } 5 \text { min warm up and } 5 \text { min for recovery } \\
\text { Control: no sham stimulation }\end{array}$
\end{tabular}

Interventions for preventing critical illness polyneuropathy and critical illness myopathy (Review) 
Routsi 2010 (Continued)

\begin{tabular}{l|l}
\hline Outcomes & MRC sum-score, weaning duration, ICU stay \\
\hline Notes & $\begin{array}{l}\text { Single centre study } \\
\text { The research project was co-financed by the European Union (European Social Fund) } \\
\text { and the Greek Ministry of Development }\end{array}$ \\
\hline
\end{tabular}

\section{Risk of bias}

\begin{tabular}{|c|c|c|}
\hline Bias & Authors' judgement & Support for judgement \\
\hline $\begin{array}{l}\text { Random sequence generation (selection } \\
\text { bias) }\end{array}$ & High risk & $\begin{array}{l}\text { Quote: "patients with an odd number were assigned to the EMS } \\
\text { group and patients with an even number were assigned to the } \\
\text { control group" } \\
\text { Comment: non-random component in the sequence generation }\end{array}$ \\
\hline
\end{tabular}

\begin{tabular}{|l|l} 
Allocation concealment (selection bias) High risk & $\begin{array}{l}\text { Quote: "patients with an odd number were assigned to the EMS } \\
\text { group and patients with an even number were assigned to the } \\
\text { control group" }\end{array}$
\end{tabular}

Blinding (performance bias and detection High risk bias)

Neuromuscular analysis
Quote: "MRC scale and handgrip investigators-though independent from each other-were not blinded to patients' group of randomization. Furthermore, ICU staff was not blinded due to absence of sham-EMS sessions, and this may have affected cointerventions."

Comment: Unblinding could have introduced bias
Blinding (performance bias and detection Low risk bias)

Mortality

Blinding (performance bias and detection High risk bias)

Other secondary outcomes

Incomplete outcome data (attrition bias) High risk Neuromuscular outcome
Quote: “The investigators were not blinded as to patients' allocation"

Comment: Review authors judge that unblinding probably did not induce bias for mortality

Quote: "Furthermore, ICU staff was not blinded due to absence of sham-EMS sessions, and this may have affected cointerventions"

Comment: Unblinding could have introduced bias

44/68 missing data in intervention and 44/72 in control group, reasons differ across groups (EMS vs control: 28 vs 22 deaths, 11 vs 22 impaired cognitive state, 3 vs 0 prolonged use of NMBA, 2 vs 0 consent withdrawn, 2 vs 0 no EMS session. Significantly higher APACHE II in remaining participants in the EMS group (mean $16 \pm 4$ ) vs the control group $(19 \pm 5$ ), MD $-3.00,95 \%$ CI -5.45 to -0.55

Review authors performed imputation for missing values but this involved a large proportion of participants 
Routsi 2010 (Continued)

\begin{tabular}{|c|c|c|}
\hline $\begin{array}{l}\text { Incomplete outcome data (attrition bias) } \\
\text { Mortality }\end{array}$ & Low risk & $\begin{array}{l}\text { Quote: "Analysis of patient data was by intention to treat. Pa- } \\
\text { tients randomised to the EMS group that did not finally receive } \\
\text { any EMS session were not included in the analysis." } \\
\text { Comment: } 2 \text { participants did not receive EMS. There was a } \\
\text { small amount of missing data. Review authors judged that this } \\
\text { was not likely to have introduced bias }\end{array}$ \\
\hline $\begin{array}{l}\text { Incomplete outcome data (attrition bias) } \\
\text { Other secondary outcomes }\end{array}$ & Low risk & $\begin{array}{l}\text { Quote: "Analysis of patient data was by intention to treat. Pa- } \\
\text { tients randomised to the EMS group that did not finally receive } \\
\text { any EMS session were not included in the analysis." } \\
\text { Comment: } 2 \text { participants did not receive EMS. There was a } \\
\text { small amount of missing data. Review authors judged that this } \\
\text { was not likely to have introduced bias }\end{array}$ \\
\hline Selective reporting (reporting bias) & High risk & $\begin{array}{l}\text { Comment: } \\
\text { study protocol is available at www.clinicaltrials.gov. Secondary } \\
\text { outcome measures mentioned: a previous publication on only } \\
\text { the first } 26 \text { participants reported muscle mass preservation; there } \\
\text { has been no report (yet) of muscle properties and structure. No } \\
\text { report of formal assessment of severe adverse events }\end{array}$ \\
\hline Diagnostic criteria for CIP/CIM & Low risk & $\begin{array}{l}\text { Quote: "Patients with an MRC sum score of less than } 48 \text { of } 60 \\
\text { were diagnosed with CIPNM" }\end{array}$ \\
\hline Other bias & Low risk & The study appears to be free of other sources of bias \\
\hline
\end{tabular}

Schweickert 2009

\begin{tabular}{ll}
\hline Methods & Parallel-group RCT \\
\hline Participants & 104 sedated medical ICU patients $\geq 18$ years who had been on mechanical ventilation \\
& $\begin{array}{l}\text { for less than } 72 \text { hours, who were expected to continue for at least } 24 \text { hours, and who } \\
\text { met criteria for baseline functional independence }\end{array}$ \\
& $\begin{array}{l}\text { Exclusion criteria consisted of rapidly-developing neuromuscular disease, cardiopul- } \\
\text { monary arrest, irreversible disorders with 6-month mortality estimated at more than } \\
50 \%, \text { raised intracranial pressure, absent limbs, or enrolment in another trial } \\
\text { Age (median, in years): intervention group 58; control group 54 } \\
\text { Percentage male: intervention group 41\%; control group 58\% }\end{array}$ \\
\hline
\end{tabular}

Interventions

Intervention: physical and occupational therapy co-ordinated with daily interruption of sedatives consisting of: 1 . passive range of motion for all limbs in unco-operative participants (10 repetitions in all cardinal directions); 2. if interaction achieved, active assisted and active range of motion exercises in the supine position; 3. advancement to bed mobility activities including transferring to upright sitting; 4. participation in activities of daily living (ADL) and exercise, encouraging increased independence with functional tasks; and 5. transfer training, pre-gait exercise and walking. Control: daily interruption of sedatives with physical and occupational therapy delivered as ordered

Interventions for preventing critical illness polyneuropathy and critical illness myopathy (Review) 


\begin{tabular}{l|l}
\hline Outcomes & $\begin{array}{l}\text { Functional outcomes at hospital discharge, duration of delirium, ventilator-free days } \\
\text { compared with standard care }\end{array}$ \\
\hline Notes & $\begin{array}{l}\text { 2-centre trial } \\
\text { Time to first physiotherapy session was } 1.5 \text { days in the intervention group and } 7.4 \text { days } \\
\text { in the control group; rates and timing of physical and occupational therapy in the control } \\
\text { group may have been affected and the control group could have been at disadvantage } \\
\text { No funding }\end{array}$ \\
\hline
\end{tabular}

\section{Risk of bias}

\section{Bias}

Random sequence generation (selection Low risk bias)

\begin{tabular}{lll} 
Allocation concealment (selection bias) & Low risk \\
\hline $\begin{array}{l}\text { Blinding (performance bias and detection } \\
\text { bias) }\end{array}$ & Low risk
\end{tabular}
bias)

Neuromuscular analysis

Blinding (performance bias and detection Low risk bias)

Mortality

Blinding (performance bias and detection High risk bias)

Other secondary outcomes

\begin{tabular}{l|l} 
& \\
\hline $\begin{array}{l}\text { Incomplete outcome data (attrition bias) } \\
\text { Neuromuscular outcome }\end{array}$ & High risk
\end{tabular}

\section{Authors' judgement Support for judgement}

Quote: “computer generated, permuted block randomisation scheme was used"

Quote: “consecutively numbered, sealed, opaque envelope”

Quote: "the nature of the intervention prevented any blinding from patients and health care providers", "therapists who undertook patient assessments were blinded to treatment assignment" Comment: Review authors judge that blinding outcome assessors is probably sufficient to avoid substantial risk of bias

Comment: Review authors judge that blinding outcome assessors was sufficient to avoid bias

Quote: "the nature of the intervention prevented any blinding from patients and health care providers"... "Decisions about sedation initiation or reinitiation, extubation, and ICU and hospital discharge were not controlled by protocol and might have been affected by knowledge of the intervention"

Comment: Unblinding could have introduced bias

Quote: "Data were analysed by an intention-to-treat approach. Patients who died during the study were assigned scores of 0 for ventilator-free days, strength testing (MRC examination and hand grip), ADL total, walk distance, and Barthel Index score." Comment: adequate imputation performed but this involved a substantial amount of data

Incomplete outcome data (attrition bias) Low risk Quote: “All 104 patients were included in the analysis" Mortality

Incomplete outcome data (attrition bias) Low risk Other secondary outcomes
Quote: "All 104 patients were included in the analysis" 
Schweickert 2009 (Continued)

\begin{tabular}{|c|c|c|}
\hline Selective reporting (reporting bias) & Low risk & $\begin{array}{l}\text { Comment: The study protocol is available } \\
\text { at www.clinicaltrials.gov. The paper reports all the prespecified } \\
\text { outcome measures }\end{array}$ \\
\hline Diagnostic criteria for CIP/CIM & Low risk & Comment: MRC sum-score was used \\
\hline Other bias & Low risk & The study appears to be free of other bias \\
\hline
\end{tabular}

Steinberg 2006

\begin{tabular}{ll}
\hline Methods & Parallel-group RCT \\
\hline Participants & $\begin{array}{l}180 \text { patients with ARDS of at least } 7 \text { days duration and maximal } 28 \text { days' duration } \\
\text { Age (in years): intervention group } 49 \pm 19 ; \text { control group } 49 \pm 17 \\
\text { Percentage male: intervention group } 40 \% \text {; control group } 58 \%\end{array}$ \\
\hline Interventions & $\begin{array}{l}\text { Intravenous methylprednisolone sodium succinate diluted in } 50 \mathrm{~mL} \text { of } 5 \% \text { dextrose in } \\
\text { water (single dose of } 2 \mathrm{mg} / \mathrm{kg}, \text { followed by } 0.5 \mathrm{mg} / \mathrm{kg} 4 \text { times a days for } 14 \text { days, followed } \\
\text { by } 0.5 \mathrm{mg} / \mathrm{kg} \text { twice daily for } 7 \text { days, then tapering the dose) vs placebo }\end{array}$ \\
\hline Outcomes & $\begin{array}{l}\text { Primary end point was mortality at } 60 \text { days } \\
\text { Secondary end points were ventilator-free days at } 28 \text { days, organ failure-free days at } 28 \\
\text { days and markers of inflammation and fibroproliferation at } 7 \text { days } \\
\text { In the first } 88 \text { participants the safety board ordered retrospective evaluation of neuromy- } \\
\text { opathy. The trial evaluated the next } 92 \text { participants prospectively }\end{array}$ \\
\hline Notes & $\begin{array}{l}\text { Multicentre } \\
\text { An adequate intention-to-treat analysis was performed concerning the primary outcome } \\
\text { of the trial Concerning CIP/CIM, however, data were only prospectively available in } 92 / \\
180 \text { participants. Also, there is inconsistency in the paper concerning this exact number: } \\
\text { the paper mentions both } 91 \text { and } 92 \text { as numbers of participants: } 92 \text { once in the text vs } \\
91 \text { in a table } \\
\text { Funding not mentioned }\end{array}$ \\
\hline
\end{tabular}

Risk of bias

\begin{tabular}{|c|c|c|}
\hline Bias & Authors' judgement & Support for judgement \\
\hline $\begin{array}{l}\text { Random sequence generation (selection } \\
\text { bias) }\end{array}$ & Low risk & $\begin{array}{l}\text { Quote from published protocol (www.ARDSnet.org): "The ran- } \\
\text { domization scheme to be employed will consist of centralized, } \\
\text { random permuted blocks."..."and an assignment will be made } \\
\text { by computer-generated randomisations" } \\
\text { Comment: probably done }\end{array}$ \\
\hline Allocation concealment (selection bias) & Low risk & $\begin{array}{l}\text { Quote from published protocol (www.ARDSnet.org): "the data } \\
\text { coordinating center will be called and an assignment will be } \\
\text { made by computer-generated randomisations" }\end{array}$ \\
\hline
\end{tabular}

Interventions for preventing critical illness polyneuropathy and critical illness myopathy (Review) 
Comment: probably done

\begin{tabular}{ll}
\hline $\begin{array}{l}\text { Blinding (performance bias and detection } \\
\text { bias) }\end{array}$ & Low risk \\
Neuromuscular analysis & $\begin{array}{l}\text { Quote: "To receive either methylprednisolone or placebo in a } \\
\text { double blind fashion" } \\
\text { Quote from published protocol (www.ARDSnet.org): "the } \\
\text { pharmacy which will dispense either MPSS or placebo based on } \\
\text { a predetermined list in the research pharmacy" } \\
\text { Comment: probably done }\end{array}$ \\
\hline
\end{tabular}

Blinding (performance bias and detection Low risk bias) Mortality
Quote: “To receive either methylprednisolone or placebo in a double blind fashion"

Quote from published protocol (www.ARDSnet.org): "the pharmacy which will dispense either MPSS or placebo based on a predetermined list in the research pharmacy"

Comment: probably done

Blinding (performance bias and detection Low risk bias)

Other secondary outcomes
Quote: “To receive either methylprednisolone or placebo in a double blind fashion"

Quote from published protocol (www.ARDSnet.org): "the pharmacy which will dispense either MPSS or placebo based on a predetermined list in the research pharmacy"

Comment: probably done
Incomplete outcome data (attrition bias) High risk Neuromuscular outcome
Data on neuromuscular outcome missing in the first 88 of a total of 180 participants, obtained by retrospective chart review Comment: reason for missing data probably not related to outcome. Review authors performed imputation for missing data but this involved a substantial amount of data

Data are reported on the total population randomised

Incomplete outcome data (attrition bias) Low risk Mortality

Incomplete outcome data (attrition bias) Low risk

Data are reported on the total population randomised Other secondary outcomes

Selective reporting (reporting bias) Low risk

Study protocol published at www.ARDSnet.org

All the prespecified outcome measures are reported in the paper

Diagnostic criteria for CIP/CIM High risk

Quote: “we reviewed the charts of all 88 previously enrolled patients for evidence of neuromyopathy, as defined by the presence of the terms "myopathy", "myositis", "neuropathy", "paralysis" or "unexplained weakness" in the medical record. The charts of the final 91 patients who were enrolled were reviewed prospectively."

Comment: no predefined criteria used 
Van den Berghe 2005

\begin{tabular}{l|l}
\hline Methods & Parallel-group RCT \\
\hline Participants & $\begin{array}{l}405 \text { patients staying in a surgical ICU for at least } 7 \text { days } \\
\text { Age (in years): intervention group } 61 \pm 15 ; \text { control group } 61 \pm 16 \\
\text { Percentage male: intervention group } 67 \% \text {; control group } 69 \%\end{array}$ \\
\hline Interventions & $\begin{array}{l}\text { Intensive insulin therapy (IIT) (insulin infusion was titrated to achieve blood glucose } \\
\text { levels of } 80 \text { to } 110 \mathrm{mg} / \mathrm{dL}) \text { versus conventional insulin therapy (CIT) (insulin was started } \\
\text { if blood glucose }>215 \mathrm{mg} / \mathrm{dL}, \text { tapered if }<180 \mathrm{mg} / \mathrm{dL})\end{array}$ \\
\hline Outcomes & $\begin{array}{l}\text { Incidence of CIP/CIM, based on presence of abundant spontaneous electrical activity } \\
\text { on electrophysiological examination, and need for prolonged mechanical ventilation (at } \\
\text { least } 14 \text { days of mechanical ventilation) }\end{array}$ \\
\hline Notes & $\begin{array}{l}\text { Single centre } \\
\text { The figures reported (Van den Berghe } 2005) \text { are slightly different from those reported } \\
\text { in the original trial (Van den Berghe } 2001) \text { due to a statistical error in the query in the } \\
\text { latter report, where only patients staying more than } 7 \text { days were considered instead of at } \\
\text { least } 7 \text { days } \\
\text { Sponsors of the study were not involved in the study design, data collection, analysis or } \\
\text { interpretation of the data, or preparation of the manuscript }\end{array}$ \\
\hline
\end{tabular}

\section{Risk of bias}

\begin{tabular}{|c|c|c|}
\hline Bias & Authors' judgement & Support for judgement \\
\hline $\begin{array}{l}\text { Random sequence generation (selection } \\
\text { bias) }\end{array}$ & Low risk & $\begin{array}{l}\text { Quote: "Prospective, randomised controlled study...use of } \\
\text { sealed envelopes, with stratification according to the type of crit- } \\
\text { ical illness" } \\
\text { Personal communication: "shuffling of envelopes" }\end{array}$ \\
\hline Allocation concealment (selection bias) & Low risk & $\begin{array}{l}\text { Quote: “...use of sealed envelopes” } \\
\text { Personal communication: } \\
\text { "Opaque and sequentially numbered" }\end{array}$ \\
\hline $\begin{array}{l}\text { Blinding (performance bias and detection } \\
\text { bias) } \\
\text { Neuromuscular analysis }\end{array}$ & Low risk & $\begin{array}{l}\text { Quote: "The presence of CIPNP was prospectively assessed elec- } \\
\text { tromyographically in all } 405 \text { patients still in ICU on day } 7 \text { and } \\
\text { subsequently on a weekly basis by one electrophysiologist who } \\
\text { was unaware of the treatment assignments" } \\
\text { Comment: review authors judge that blinding of the outcome } \\
\text { assessor was probably sufficient to avoid bias }\end{array}$ \\
\hline $\begin{array}{l}\text { Blinding (performance bias and detection } \\
\text { bias) } \\
\text { Mortality }\end{array}$ & Low risk & $\begin{array}{l}\text { Personal communication: mortality was obtained by review of } \\
\text { participant charts by a study nurse, unaware of treatment allo- } \\
\text { cation } \\
\text { Comment: review authors judge that blinding of the outcome } \\
\text { assessor was probably sufficient to avoid bias }\end{array}$ \\
\hline
\end{tabular}


Blinding (performance bias and detection Low risk bias)

Other secondary outcomes
Quote: "it was not feasible to conduct the study in a strictly blinded fashion because adjustment of the insulin dose requires blood glucose monitoring. To minimize bias, we assigned responsibility for adjustment of the insulin dose to a team of nurses and to a study physician who was not taking part in clinical decisions, with strictly blinded analysis of important outcome measures."..."To minimize the possibility of bias caused by delays in the transfer of patients to a regular ward because of the unavailability of beds, patients were considered to be ready for discharge when they no longer needed vital-organ support and were receiving at least two thirds of their caloric intake by the normal enteral route"

Comment: Review authors judge that the use of strict protocols and definition of ready for discharge was probably sufficient to avoid substantial risk of bias despite unblinding of treating personnel
Incomplete outcome data (attrition bias) High risk Neuromuscular outcome
224/783 CIT group participants and 181/765 IIT group participants had neuromuscular data available

Comment: review authors judge that the reason for missing data is unlikely to be related to outcome and review authors also performed imputation for participants with missing data but this involved substantial amount of data
Incomplete outcome data (attrition bias) Low risk Mortality
Figures are reported for the total population randomised

Incomplete outcome data (attrition bias) Low risk

Data are reported for the total population randomised Other secondary outcomes

\begin{tabular}{|c|c|c|}
\hline Selective reporting (reporting bias) & Low risk & $\begin{array}{l}\text { The published report includes all expected outcomes and the } \\
\text { approved study protocol is available }\end{array}$ \\
\hline Diagnostic criteria for CIP/CIM & Low risk & Predetermined electrophysiological criteria were used \\
\hline Other bias & High risk & $\begin{array}{l}\text { The study was prematurely stopped due to a formal stopping } \\
\text { rule (Lan and Demets) } \\
\text { Comment: prematurely stopped for a data-dependent reason }\end{array}$ \\
\hline
\end{tabular}

ARDS: adult respiratory distress syndrome; CIP/CIM: critical illness polyneuropathy/critical illness myopathy; COPD: chronic obstructive pulmonary disease; ICU: intensive care unit; MRC: medical research council; RCT: randomised controlled trial; vs: versus 


\begin{tabular}{ll}
\hline Study & Reason for exclusion \\
\hline Berard 2000 & $\begin{array}{l}\text { No clinical or electrophysiological data on weakness, outcome is plasma amino acid concentration and nitrogen } \\
\text { balance }\end{array}$ \\
\hline Bouletreau 1985 & $\begin{array}{l}\text { No clinical or electrophysiological data on weakness, outcome is nitrogen balance, excretion of creatinine, 3- } \\
\text { methyl histidine }\end{array}$ \\
\hline Brunello 2010 & No interventional study \\
\hline Burtin 2009 & No incidence of CIP or CIM as a primary or secondary outcome \\
\hline Caruso 2005 & No incidence of CIP or CIM as a primary or secondary outcome \\
\hline Chen 2011 & No incidence of CIP or CIM as a primary or secondary outcome \\
\hline Chiang 2006 & No ICU patients \\
\hline
\end{tabular}

Fläring $2003 \quad$ No ICU patients, no clinical or electrophysiological data on weakness, outcome is muscle glutathione, free amino acids in skeletal muscle and plasma

Gamrin $2000 \quad$ No clinical or electrophysiological data on weakness, outcome is muscle protein synthesis and muscle free glutamine

Gerovasili 2009a No clinical or electrophysiological data on weakness

Gerovasili 2009b No clinical or electrophysiological data on weakness, only reports on muscle mass measured with ultrasonography

Gruther $2010 \quad$ No clinical or electrophysiological data on weakness, only reports on muscle mass measured with ultrasonography

\begin{tabular}{ll}
\hline Hsieh 2006 & Not an RCT \\
\hline Huang 2006 & No clinical or electrophysiological data on weakness \\
\hline Johnson 1993 & No incidence of CIP or CIM as a primary or secondary outcome \\
\hline Karatzanos 2012 & Subanalysis of data from Routsi 2010 \\
\hline Knox 1996 & Not an RCT \\
\hline Kuhls 2007 & No clinical nor electrophysiological data on weakness, outcome measure is nitrogen balance \\
\hline Martin 2011 & No incidence of CIP or CIM as a primary or secondary outcome \\
\hline $\begin{array}{l}\text { Menadue 2010 } \\
\text { Interventions for preventing critical illness polyneuropathy and critical illness myopathy (Review) } \\
\text { Copyright @ 2014 The Cochrane Collaboration. Published by John Wiley \& Sons, Ltd. }\end{array}$
\end{tabular}

Copyright $\odot 2014$ The Cochrane Collaboration. Published by John Wiley \& Sons, Ltd. 
(Continued)

\begin{tabular}{|c|c|}
\hline Miao 2005 & No clinical nor electrophysiological data on weakness \\
\hline Mohr 1997 & Retrospective analysis \\
\hline Morris 2008 & No incidence of CIP or CIM as a primary or secondary outcome \\
\hline Nava 1998 & No incidence of CIP or CIM as a primary or secondary outcome \\
\hline Paddon-Jones 2005 & No ICU patients, healthy volunteers \\
\hline Pichard 1996 & No incidence of CIP or CIM as a primary or secondary outcome \\
\hline Porta 2005 & No ICU patients, concerns rehabilitation after extubation in intermediate care unit \\
\hline Rodriguez 2012 & Randomisation of body parts \\
\hline Routsi 2009 & No incidence of CIP or CIM as a primary or secondary outcome \\
\hline Salisbury 2010 & Studies rehabilitation strategies during the ward phase after critical illness \\
\hline Sevette 2005 & No ICU patients, no clinical or electrophysiological data on weakness \\
\hline Takala 1999a & No incidence of CIP or CIM as a primary or secondary outcome \\
\hline Takala 1999b & No incidence of CIP or CIM as a primary or secondary outcome \\
\hline Tjäder 2004 & $\begin{array}{l}\text { No clinical or electrophysiological data on weakness, outcome is plasma glutamine levels, free muscle glutamine, } \\
\text { muscle protein synthesis and content }\end{array}$ \\
\hline Toledo 2007 & No ICU patients \\
\hline Vivodtzev 2006 & No ICU patients \\
\hline Watters 1997 & No incidence of CIP or CIM as a primary or secondary outcome \\
\hline Zanotti 2003 & No incidence of CIP or CIM as a primary or secondary outcome \\
\hline Ziegler 1990 & Not an RCT, no clinical or electrophysiological data on weakness \\
\hline
\end{tabular}

CIM: critical illness myopathy; CIP: critical illness polyneuropathy; ICU: intensive care unit; RCT: randomised controlled trial 
Characteristics of studies awaiting assessment [ordered by study ID]

\section{Abokhabar 2012}

\begin{tabular}{l|l}
\hline Methods & RCT \\
\hline Participants & $\mathrm{N}=80$ critically ill patients, mechanically ventilated for at least 24 hours \\
\hline Interventions & Once daily electrical muscle stimulation vs conventional treatment \\
\hline Outcomes & Muscle weakness evaluated using MRC sum-score and duration of mechanical ventilation \\
\hline Notes & Single centre, abstract \\
\hline
\end{tabular}

\section{Alia 2011}

Methods RCT

Participants $\quad \mathrm{N}=83$ patients with chronic obstructive pulmonary disease exacerbation receiving invasive or non-invasive ventilation

Interventions Corticosteroids $0.5 \mathrm{mg} / \mathrm{kg} 4$ times daily, tempered over 10 days vs placebo

Outcomes Duration of mechanical ventilation, length of ICU stay, need for intubation, weakness assessed with MRC sum-score

Notes Multicentre

\section{Brunner 2013}

\begin{tabular}{ll}
\hline Methods & RCT \\
\hline Participants & $\begin{array}{l}\mathrm{N}=38 \text { critically ill patients with multiple organ failure, systemic inflammatory response syndrome or sepsis and early } \\
\text { signs of critical illness polyneuromyopathy }\end{array}$ \\
\hline Interventions & IgM-enriched intravenous immunoglobulin vs placebo for 3 days \\
\hline Outcomes & Electrophysiology and muscle biopsy \\
\hline Notes & Terminated early due to futility \\
\hline
\end{tabular}

\section{Devost 2011}

\begin{tabular}{l|l} 
Methods & Randomised body parts \\
\hline Participants & Mechanical ventilation for at least 48 hours \\
\hline Interventions & $\begin{array}{l}60 \text { minutes of daily quadriceps electrical stimulation of one leg in a randomised order for } 10 \text { days, then of both legs } \\
\text { for } 10 \text { additional days }\end{array}$
\end{tabular}




\section{Devost 2011 (Continued)}

\begin{tabular}{ll} 
Outcomes & $\begin{array}{l}\text { Non-voluntary (magnetic stimulation of the legs) and voluntary muscle strength (MRC sum-scores and handgrip } \\
\text { strength) }\end{array}$ \\
\hline Notes & Abstract \\
\hline
\end{tabular}

Files 2013

\begin{tabular}{ll}
\hline Methods & RCT \\
\hline Participants & $\mathrm{N}=100$ critically ill patients with acute respiratory failure \\
\hline Interventions & Early rehabilitation vs usual care \\
\hline Outcomes & Grip strength, duration of mechanical ventilation, ICU stay, hospital stay, death \\
\hline Notes & Abstract \\
\hline
\end{tabular}

\section{Gerovasili 2011}

\begin{tabular}{l|l}
\hline Methods & RCT \\
\hline Participants & $\mathrm{N}=172$ critically ill patients with APACHE II $\geq 13$ \\
\hline Interventions & Daily electrical muscle stimulation in upper and lower limbs vs control \\
\hline Outcomes & Strength at awakening based on MRC sum-score handgrip dynamometry \\
\hline Notes & Abstract \\
\hline Hermans 2013 & RCT \\
\hline Methods & $\mathrm{N}=600$ awake, co-operative patients from medical and surgical ICU. In ICU for at least 8 days \\
\hline Participants & Early (within 48 hours) vs late (not in the first week) supplementation of deficient enteral feeding \\
\hline Interventions
\end{tabular}


Mikaeili 2012

\begin{tabular}{ll}
\hline Methods & RCT \\
\hline Participants & $\mathrm{N}=40$ medical ICU patients \\
\hline Interventions & Euglycemic control $(80$ to $140 \mathrm{mg} / \mathrm{dL})$ vs conventional control $(180$ to $200 \mathrm{mg} / \mathrm{dL})$ \\
\hline Outcomes & Duration of mechanical ventilation and the presence of critical illness polyneuropathy \\
\hline Notes & None \\
\hline
\end{tabular}

Paternostro-Sluga 2012

\begin{tabular}{ll}
\hline Methods & RCT \\
\hline Participants & $\mathrm{N}=40$ critically ill patients after cardiac or thoracic surgery \\
\hline Interventions & $\begin{array}{l}\text { Daily }(2 \times 30 \text { minutes }) \text { electrical stimulation of the quadriceps femoris, until ICU discharge or up to } 14 \text { days vs sham } \\
\text { stimulation }\end{array}$ \\
\hline Outcomes & Nitrogen excretion, muscle strength with MRC sum score \\
\hline Notes & Abstract \\
\hline
\end{tabular}

MRC: Medical Research Council; RCT: randomised controlled trial

Characteristics of ongoing studies [ordered by study ID]

\section{Kho 2012}

\begin{tabular}{l|l}
\hline Trial name or title & Use of neuromuscular electrostimulation (NMES) for treatment or prevention of ICU-associated weakness \\
\hline Methods & RCT \\
\hline Participants & $\begin{array}{l}\text { Medical ICU, mechanically ventilated for at least 1 day, expected to stay in ICU for at least an additional } 2 \\
\text { days }\end{array}$ \\
\hline Interventions & $\begin{array}{l}\text { Electrical stimulation of the quadriceps, tibialis anterior, gastrocnemius muscles for } 60 \text { minutes a day vs sham } \\
\text { stimulation }\end{array}$ \\
\hline Outcomes & Lower extremity muscle strength at hospital discharge \\
\hline Starting date & June 2008 \\
\hline Contact information & Michelle Kho, Johns Hopkins Hospital, michelle.kho@jhmi.edu
\end{tabular}


Kho 2012 (Continued)

\begin{tabular}{l|l}
\hline Notes $\quad$ NCT00709124. Protocol \\
\hline
\end{tabular}

Parry 2012

\begin{tabular}{|c|c|}
\hline Trial name or title & eRiCC trial: Early rehabilitation in critical care \\
\hline Methods & RCT \\
\hline Participants & $\begin{array}{l}N=80 \text {, sepsis or severe sepsis, expected duration of mechanical ventilation of } \geq 48 \text { hours and remaining in } \\
\text { the ICU } \geq 4 \text { days }\end{array}$ \\
\hline Interventions & $\begin{array}{l}\text { Control: usual mobilisation for up to } 15 \text { minutes, but no longer } \\
\text { Intervention: usual mobilisation and within } 72 \text { hours from admission, electrical muscle stimulation assisted } \\
\text { supine cycling in one leg, and cycling with sham stimulation on the other leg. The cycling will take place for } \\
1 \text { hour, } 5 \text { days a week }\end{array}$ \\
\hline Outcomes & Muscle mass, muscle strength, physical function \\
\hline Starting date & 30 May 2012 \\
\hline Contact information & $\begin{array}{l}\text { Selina Parry, The University of Melbourne School of Physiotherapy Level } 1200 \text { Berkeley Street Parkville VIC } \\
3010 \text { Australia. selina.parry@austin.org.au }\end{array}$ \\
\hline Notes & ACTRN12612000528853. Single centre, protocol \\
\hline
\end{tabular}

ICU: intensive care unit; RCT: randomised controlled trial 
DATA AND ANALYSES

Comparison 1. Intensive insulin therapy (IIT) versus conventional insulin therapy (CIT)

\begin{tabular}{|c|c|c|c|c|}
\hline Outcome or subgroup title & $\begin{array}{l}\text { No. of } \\
\text { studies }\end{array}$ & $\begin{array}{c}\text { No. of } \\
\text { participants }\end{array}$ & Statistical method & Effect size \\
\hline 1 Occurrence of CIP/CIM & 2 & & Risk Ratio (M-H, Fixed, 95\% CI) & Subtotals only \\
\hline $\begin{array}{l}1.1 \text { In total population } \\
\text { randomised }\end{array}$ & 2 & 2748 & Risk Ratio (M-H, Fixed, 95\% CI) & $0.70[0.60,0.82]$ \\
\hline 1.2 In screened population & 2 & 825 & Risk Ratio (M-H, Fixed, 95\% CI) & $0.65[0.55,0.77]$ \\
\hline $\begin{array}{l}2 \text { Duration of mechanical } \\
\text { ventilation }\end{array}$ & 2 & & Mean Difference (IV, Fixed, 95\% CI) & Subtotals only \\
\hline $\begin{array}{l}2.1 \text { In total population } \\
\text { randomised }\end{array}$ & 2 & 2748 & Mean Difference (IV, Fixed, 95\% CI) & $-2.0[-2.93,-1.07]$ \\
\hline 2.2 In screened population & 2 & 825 & Mean Difference (IV, Fixed, 95\% CI) & $-2.55[-4.60,-0.51]$ \\
\hline $\begin{array}{l}2.3 \text { In ICU survivors, in total } \\
\text { population randomised }\end{array}$ & 2 & 2344 & Mean Difference (IV, Fixed, 95\% CI) & $-1.0[-1.86,-0.14]$ \\
\hline $\begin{array}{l}2.4 \text { In ICU survivors, in } \\
\text { screened population }\end{array}$ & 2 & 594 & Mean Difference (IV, Fixed, 95\% CI) & $-1.59[-3.98,0.79]$ \\
\hline 3 Duration of ICU stay & 2 & & Mean Difference (IV, Fixed, 95\% CI) & Subtotals only \\
\hline $\begin{array}{l}3.1 \text { In total population } \\
\text { randomised }\end{array}$ & 2 & 2748 & Mean Difference (IV, Fixed, 95\% CI) & $-1.48[-2.43,-0.54]$ \\
\hline 3.2 In screened population & 2 & 825 & Mean Difference (IV, Fixed, 95\% CI) & $-3.59[-5.70,-1.48]$ \\
\hline $\begin{array}{l}3.3 \text { In ICU survivors, in total } \\
\text { population randomised }\end{array}$ & 2 & 2344 & Mean Difference (IV, Fixed, 95\% CI) & $-1.0[-1.90,-0.10]$ \\
\hline $\begin{array}{l}3.4 \text { In ICU survivors of } \\
\text { screened population }\end{array}$ & 2 & 594 & Mean Difference (IV, Fixed, 95\% CI) & $-2.18[-4.66,0.30]$ \\
\hline 4 Death & 2 & & Risk Ratio (M-H, Fixed, 95\% CI) & Subtotals only \\
\hline $\begin{array}{l}\text { 4.1 At } 30 \text { days after ICU } \\
\text { admission, in total population } \\
\text { randomised }\end{array}$ & 2 & 2748 & Risk Ratio (M-H, Fixed, 95\% CI) & $0.94[0.80,1.10]$ \\
\hline $\begin{array}{l}4.2 \text { At } 30 \text { days after ICU } \\
\text { admission, in screened } \\
\text { population }\end{array}$ & 2 & 825 & Risk Ratio (M-H, Fixed, 95\% CI) & $0.91[0.72,1.14]$ \\
\hline $\begin{array}{l}4.3 \text { At } 180 \text { days after ICU } \\
\text { admission, in total population } \\
\text { randomised }\end{array}$ & 2 & 2748 & Risk Ratio (M-H, Fixed, 95\% CI) & $0.87[0.76,1.00]$ \\
\hline $\begin{array}{l}\text { 4.4 At } 180 \text { days after } \\
\text { ICU admission, in screened } \\
\text { population }\end{array}$ & 2 & 825 & Risk Ratio (M-H, Fixed, 95\% CI) & $0.78[0.66,0.93]$ \\
\hline 5 Serious adverse events & 2 & & Risk Ratio (M-H, Fixed, 95\% CI) & Subtotals only \\
\hline $\begin{array}{l}5.1 \text { In total population } \\
\text { randomised - hypoglycaemia }\end{array}$ & 2 & 2748 & Risk Ratio (M-H, Fixed, 95\% CI) & $6.27[4.15,9.49]$ \\
\hline $\begin{array}{l}5.2 \text { In total population } \\
\text { randomised- at least } 2 \\
\text { hypoglycaemic events }\end{array}$ & 2 & 2748 & Risk Ratio (M-H, Fixed, 95\% CI) & $5.83[2.37,14.35]$ \\
\hline
\end{tabular}

Interventions for preventing critical illness polyneuropathy and critical illness myopathy (Review)

Copyright $\odot 2014$ The Cochrane Collaboration. Published by John Wiley \& Sons, Ltd. 
5.3 In total population

randomised - death within 24

hours of last hypoglycaemic

event

5.4 In screened population -

$2 \quad 825$

Risk Ratio (M-H, Fixed, 95\% CI)

$6.93[4.10,11.72]$

hypoglycaemia

5.5 In screened population -

2

825 Risk Ratio (M-H, Fixed, 95\% CI)

$8.04[2.69,24.03]$

at least 2 hypoglycaemic events

5.6 In screened population -

2

825 Risk Ratio (M-H, Fixed, 95\% CI)

$0.77[0.15,3.96]$

death within 24 hours of last

hypoglycaemic event

\section{Comparison 2. Corticosteroids versus placebo}

\begin{tabular}{|c|c|c|c|c|}
\hline Outcome or subgroup title & $\begin{array}{l}\text { No. of } \\
\text { studies }\end{array}$ & $\begin{array}{c}\text { No. of } \\
\text { participants }\end{array}$ & Statistical method & Effect size \\
\hline 1 Occurrence of CIP/CIM & 1 & & Risk Ratio (M-H, Fixed, 95\% CI) & Subtotals only \\
\hline $\begin{array}{l}1.1 \text { In total population } \\
\text { randomised }\end{array}$ & 1 & 180 & Risk Ratio (M-H, Fixed, 95\% CI) & $1.27[0.77,2.08]$ \\
\hline 1.2 In screened population & 1 & 92 & Risk Ratio (M-H, Fixed, 95\% CI) & $1.09[0.53,2.26]$ \\
\hline 2 Death & 1 & & Risk Ratio (M-H, Fixed, 95\% CI) & Subtotals only \\
\hline $\begin{array}{l}2.1 \text { Death at } 180 \text { days in total } \\
\text { population randomised }\end{array}$ & 1 & 180 & Risk Ratio (M-H, Fixed, 95\% CI) & $0.99[0.64,1.52]$ \\
\hline $\begin{array}{l}3 \text { Serious adverse events } \\
\text { (dichotomous data) }\end{array}$ & 1 & & Risk Ratio (M-H, Fixed, 95\% CI) & Subtotals only \\
\hline 3.1 Shock & 1 & 180 & Risk Ratio (M-H, Fixed, 95\% CI) & $0.41[0.17,1.01]$ \\
\hline 3.2 Serious infection & 1 & 180 & Risk Ratio (M-H, Fixed, 95\% CI) & $0.68[0.42,1.11]$ \\
\hline $\begin{array}{l}3.3 \text { Suspected or probable } \\
\text { pneumonia }\end{array}$ & 1 & 180 & Risk Ratio (M-H, Fixed, 95\% CI) & $0.44[0.18,1.09]$ \\
\hline $\begin{array}{l}4 \text { Serious adverse events } \\
\text { (continuous data) }\end{array}$ & 1 & & Mean Difference (IV, Fixed, 95\% CI) & Subtotals only \\
\hline $\begin{array}{l}4.1 \text { Blood glucose }(\mathrm{mg} / \mathrm{dL}) \text { on } \\
\text { day } 7\end{array}$ & 1 & 180 & Mean Difference (IV, Fixed, 95\% CI) & $15.0[-3.41,33.41]$ \\
\hline
\end{tabular}

Comparison 3. Early physical therapy versus control

\begin{tabular}{|c|c|c|c|c|}
\hline Outcome or subgroup title & $\begin{array}{l}\text { No. of } \\
\text { studies }\end{array}$ & $\begin{array}{c}\text { No. of } \\
\text { participants }\end{array}$ & Statistical method & Effect size \\
\hline 1 Occurrence of CIP/CIM & 1 & & Risk Ratio (M-H, Fixed, 95\% CI) & Subtotals only \\
\hline $\begin{array}{l}1.1 \text { In total population } \\
\text { randomised }\end{array}$ & 1 & 104 & Risk Ratio (M-H, Fixed, 95\% CI) & $0.81[0.60,1.08]$ \\
\hline 1.2 In screened population & 1 & 82 & Risk Ratio (M-H, Fixed, 95\% CI) & $0.62[0.39,0.96]$ \\
\hline 2 Serious adverse events & 1 & & Risk Ratio (M-H, Fixed, 95\% CI) & Subtotals only \\
\hline
\end{tabular}




\section{Comparison 4. Electrical muscle stimulation versus control}

\begin{tabular}{lcccl} 
Outcome or subgroup title & $\begin{array}{c}\text { No. of } \\
\text { studies }\end{array}$ & $\begin{array}{c}\text { No. of } \\
\text { participants }\end{array}$ & Statistical method & Effect size \\
\hline $\begin{array}{c}1 \text { Occurrence of CIP/CIM } \\
\begin{array}{c}1.1 \text { In the total population } \\
\text { randomised }\end{array}\end{array}$ & 1 & 140 & $\begin{array}{c}\text { Risk Ratio (M-H, Fixed, 95\% CI) } \\
\quad \text { Risk Ratio (M-H, Fixed, 95\% CI) }\end{array}$ & Subtotals only \\
$\quad 1.2$ In screened population & 1 & 52 & Risk Ratio (M-H, Fixed, 95\% CI) & $0.94[0.78,1.15]$ \\
\hline
\end{tabular}

Analysis I.I. Comparison I Intensive insulin therapy (IIT) versus conventional insulin therapy (CIT), Outcome I Occurrence of CIP/CIM.

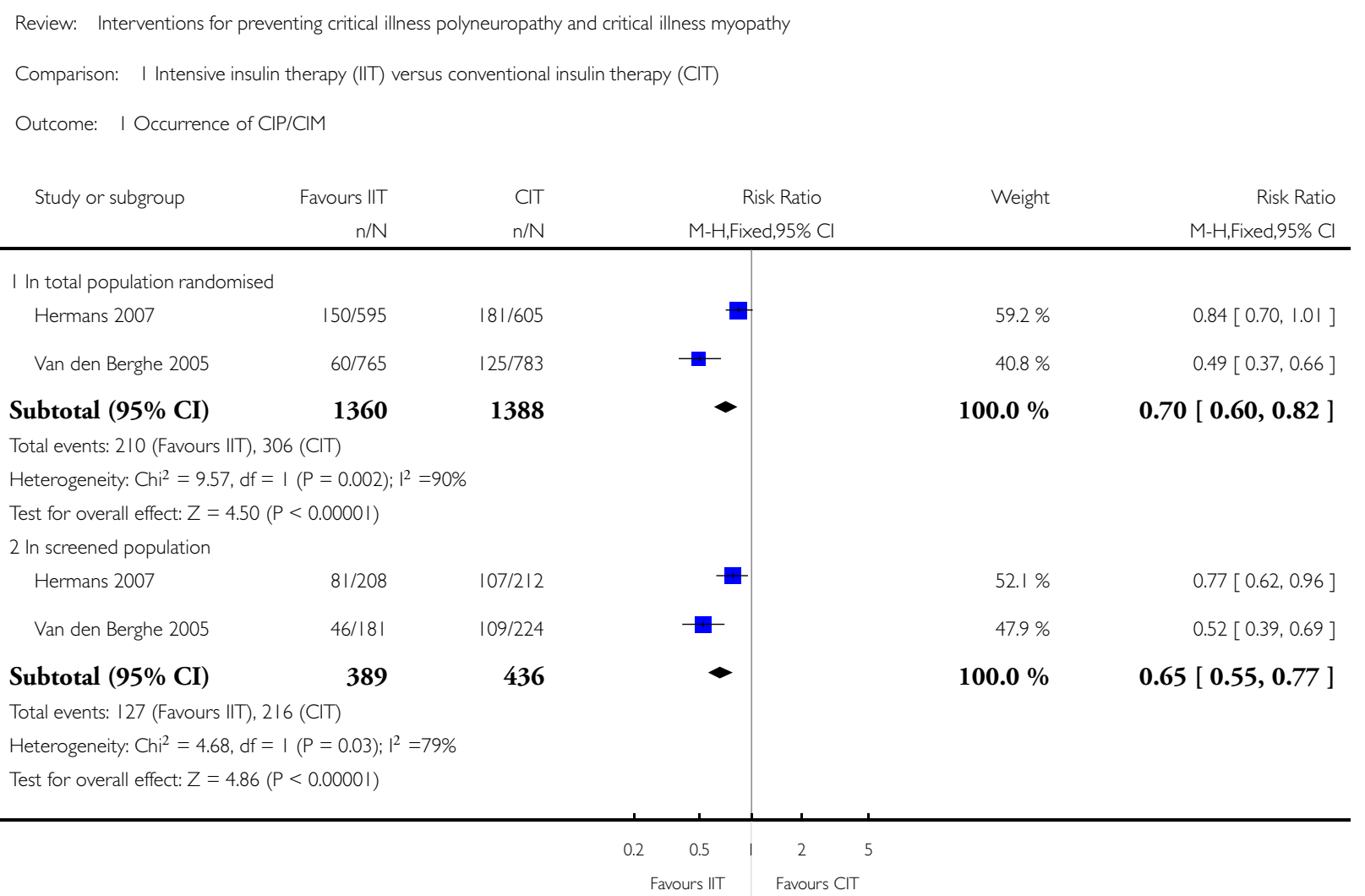


Analysis I.2. Comparison I Intensive insulin therapy (IIT) versus conventional insulin therapy (CIT), Outcome 2 Duration of mechanical ventilation.

Review: Interventions for preventing critical illness polyneuropathy and critical illness myopathy

Comparison: I Intensive insulin therapy (IIT) versus conventional insulin therapy (CIT)

Outcome: 2 Duration of mechanical ventilation

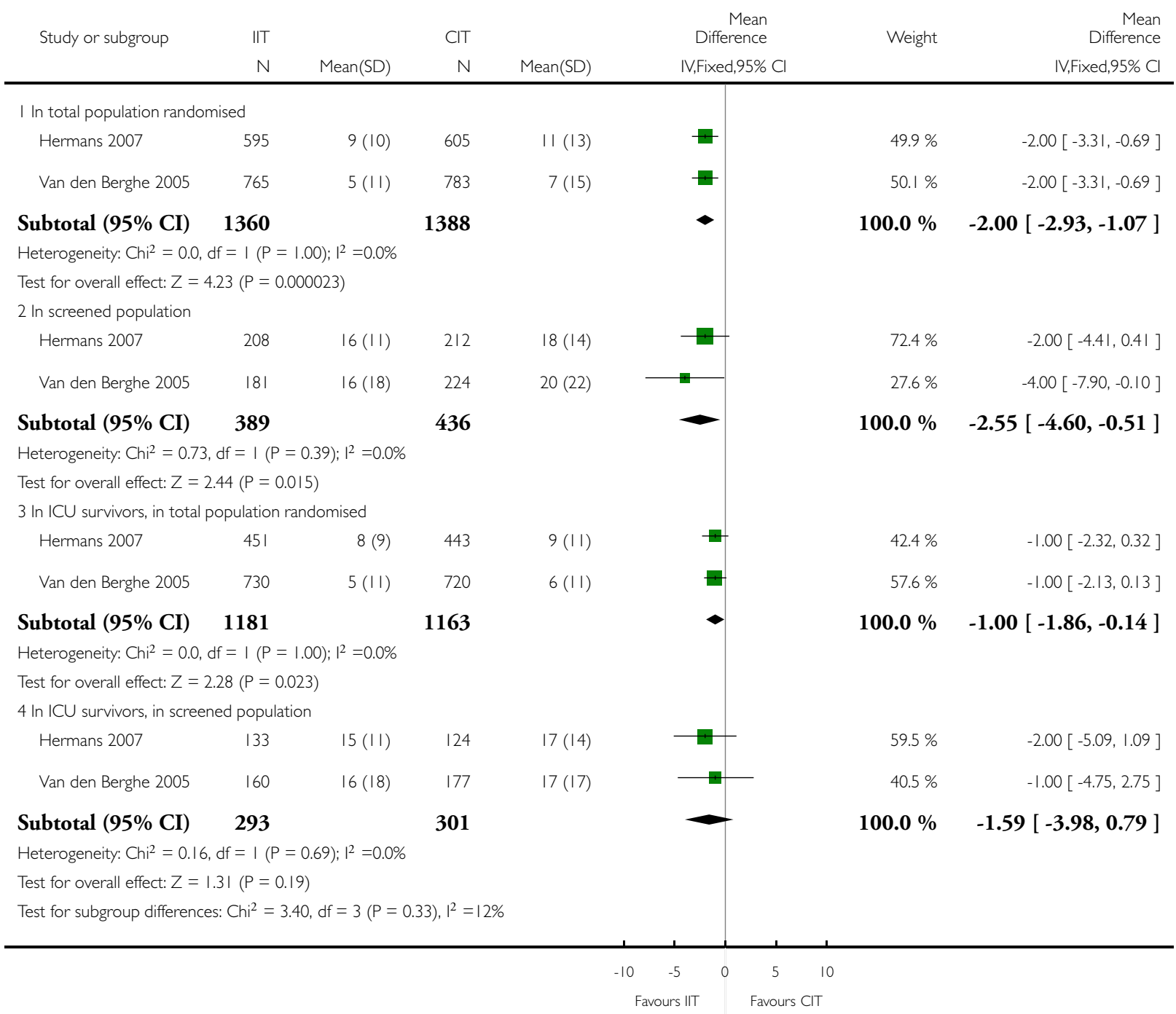

Interventions for preventing critical illness polyneuropathy and critical illness myopathy (Review) 


\section{Analysis I.3. Comparison I Intensive insulin therapy (IIT) versus conventional insulin therapy (CIT),}

Outcome 3 Duration of ICU stay.

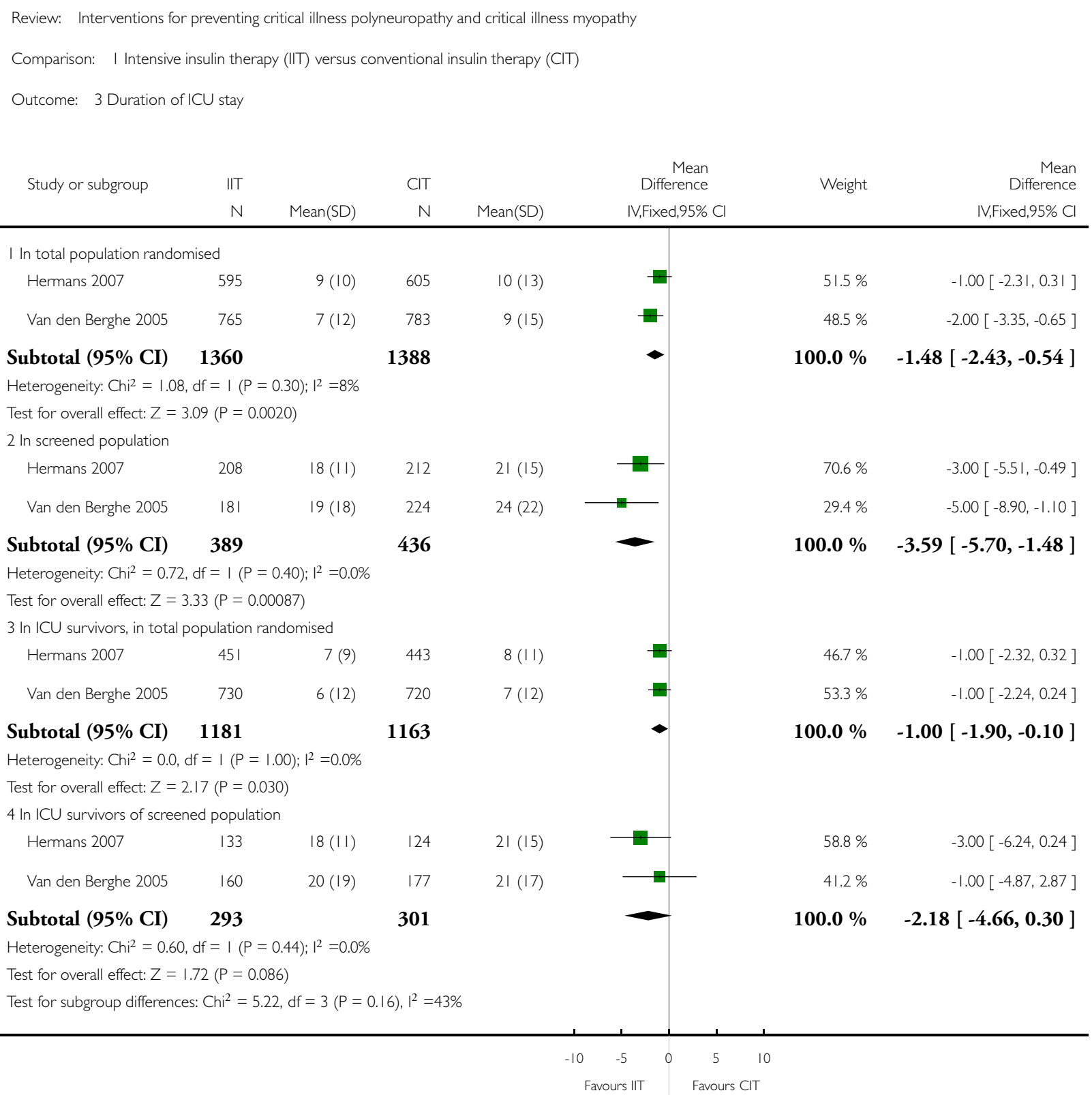


Analysis I.4. Comparison I Intensive insulin therapy (IIT) versus conventional insulin therapy (CIT), Outcome 4 Death.

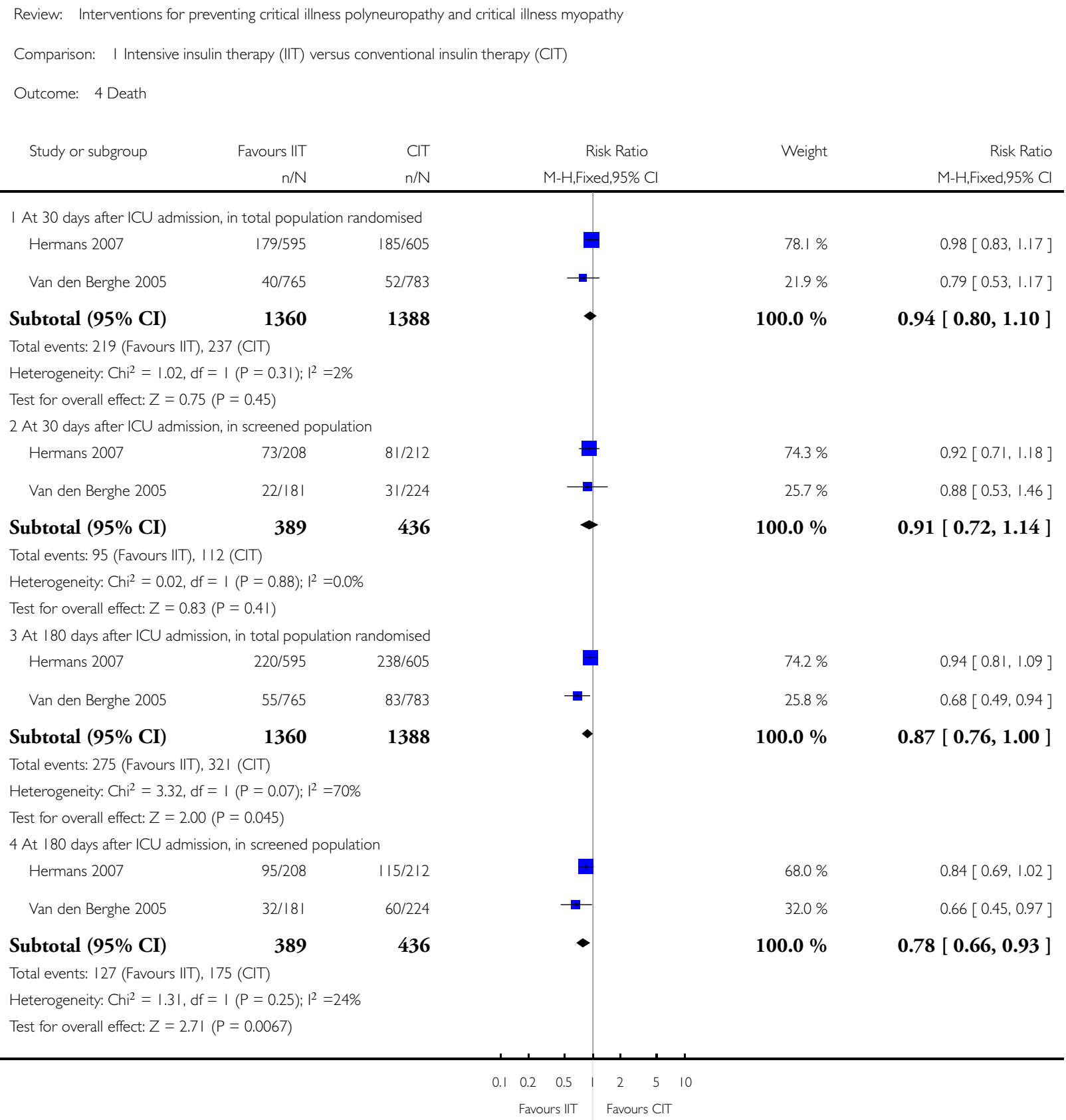


Analysis I.5. Comparison I Intensive insulin therapy (IIT) versus conventional insulin therapy (CIT), Outcome 5 Serious adverse events.

Review: Interventions for preventing critical illness polyneuropathy and critical illness myopathy

Comparison: I Intensive insulin therapy (IIT) versus conventional insulin therapy (CIT)

Outcome: 5 Serious adverse events

$\begin{array}{lllll}\text { Study or subgroup } & \text { Favours IIT } & \text { CIT } & \text { Risk Ratio } & \text { Weight }\end{array}$

$\mathrm{n} / \mathrm{N} \quad \mathrm{M} / \mathrm{N}-\mathrm{H}, \mathrm{Fixed}, 95 \% \mathrm{Cl}$

$\mathrm{M}-\mathrm{H}, \mathrm{Fixed}, 95 \% \mathrm{Cl}$

I In total population randomised - hypoglycaemia

$19 / 605$

Weight

$76.1 \%$

$5.94[3.70,9.54]$

Hermans 2007

Hermans $2007 \quad$ III/595 19/605

Van den Berghe $2005 \quad$ 43/765 6/783

Subtotal (95\% CI)

$1360 \quad 1388$

Total events: 154 (Favours IIT), 25 (CIT)

Heterogeneity: Chi $^{2}=0.18, \mathrm{df}=\mathrm{I}(\mathrm{P}=0.67) ; \mathrm{I}^{2}=0.0 \%$

Test for overall effect: $Z=8.71(P<0.00001)$

2 In total population randomised- at least 2 hypoglycaemic events

Hermans $2007 \quad 23 / 595 \quad 5 / 605$

Van den Berghe $2005 \quad$ 8/765 0/783

Subtotal (95\% CI)

1360

1388

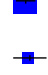

$\checkmark$

$23.9 \%$

$100.0 \%$

$90.9 \%$

$9.1 \%$

$100.0 \%$

Total events: 31 (Favours IIT), 5 (CIT)

Heterogeneity: Chi $^{2}=0.77, \mathrm{df}=\mathrm{I}(\mathrm{P}=0.38) ; \mathrm{I}^{2}=0.0 \%$

Test for overall effect: $Z=3.84(P=0.00012)$

3 In total population randomised - death within 24 hours of last hypoglycaemic event

Hermans 2007

$5 / 595$

Van den Berghe 2005

$0 / 765$

Subtotal (95\% CI)

1360

Total events: 5 (Favours IIT), 3 (CIT)

Heterogeneity: $\mathrm{Chi}^{2}=1.20, \mathrm{df}=\mathrm{I}(\mathrm{P}=0.27) ; \mathrm{I}^{2}=17 \%$

Test for overall effect: $Z=0.69(P=0.49)$

4 In screened population - hypoglycaemia

Hermans 2007

$68 / 208$

Van den Berghe 2005

$28 /|8|$

Subtotal (95\% CI)

389

Total events: 96 (Favours IIT), 15 (CIT)

Heterogeneity: $\mathrm{Chi}^{2}=0.00, \mathrm{df}=\mathrm{I}(\mathrm{P}=1.00) ; \mathrm{I}^{2}=0.0 \%$

Test for overall effect: $Z=7.23(P<0.0000 \mathrm{I})$

5 In screened population - at least 2 hypoglycaemic events

Hermans 2007

19/208

$7 / 181$

Van den Berghe 2005
2/605

1/783

1388

$10 / 212$

$5 / 224$

436
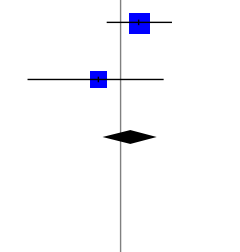

뭄

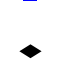

$-$

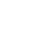

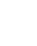




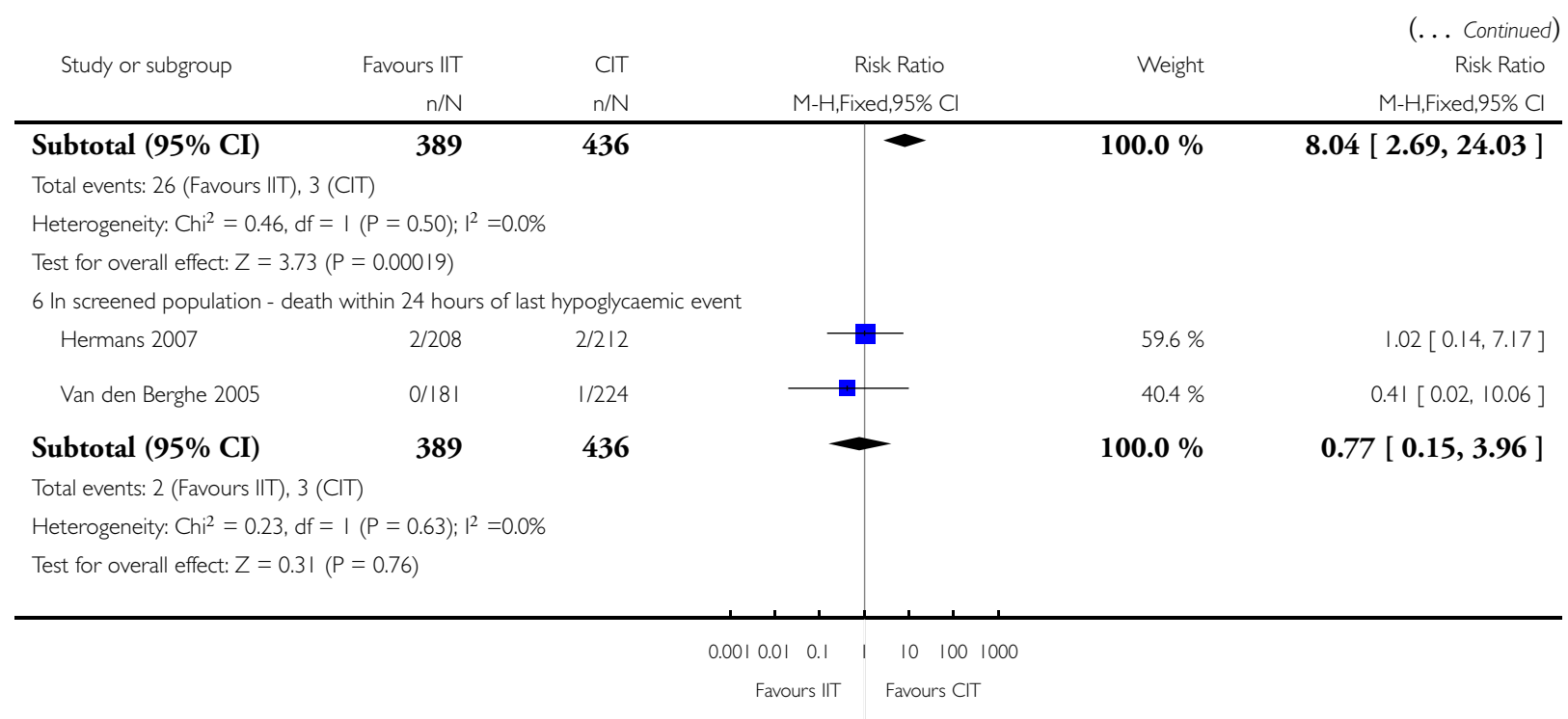


Analysis 2.I. Comparison 2 Corticosteroids versus placebo, Outcome I Occurrence of CIP/CIM.

Review: Interventions for preventing critical illness polyneuropathy and critical illness myopathy

Comparison: 2 Corticosteroids versus placebo

Outcome: I Occurrence of CIP/CIM

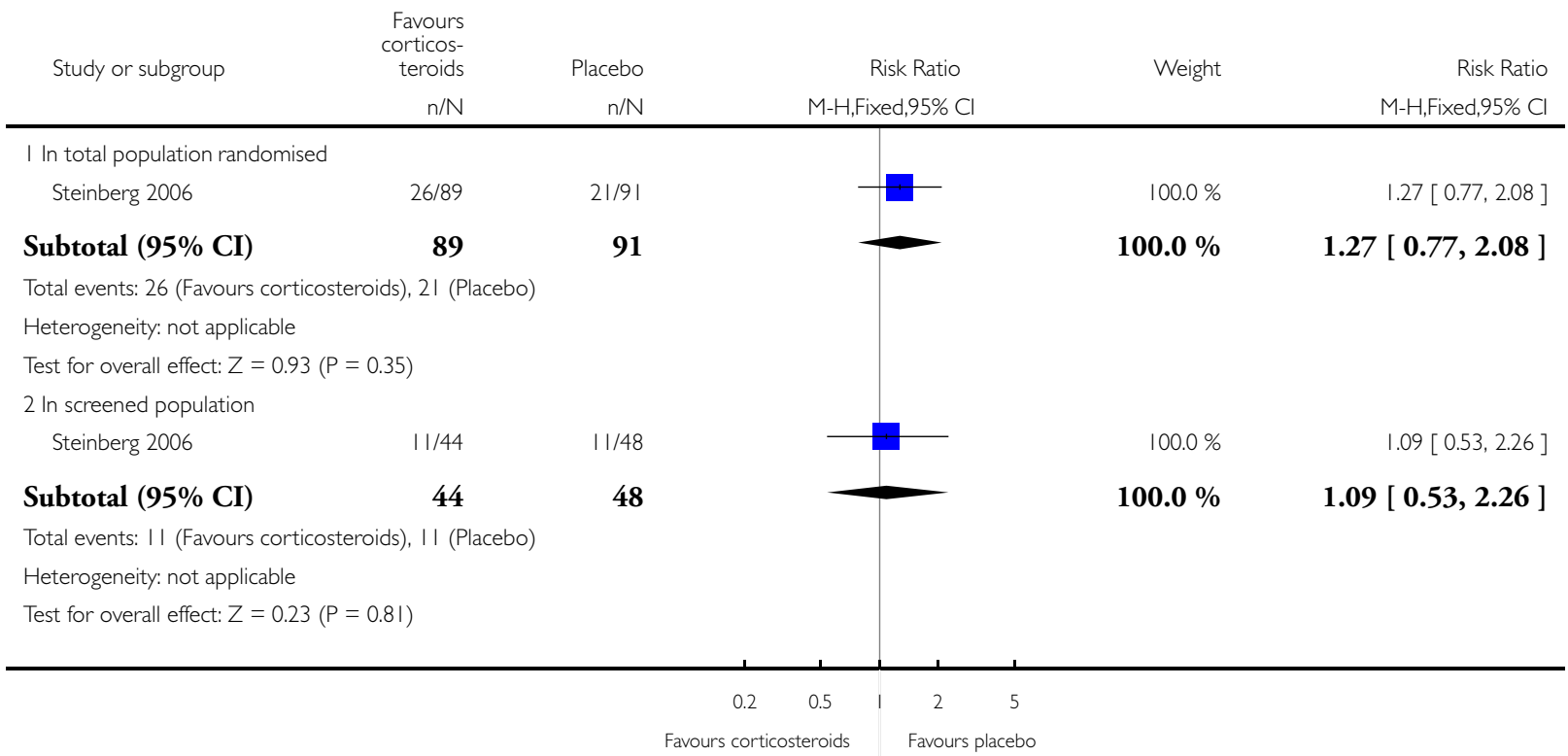


Analysis 2.2. Comparison 2 Corticosteroids versus placebo, Outcome 2 Death.

Review: Interventions for preventing critical illness polyneuropathy and critical illness myopathy

Comparison: 2 Corticosteroids versus placebo

Outcome: 2 Death

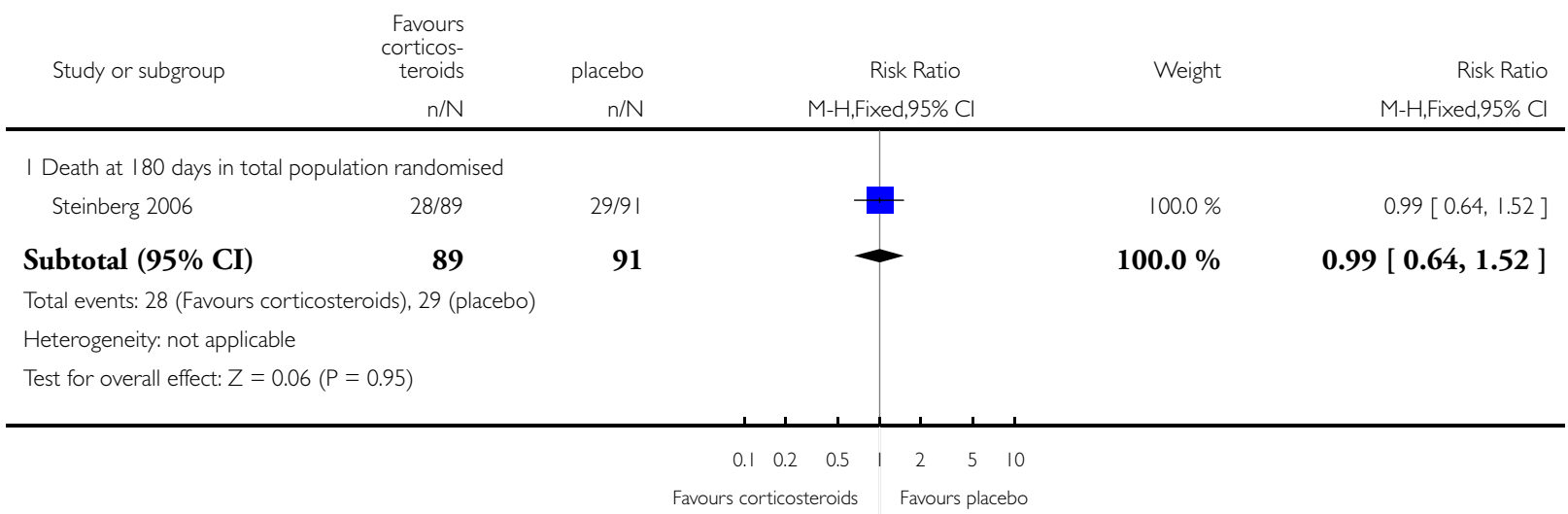


Analysis 2.3. Comparison 2 Corticosteroids versus placebo, Outcome 3 Serious adverse events (dichotomous data).

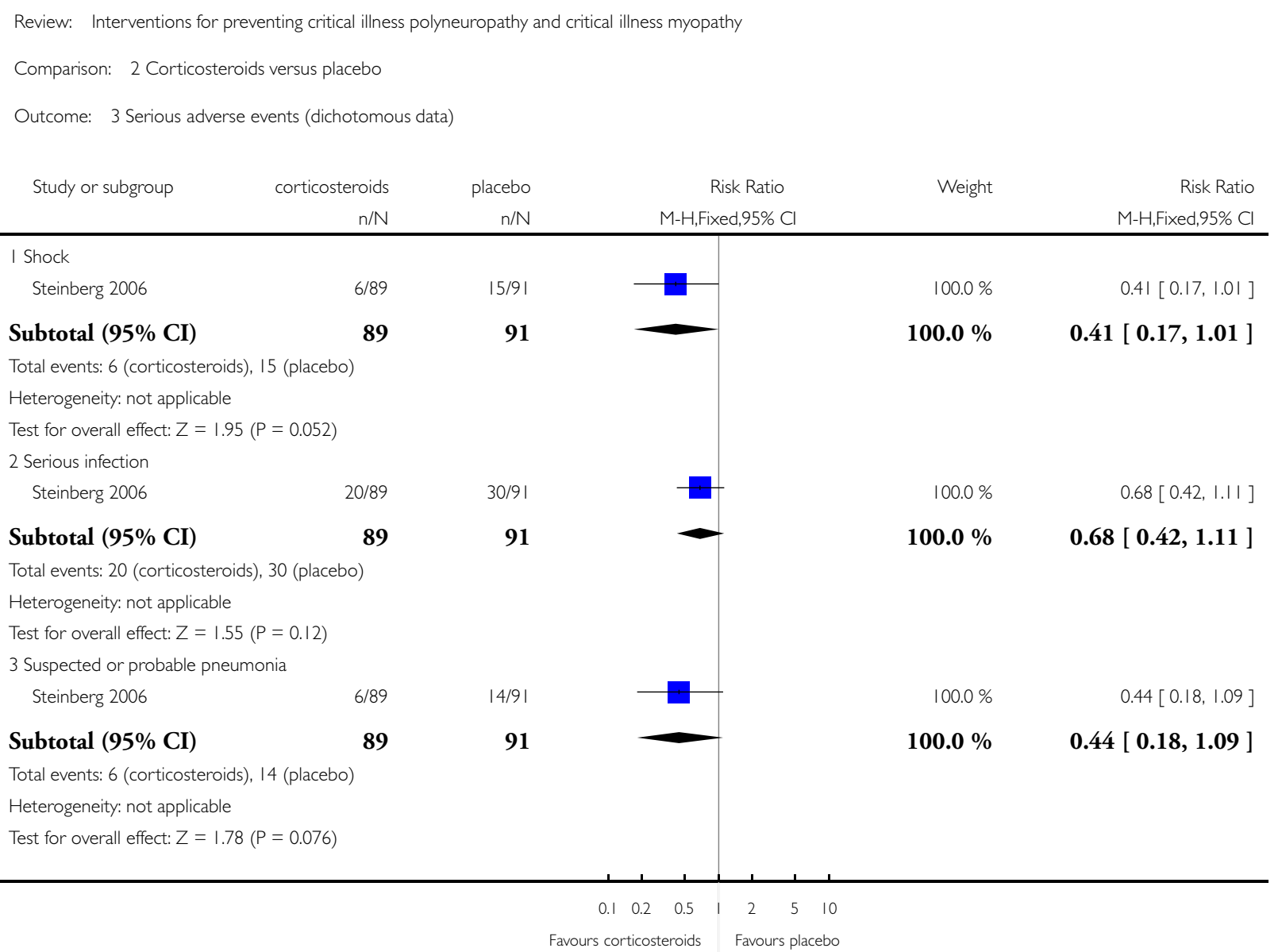


Analysis 2.4. Comparison 2 Corticosteroids versus placebo, Outcome 4 Serious adverse events (continuous data).

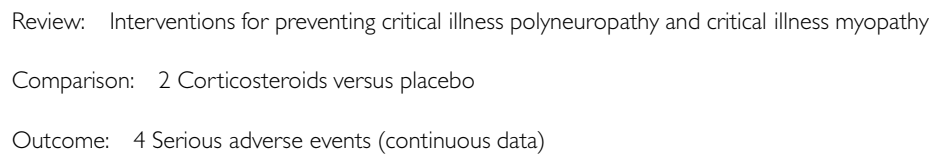

$\begin{array}{lllll}N & \text { Mean(SD) N } \quad \text { Mean(SD) IV,Fixed,95\% Cl Fixed,95\% Cl }\end{array}$

89

91

Test for overall effect: $Z=1.60(P=0.11)$

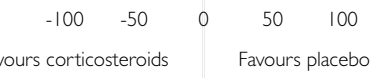


Analysis 3.I. Comparison 3 Early physical therapy versus control, Outcome I Occurrence of CIP/CIM.

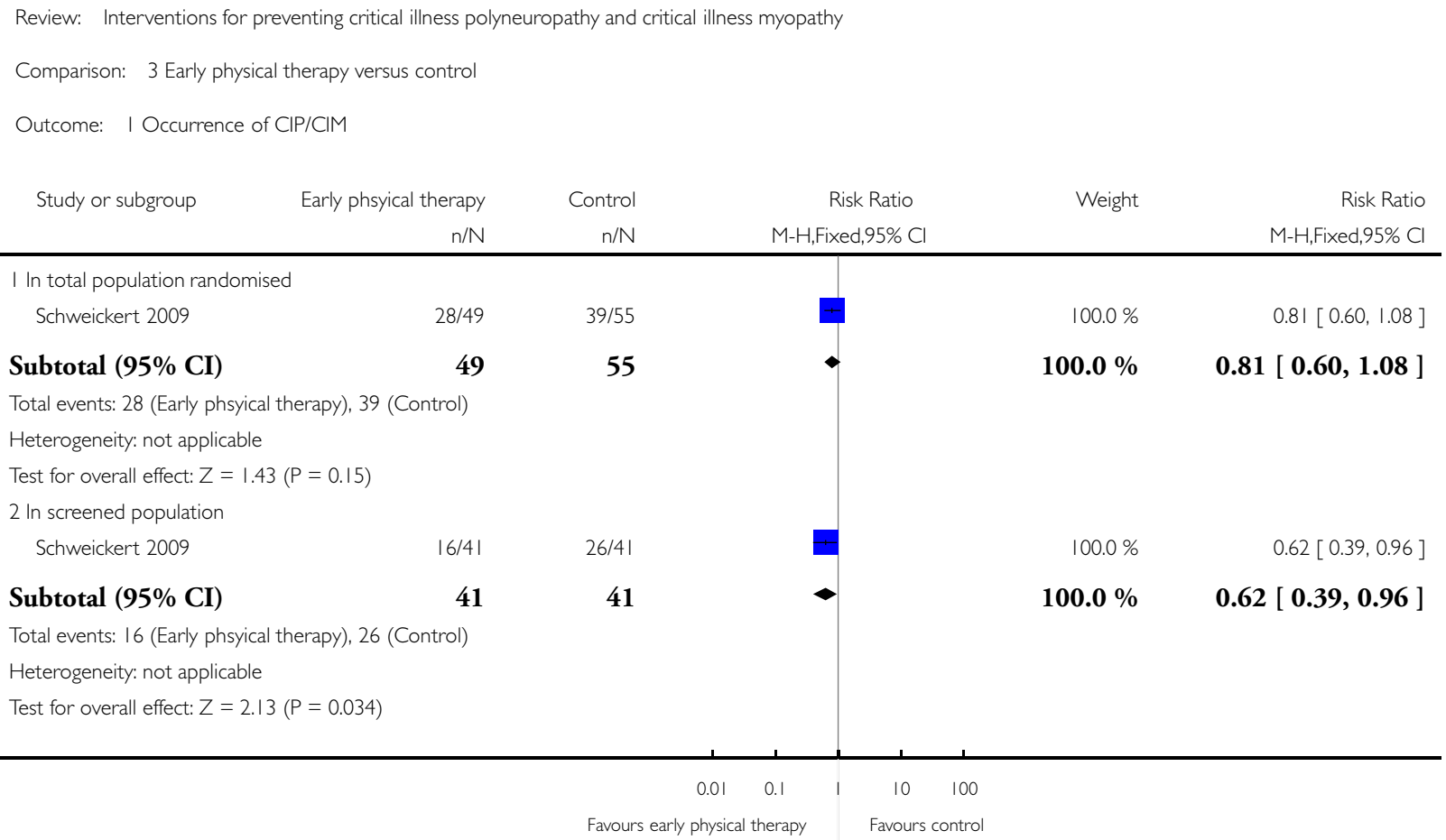




\section{Analysis 3.2. Comparison 3 Early physical therapy versus control, Outcome 2 Serious adverse events.}

Review: Interventions for preventing critical illness polyneuropathy and critical illness myopathy

Comparison: 3 Early physical therapy versus control

Outcome: 2 Serious adverse events

Control Risk Ratio

Weight

Risk Ratio

$\mathrm{n} / \mathrm{N}$

$\mathrm{n} / \mathrm{N}$

M-H,Fixed,95\% C

M-H,Fixed,95\% Cl

I In total population randomised

Schweickert 2009

1/49 0/55

Subtotal (95\% CI)

49

$0 / 55$

Total events: I (Early phsyical therapy), 0 (Control)

Heterogeneity: not applicable

Test for overall effect: $Z=0.75(P=0.45)$

$100.0 \%$

$3.36[0.14,80.62]$

$100.0 \%$

$3.36[0.14,80.62]$

$\begin{array}{lllllll}0.001 & 0.01 & 0.1 & \mid & 10 & 100 & 1000\end{array}$

Favours early physical therapy Favours control 
Analysis 4.I. Comparison 4 Electrical muscle stimulation versus control, Outcome I Occurrence of CIP/CIM.

Review: Interventions for preventing critical illness polyneuropathy and critical illness myopathy

Comparison: 4 Electrical muscle stimulation versus control

Outcome: I Occurrence of CIP/CIM

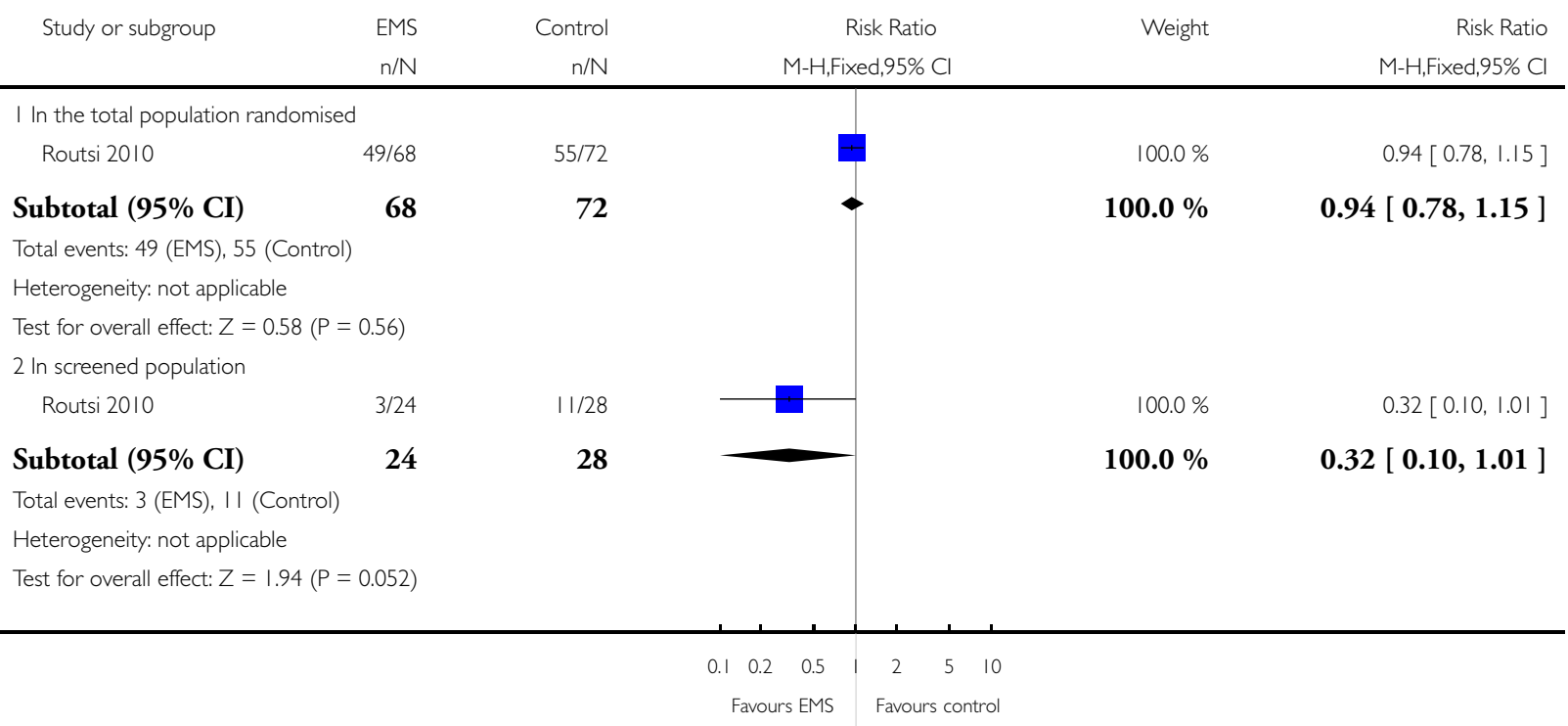

\section{ADDITIONAL TABLES}

Table 1. MRC sum-score

\section{A. Muscle groups}

Shoulder abduction

Elbow flexion

Wrist dorsiflexion

Hip flexion

Knee extension

Ankle dorsiflexion

B. Score

0 No visible/palpable contraction

Copyright (C) 2014 The Cochrane Collaboration. Published by John Wiley \& Sons, Ltd. 
Table 1. MRC sum-score (Continued)

1 Visible contraction, no movement of the limb

2 Movement of the limb, but not against gravity

3 Movement against gravity

4 Movement against gravity and resistance, submaximal

5 Normal muscle force

\section{A P P E N D I C E S}

\section{Appendix I. CENTRAL search strategy}

\#1Polyneuropath* or Muscle Weakness or Rhabdomyolysis or Quadriplegia or Paresis

\#2quadriplegia or weakness or neuromyopath* or "motor syndrome" or "muscle function" or "muscle strength" or "respiratory failure" \#3(\#1 OR \#2)

\#4"Intensive Care" or "Critical Illness" or "intensive care" or "ventilator weaning” or (respiration NEAR/2 artificial)

\#5(critical NEXT/2 illness) or (critically NEAR/2 ill)

\#6(\#4 OR \#5)

\#7therapeutic* or "enteral nutrition" or "enteral feeding" or "enteral nutrition" or "parenteral nutrition" or "parenteral feeding" or "parenteral nutrition" or glucocorticoid* or exercise therapy" or kinesiotherap* or "diet therapy"

\#8(therapies NEAR/2 investigational) or "experimental therap*“" or "investigational therap*" or "amino acid*” or arginine or arg or glutamine or glu or antioxidant* or "anti oxidant*" or acetylcysteine or n-acetylcycteine or NAC or glutathione or "growth hormone" or $\mathrm{GH}$

\#9androgens* or testosterone or oxandrolone "Insulin-Like Growth Factor I" or "insulin-like growth factor" or igf-1 or immunoglobulin* or insulin or iit or (insulin NEAR/5 therapy) or (insulin NEAR/5 treatment)

\#10physiotherapy or "physical therap*" "electric stimulation" or electrostimulation or (electrical NEAR/2 stimulation) or rehabilitation or "breathing exercise*" or magnesium

\#11(\#7 OR \#8 OR \#9 OR \#10)

\#12(\#3 AND \#6 AND \#11)

\section{Appendix 2. MEDLINE (OvidSP) search strategy}

1 randomized controlled trial.pt.

2 controlled clinical trial.pt.

3 randomized.ab.

4 placebo.ab.

5 drug therapy.fs.

6 randomly.ab.

7 trial.ab.

8 groups.ab.

9 or/ $1-8$

10 exp animals/ not humans.sh.

Interventions for preventing critical illness polyneuropathy and critical illness myopathy (Review)

Copyright @ 2014 The Cochrane Collaboration. Published by John Wiley \& Sons, Ltd. 
119 not 10

12 polyneuropathies/

13 muscle Weakness/

14 rhabdomyolysis/

15 quadriplegia/

16 paresis/

17 neuromuscular manifestation $\$ 1 . t w$.

18 (polyneuropath\$ or myopath\$).tw.

19 polyneuromyopath $\$$.tw.

20 neuromuscular disorder $\$ . t w$.

21 neuromuscular disease $\$$.tw.

22 paresis.tw.

23 quadriplegia.tw.

24 weakness.tw.

25 neuromyopath $\$$.tw.

26 motor syndrome.tw.

27 muscle function.tw.

28 muscle strength/

29 (muscle strength or respiratory failure).tw.

30 or/12-29

31 intensive Care/

32 critical Illness/

33 intensive care.tw.

34 critical\$ ill\$.tw.

35 ventilator weaning/

36 respiration, artificial/

37 or/31-36

38 therapeutics/

39 enteral nutrition/ or enter\$ feed\$.tw. or enter\$ nutrition.tw.

40 parenteral nutrition/ or parenter\$ feed $\$$.tw. or parenter\$ nutrition.tw.

41 glucocorticoids/ or glucocorticoids.tw.

42 exercise therapy/ or kinesiotherap\$.tw.

43 diet therapy/

44 pc.fs.

45 rh.fs.

46 therapies investigational/ or experimental therap\$.tw. or investigational therap\$.tw.

47 amino acids/ or amino acids.tw.

48 arginine/ or arginine.tw. or arg.tw.

49 glutamine/ or glutamine.tw. or glu.tw.

50 antioxidants/ or antioxidant\$.tw. or anti oxidant\$.tw.

51 acetylcysteine/ or n-acetylcycteine.tw. or NAC.tw. or glutathione.tw.

52 growth hormone/ or growth hormone.tw. or GH.tw.

53 androgens/ or androgen\$.tw. or testosterone.tw. or oxandrolone.tw.

54 Insulin-Like Growth Factor I/ or insulin-like growth factor.tw. or igf-1.tw.

55 immunoglobulins/ or immunoglobulin\$.tw.

56 insulin/ or insulin.tw.

57 iit.mp.

58 (insulin adj5 therapy).tw.

59 (insulin adj5 treatment).tw.

60 physical therapy modalities/ or physiotherap\$.tw. or physical therap\$.tw.

61 electric stimulation therapy/ or electrostimulation.mp. or (electric $\$$ adj2 stimulation).tw.

62 rehabilitation.tw. or rehabilitation/

63 breathing exercises/

Interventions for preventing critical illness polyneuropathy and critical illness myopathy (Review)

Copyright $\odot 2014$ The Cochrane Collaboration. Published by John Wiley \& Sons, Ltd. 
64 breathing exercise $\$$.tw.

65 magnesium.mp.

66 or/38-65

6711 and 30 and 37 and 66

\section{Appendix 3. EMBASE (OvidSP) search strategy}

1 crossover-procedure/

2 double-blind procedure/

3 randomized controlled trial/

4 single-blind procedure/

5 (random $\$$ or factorial $\$$ or crossover $\$$ or cross over $\$$ or cross-over $\$$ or placebo $\$$ or (doubl $\$$ adj blind $\$$ ) or (singl $\$$ adj blind $\$$ ) or assign $\$$ or allocat $\$$ or volunteer\$).tw.

6 or/ $1-5$

7 exp animals/

8 exp humans/

97 not $(7$ and 8$)$

106 not 9

11 limit 10 to embase

12 polyneuropathy/

13 muscle weakness/

14 RHABDOMYOLYSIS/

15 QUADRIPLEGIA/

16 PARESIS/

17 neuromuscular manifestation $\$ 1 . \mathrm{mp}$.

18 (polyneuropath\$ or myopath\$).mp.

19 polyneuromyopath $\$ . m p$.

20 neuromuscular disorder\$.mp.

21 neuromuscular disease $\$ . m p$.

22 paresis.mp.

23 quadriplegia.mp.

24 muscle weakness.mp.

25 neuromyopath\$.mp.

26 motor syndrome.mp.

27 muscle function.mp.

28 muscle strength/

29 muscle force/

30 respiratory failure/

31 (muscle strength or respiratory failure or muscle dysfunction or muscle force or acquired weakness).mp.

32 or/12-31

33 intensive care/

34 critical illness/

35 intensive care.mp.

36 intensive care.mp.

37 ventilator weaning. mp.

38 artificial ventilation/

39 or/33-38

40 therapy/

41 enteric feeding/ or enter\$ feed\$.tw. or enter\$ nutrition.mp.

42 parenteral nutrition/ or parenter\$ feed\$.mp. or parenter\$ nutrition.mp.

43 glucocorticoids/ or glucocorticoids.mp.

44 kinesiotherapy/ or kinesiotherap\$.mp. or exercise therapy.mp.

Interventions for preventing critical illness polyneuropathy and critical illness myopathy (Review)

Copyright @ 2014 The Cochrane Collaboration. Published by John Wiley \& Sons, Ltd. 
45 diet therapy/ or diet therapy.mp.

46 (pc or rh).fs.

47 experimental therapy/ or (experimental therap\$.tw. or investigational therap\$).mp.

$48 \mathrm{amino} \mathrm{acid} /$ or amino acids.mp.

49 arginine/ or arginine.mp.

50 glutamine/ or glutamine.mp.

51 antioxidant/ or antioxidant\$.tw. or anti oxidant\$.mp.

52 acetylcysteine/ or (n-acetylcycteine or NAC or glutathione).mp.

53 growth hormone/ or (growth hormone or GH).mp.

54 androgen/ or (androgen $\$$ or testosterone or oxandrolone).mp.

55 somatomedin $\mathrm{C} /$ or (insulin-like growth factor or igf-1).mp.

56 immunoglobulin/ or immunoglobulin\$.mp.

57 insulin/ or insulin.mp.

58 iit.mp.

59 (insulin adj5 therapy).mp.

60 (insulin adj5 treatment).mp.

61 physiotherapy/ or (physiotherap\$ or physical therap\$).mp.

62 electrostimulation/

63 (electric $\$$ adj2 stimulation).mp.

6462 not 63

65 electrostimulation/ or electrostimulation.mp.

66 rehabilitation/ or rehabilitation.mp.

67 breathing exercise/ or breathing exercise.mp.

68 corticosteroid\$.mp.

69 magnesium.mp.

70 or/40-69

7111 and 32 and 39 and 70

\section{WHAT'S NEW}

Last assessed as up-to-date: 4 October 2011.

\begin{tabular}{l|l|l}
\hline Date & Event & Description \\
\hline 13 December 2013 & New citation required and conclusions have changed & $\begin{array}{l}\text { We identified two new studies for inclusion based on } \\
\text { searches to October } 2011 \text { and extensively revised the } \\
\text { review including changes to inclusion criteria }\end{array}$ \\
\hline 4 October 2011 & New search has been performed & $\begin{array}{l}\text { Searches updated to October 2011 and integrated into } \\
\text { the review. A further search to December 2013 revealed } \\
\text { further studies currently awaiting assessment }\end{array}$ \\
\hline
\end{tabular}

Interventions for preventing critical illness polyneuropathy and critical illness myopathy (Review) 


\section{H I S T O R Y}

Protocol first published: Issue 4, 2007

Review first published: Issue 1, 2009

\begin{tabular}{l|l} 
Date Event & Description
\end{tabular}

19 August 2012 New citation required and conclusions have changed Converted to new review format.

\section{CONTRIBUTIONS OFAUTHORS}

Greet Van den Berghe initiated and supervised the project. Greet Hermans and Bernard De Jonghe independently extracted the data. Greet Hermans contacted corresponding authors for additional data and wrote the first draft. Bernard de Jonghe and Frans Bruyninckx commented on the first draft and made revisions. Greet Van den Berghe reviewed and commented on the revised draft prior to submission for formal review.

\section{DECLARATIONSOF INTEREST}

Greet Hermans and Greet Van den Berghe have been involved in trials included in the review.

Frans Bruyninckx and Bernard De Jonghe have no known conflicts of interest.

\section{DIFFERENCES BETWEEN PROTOCOLANDREVIEW}

During the process of updating the review, and after extensive discussion between the authors and the editorial board, it was decided to refine inclusion criteria in order to improve clarity and further reduce bias in the review. Therefore, the review includes only studies that report the incidence of CIP or CIM as a primary or secondary outcome.

We used the Cochrane 'Risk of bias' tool to assess studies, which was introduced after publication of our protocol. For this update we included 'Summary of findings' tables.

\section{NDEX TERMS Medical Subject Headings (MeSH)}

Adrenal Cortex Hormones [therapeutic use]; Human Growth Hormone [therapeutic use]; Hypoglycemia [chemically induced]; Hypoglycemic Agents [adverse effects; therapeutic use]; Insulin [adverse effects; therapeutic use]; Length of Stay [statistics \& numerical data]; Muscular Diseases [mortality; * prevention \& control]; Polyneuropathies [mortality; * prevention \& control]; Randomized Controlled Trials as Topic; Recombinant Proteins [therapeutic use]; Respiration, Artificial [utilization] 


\section{MeSH check words}

Humans 